\title{
ANÁLISE MICROSCÓPICA DA SIALOMETAPLASIA NECROSANTE E APRESENTAÇÃO DE UMA HIPÓTESE SOBRE SUAS RELAÇÕES ETIOPATOGÊNICAS, EM ESPECIAL COM APARELHOS DISJUNTORES PALATINOS
}

\section{VALDOMIRO REBELLATO JÚNIOR}

Dissertação apresentada à Faculdade de Odontologia de Bauru da Universidade de São Paulo, como parte dos requisitos para obtenção do título de Mestre em Odontologia, área de Patologia Bucal

(Edição Revisada) 


\section{ANÁLISE MICROSCÓPICA DA SIALOMETAPLASIA NECROSANTE E APRESENTAÇÃO DE UMA HIPÓTESE SOBRE SUAS RELAÇÕES ETIOPATOGÊNICAS, EM ESPECIAL COM APARELHOS DISJUNTORES PALATINOS}

\section{VALDOMIRO REBELLATO JÚNIOR}

Dissertação apresentada à Faculdade de Odontologia de Bauru da Universidade de São Paulo, como parte dos requisitos para obtenção do título de Mestre em Odontologia, área de Patologia Bucal

Orientador: Prof. Dr. Alberto Consolaro

(Edição Revisada) 


\section{Ficha Técnica}

Valdomiro Rebellato Júnior: concepção original, execução, texto, digitação e formatação.

Alberto Consolaro: concepção original, texto, orientação, fotomicrografias e revisão final.

Maria Fernanda Martins-Ortiz: análise estatística, revisão e abstract.

José Antônio Rebouças de Carvalho Júnior: caso clínico.

Rubens Kazuo Kato: desenhos e esquemas gráficos.

Fátima Aparecida Silveira: histotécnica.

Maria Cristina Carrara Felippe: auxílio administrativo e técnico.

Valdir João Afonso: revisão final e vernáculo.

Marcus Thame: serviços de cópias e encadernação.

\section{Rebellato Júnior, Valdomiro}

R241a Análise microscópica da sialometaplasia necrosante e apresentação de uma hipótese sobre suas relações etiopatogênicas, em especial com aparelhos disjuntores palatinos / Valdomiro Rebellato Júnior. -- Bauru, 2003.

xii, 114 p. : il. ; 30cm.

Dissertação (Mestrado) -- Faculdade de Odontologia de Bauru. Universidade de São Paulo.

Orientador: Prof. Dr. Alberto Consolaro

Autorizo, exclusivamente para fins acadêmicos e científicos, a reprodução parcial ou total desta dissertação, por processos fotocopiadores e outros meios eletrônicos.

Assinatura:

Bauru, 24 de junho de 2003.

Projeto de Pesquisa aprovado pelo Comitê de Etica em Pesquisa da Faculdade de Odontologia de Bauru, USP, na reunião do dia 26 de março de 2003. 


\section{Universidade de São Paulo Faculdade de Odontologia de Bauru}

Al. Dr. Octávio Pinheiro Brisolla, 9-75 - Bauru-SP - CEP 17012-901 - C.P. 73 PABX (0XX14)235-8000 - FAX (0XX14)223-4679

Pós-Graduação

e-mail: posgrad@fob.usp.br-Fone: (0XX14)235-8223

\section{FOLHA DE APROVAÇÃO}

Dissertação apresentada e defendida por

VALDOMIRO REBELLATO JÚNIOR

e aprovada pela Comissão Julgadora em 24 de junho de 2003.

Prof. Dr. LAURINDO ZANCO FURQUIM

Universidade Estadual de Maringá

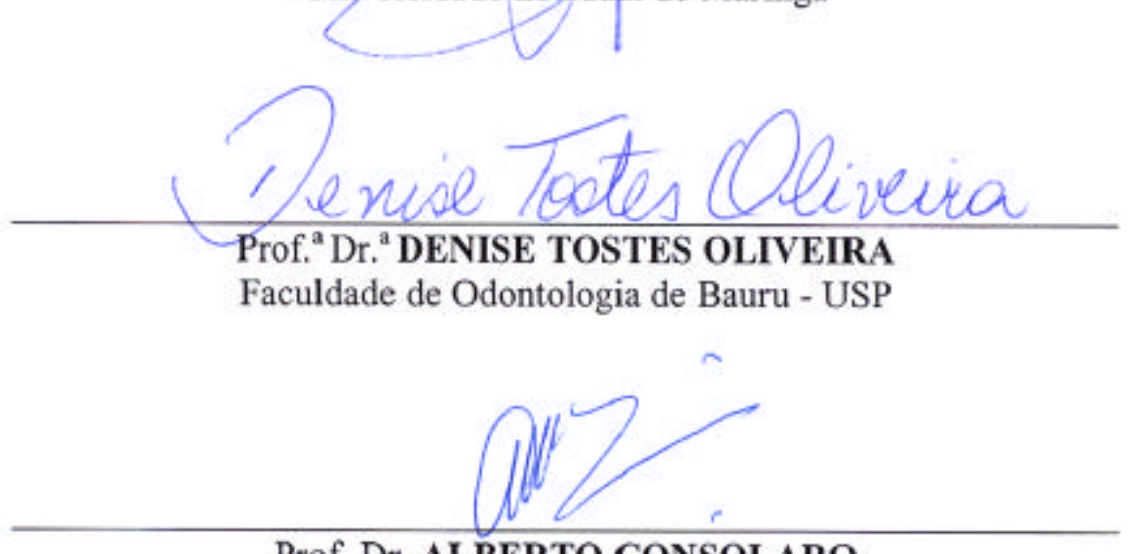

Prof. Dr. ALBERTO CONSOLARO

Presidente da Banca

Faculdade de Odontologia de Bauru - USP

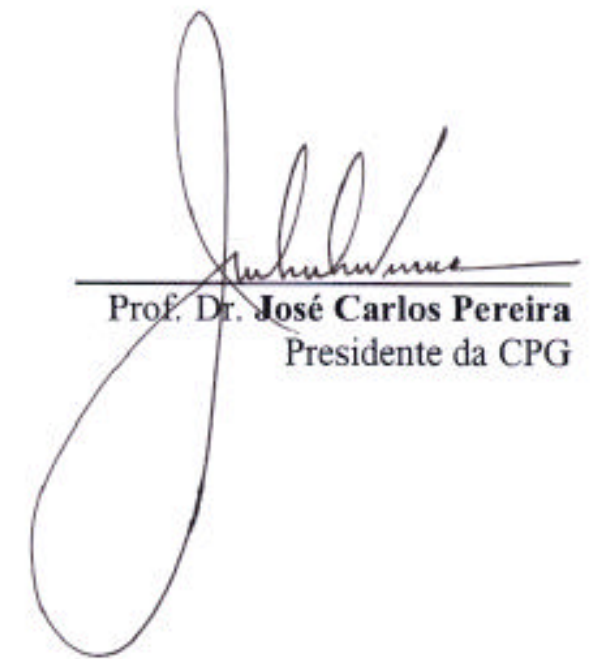




\section{VALDOMIRO REBELLATO JÚNIOR}

07 de junho de 1975

Medianeira, PR

Filiação

1993-1998

1999-2001

2000

2001-2003
Data e Local de Nascimento

Valdomiro Rebellato

Teresa Inês Marasca Rebellato

Curso de Graduação em Odontologia na Universidade Federal do Paraná, Curitiba, PR

Curso de Aperfeiçoamento em Ortodontia na Assessoria e Consultoria em Ortodontia, Pesquisa e Ensino, ACOPEN, Bauru, SP

Cirurgião-Dentista em Clínica Privada

Curso de Mestrado em Odontologia, área de Patologia Bucal pela Faculdade de Odontologia de Bauru, Universidade de São Paulo 
Dedico este trabalho...

Aos mens pais, Valdomiro Teresa, por me ensinarem que basta viver para ser feliz, nunca desistir e sempre acreditar nos sonhos;

ao mew irmão Carlos e sobrinha Rafaella, pelos momentos de felicidade, alegria e companheirismo;

à minha noiva, Daniela, por me fazer acreditar que o amor existe. 
"Parece-me que o prêmio mais alto possivel para qualquer trabalho humano nãoé $\sigma$ que se recebe por ele, mas sim oque se torna através dele"

Brock Bell 
Agradeço especialmente...

À familia Mondelli, em especial ao Adriano, por me acotherem e confiarem sempre no mew trabalho. Vocês são maravithosos,

Muito Obrigado!

\begin{abstract}
Ao mew orientador, Prof. Dr. Alberto Consolaro: Para pesquisar, aprender e principalmente ensinar Patologia, a ciência que trata das doenças, épreciso garra, determinação e, acredite, muita sauide!
\end{abstract} Agradeço de coração. 
Agradeço também...

Às familias Marasca, Rebellato e Hueb, por sempre me receberem de braços abertos;

Ao Fábio Luis Vicente, pelo suporte psicológico e força para superar os obstáculos da vída;

Ao Prof. Júlio César Sá Ferreira, por terme dado a primeira oportunidade de mostrar meutrabalho;

Ao Prof. Dr. José Antônio Rebouças de Carvalho Júnior, por nos enviar e confiar o caso clínico deste trabalho;

Às minhas colegas e amigas: carol $e$ Lídia, pelo convívio e momentos de alegria; Rosa e Rosárío, pela força, coleguismo e amizade conquistada. Se continuarmos sempre com essa determinação e disposição, iremos longe!

Aos pós-graduados Braz, Daniel, Sandra, Simone, Fernanda, Jussara, Laurindo, Mariza, Tarcília, Telma e Mirian, pelo apoio sempre prestado; 
Aos pós-graduandos Aline, Andrea, João Adolfo, Maria Fernanda, Maria Renata e Tânia, pela atenção, carinho e apoio incondicionais;

Aos Professores Doutores da Patologia: Denise Tostes Oliveira, Luis Antônio de Assis Taveira e Vanessa Soares Lara, pela contribuição em minha formação profissional;

Aos funcionários da Patologia: Bernadete Aparecida Alves Camargo, Fátima Aparecida Silveira, María Cristina Carrara Felippe e Valdir João Afonso, por tornarem $\sigma$ ambiente de trabatho sempre agradável;

Aos demais professores, funcionários, colegas e alunos da graduação e pósgraduação da FOB-USP, pelos momentos compartithados;

...finalmente a Deus, por fazer tudo valer a pena.

Meus sinceros agradecimentos 
Agradecimentos Institucionais

À direção da Faculdade de Odontologia de Bauru, Universidade de São Paulo, nas pessoas do Ex-Diretor, Professor Doutor Aymar Pavarini e da atual Diretora, Professora Doutora Maria Fidela de Lima Navarro, e em especial à Disciplina de Patologia desta faculdade;

À Comissão de Pós-Graduação da Faculdade de Odontologia de Bauru, Universidade de São Paulo, nas pessoas do Ex-Presidente, Professor Doutor Luiz Fernando Pegoraro e do atual Presidente, Professor Doutor José Carlos Pereira;

À CAPES, pelo auxítio pecuniário. 


\section{SUMÁRIO}

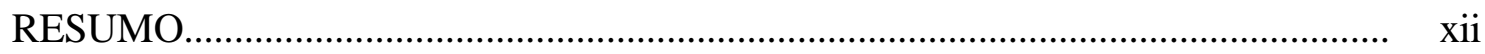

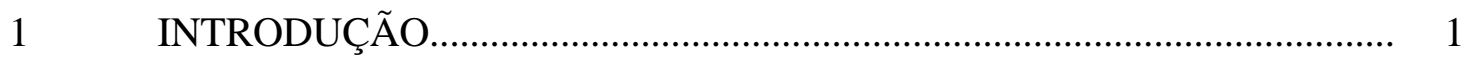

$2 \quad$ REVISÃO DA LITERATURA.............................................................. 5

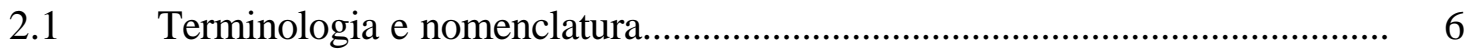

2.1.1 NECROSANTE versus NECROTIZANTE.................................................. 6

2.1.2 ENFARTE versus ENFARTO versus INFARTO........................................... 7

2.1.3 DISJUNÇÃO versus DISTRAÇÃO versus EXPANSÃO

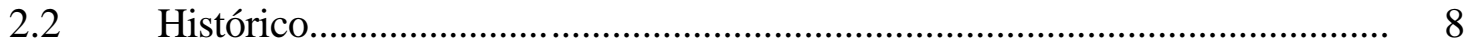

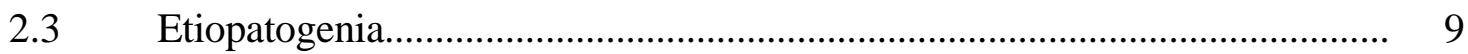

2.4 Características clínicas e radiográficas............................................................ 13

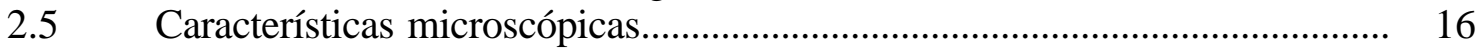

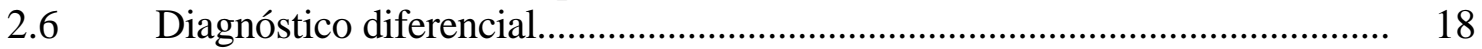

$2.7 \quad$ Tratamento.............................................................................................. 21

$3 \quad$ PROPOSIÇÃO

$4 \quad$ MATERIAL E MÉTODOS.................................................................. 24

4.1 Obtenção, seleção e caracterização da amostragem......................................... 25

4.2 Distribuição da amostragem....................................................................... 25

4.3 Caracterização da amostra........................................................................... 26

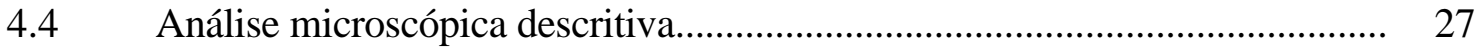

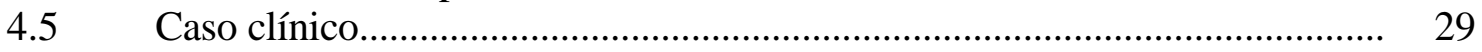

4.6 Análise estatística................................................................................... 30

4.6.1 Análise intra-examinador....................................................................... 30

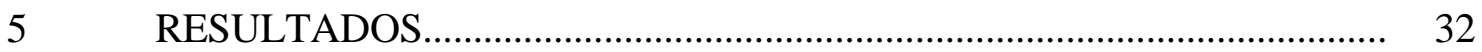

5.1 Caracterização da amostra........................................................................ 33

5.1.1 Quanto àépoca do diagnóstico do Serviço de Anatomia Patológica da FOB USP........................................................................................ 33

5.1.2 Quanto às características pessoais do paciente............................................ 34

5.1.2.1 Quanto ao gênero................................................................................. 34

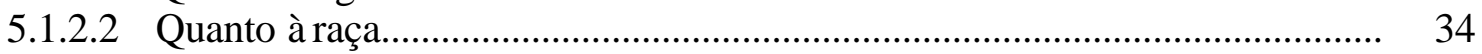

5.1.2.3 Quanto à idade............................................................................ 34

5.1.3 Quanto às características clínicas relatadas pelos profissionais....................... 35

5.1.3.1 Quanto à localização da lesão..................................................................... 35

5.1.3.2 Quanto à lesão fundamental apresentada...................................................... 35

5.1.3.3 Quanto ao momento do diagnóstico e causas relacionadas............................. 36

5.1.3.4 Quanto à sintomatologia clínica................................................................. 37

5.1.3.5 Quanto ao tempo de evolução da lesão no momento do diagnóstico................ 37

5.2 Análise das características microscópicas: resultados.................................... 38

5.2.1 Características do epitélio de revestimento................................................... 38 
5.2.2 Características do tecido conjuntivo submucoso........................................... 39

5.2.3 Características do tecido ósseo............................................................... 40

5.2.4 Características das glândulas salivares...................................................... 41

5.3 Caracterização do quadro microscópico de acordo com as fases evolutivas propostas por ANNEROTH; HANSEN ${ }^{3}$.................................................... 42

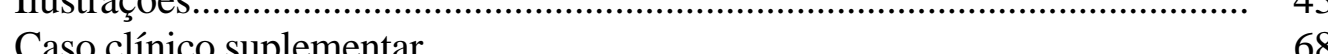

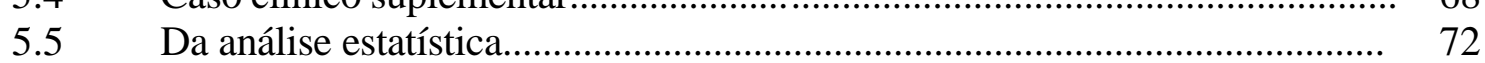

5.5.1 Teste intra-examinador........................................................................... $\quad 72$

5.5.2 Característica do epitélio estratificado pavimentoso de revestimento.............. 72

5.5.3 Severidade do infiltrado inflamatório........................................................... 73

5.5.4 Metaplasia escamosa do tecido glandular salivar........................................ 73

5.5.5 Ilhotas de células mioepiteliais no tecido glandular...................................... 74

$6 \quad$ DISCUSSÃO

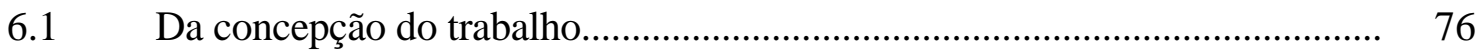

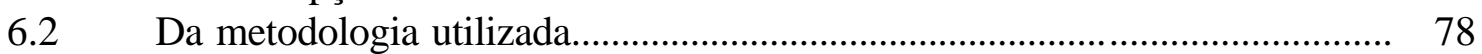

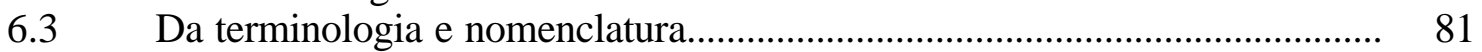

6.3.1 NECROSANTE versus NECROTIZANTE............................................... 81

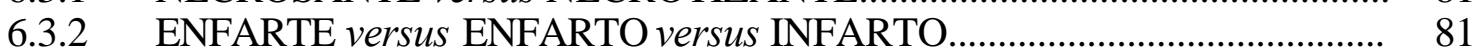

6.3.3 DISJUNÇÃO versus DISTRAÇÃO versus EXPANSÃO............................. 82

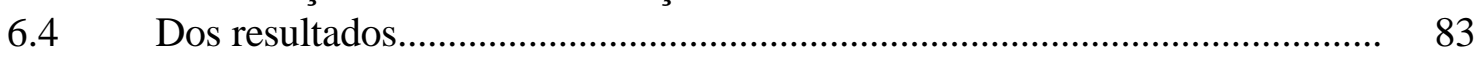

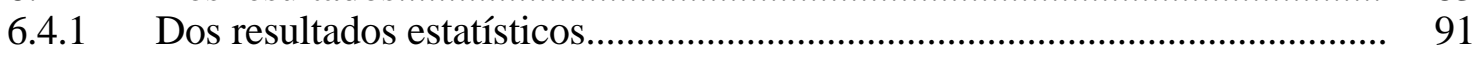

6.5 Do caso clínico e das implicações clínicas................................................. 92

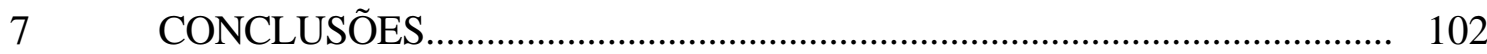

REFERÊNCIAS BIBLIOGRÁFICAS .................................................................. 104

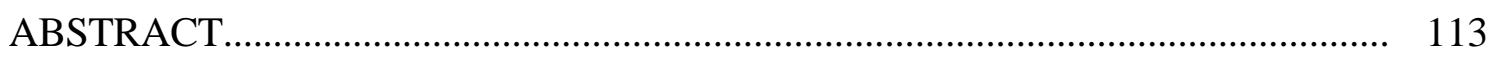

\section{APÊNDICE}




\section{RESUMO}

A sialometaplasia necrosante é uma lesão inflamatória das glândulas salivares, autolimitante, com reparação entre uma e dez semanas, cuja etiopatogenia está associada ao infarto por obstrução dos vasos sangüíneos. O seu conhecimento tem grande importância na prática diária pela semelhança com lesões malignas. As lesões necróticas no palato duro induzidas por aparelhos dentomucossuportados são provavelmente sialometaplasias necrosantes de natureza iatrogênica com relação causa-efeito estabelecida. Analisaram-se todos os espécimes de sialometaplasia necrosante dos registros do Serviço de Anatomia Patológica da FOB-USP, resgatando todos os casos cadastrados desde 1963 até 2002, a partir de seus respectivos laudos histopatológicos, descrevendo as características registradas na clínica e na análise microscópica óptica. Um caso clínico de lesão necrótica no palato duro induzida por aparelho disjuntor palatino foi explorado quanto à sua evolução, relações etiopatogênicas e conduta adotada. A partir dos resultados obtidos pelo nosso trabalho, concluímos que: 1) a sialometaplasia necrosante pode ser distinguida microscopicamente das lesões malignas. Em alguns casos torna-se fundamental a história clínica para diagnosticar de forma mais precisa e segura. Quando não existe uma relação causa-efeito, a biópsia é indispensável; 2) o soalho bucal e o palato duro são os locais mais afetados e o trauma é o agente etiológico mais comum para a sua ocorrência e 3) as lesões na mucosa palatina provocadas por aparelhos dentomucossuportados podem ser sialometaplasias necrosantes. Por apresentar uma relação causa-efeito muito bem estabelecida, em geral não são biopsiadas e diagnosticadas microscopicamente. Alívios nas trajetórias das artérias palatinas maiores devem ser confeccionados para prevenir a sua ocorrência. 
1 INTRODUÇÃO 


\section{INTRODUÇÃO}

A sialometaplasia necrosante é uma lesão inflamatória das glândulas salivares, autolimitante ${ }^{102}$, com reparação entre $u a^{87}$ e dez $z^{29,43,57,79}$ semanas, cuja etiopatogenia está associada ao infarto por obstrução dos vasos sangüíneos ${ }^{19}$.

O seu conhecimento tem grande importância na prática diária pela semelhança com lesões malignas; suas características foram admitidas em 1992 pela Organização Mundial de Saúde ${ }^{100}$. O clínico, ao receber um diagnóstico microscópico equivocado de sialometaplasia necrosante com carcinoma mucoepidermóide ou carcinoma espinocelular, será induzido a encaminhar o paciente para um médico oncologista, podendo resultar em danos físicos e psicológicos, talvez irreversíveis, ao paciente e inclusive aos seus familiares.

A obstrução parcial ou temporária dos vasos sangüíneos pode promover a necrose de estruturas das glândulas salivares caracterizando um infarto. As alterações nos tecidos glandulares e periféricos remanescentes, bem como suas repercussões clínicas decorrentes, compõem o quadro nosológico denominado sialometaplasia necrosante.

As causas atribuídas mais comuns são o traumatismo durante a mastigação $^{44,47}$, ação lesiva de próteses $^{3,5,10,47,48,56,67,68,77,79,108}$ e anestesias locais ${ }^{10,15,47,50,57,69,108}$.

A ampliação dos benefícios terapêuticos da Ortodontia e Ortopedia Funcional dos Maxilares nas últimas décadas aumentou significativamente o número e a 
variedade de aparelhos dentomucossuportados na cavidade bucal. Entre estes aparelhos estão os disjuntores palatinos, especialmente os tipo Haas ${ }^{51,52,53,54,55}$, caracterizados pela ancoragem sobre os dentes e a mucosa palatina.

A ação das placas acrílicas dos disjuntores palatinos dentomucossuportados sobre a mucosa palatina pode comprimir a artéria palatina maior. $\mathrm{Na}$ metade posterior do palato duro, o tecido conjuntivo fibroso submucoso apresenta pouca espessura e divide o espaço entre o epitélio e o periósteo com numerosas glândulas salivares menores.

A aplicação das forças nos aparelhos disjuntores palatinos dentomucossuportados comprime intensa e temporariamente a mucosa palatina. Se as forças forem bem dimensionadas e adequadamente distribuídas, a mucosa palatina, suas glândulas salivares menores e as artérias palatinas maiores permanecerão normais.

A ativação inadequada desses aparelhos, a distribuição concentrada das forças por placas acrílicas pequenas e confeccionadas sem alívio nas trajetórias das artérias palatinas maiores podem induzir lesões recróticas no palato duro decorrentes deste procedimento ortopédico.

As lesões necróticas palatinas assim induzidas podem representar verdadeiras sialometaplasias necrosantes de natureza iatrogênica, mas isto ainda não foi especificamente descrito na literatura ${ }^{16}$.

A sialometaplasia necrosante ainda é pouco conhecida pela maioria dos profissionais clínicos. Mesmo entre os especialistas em Patologia Bucal, a sialometaplasia necrosante pode gerar dúvidas e erros diagnósticos, podendo ser confundida 
com outras lesões, algumas malignas. Eventualmente pode haver a associação da sialometaplasia necrosante com outras lesões obscurecendo a malignidade ${ }^{89}$, associada a mucoceles ${ }^{89}$, e ainda em decorrência de procedimentos cirúrgicos ${ }^{49}$.

O diagnóstico definitivo da sialometaplasia necrosante pode ser baseado em uma minuciosa anamnese e exame clínico, nos quais explicitamente se estabelece uma relação causa-efeito. Em casos clínicos onde há dúvidas, o exame microscópico tende a esclarecer definitivamente o diagnóstico.

Além da remoção do provável causador, o tratamento implica no alívio dos sintomas, na remoção dos tecidos necrosados e na antibioticoterapia. $O$ prognóstico quase sempre é muito bom, com ausência de sinais ou com cicatriz variável, de acordo com o tamanho da área e momento do diagnóstico.

A frequiência de lesões necróticas relacionadas à disjunção palatina, mas não descrita na literatura, a importância do seu diagnóstico seguro, a necessidade de cuidados na confecção dos aparelhos disjuntores e as consequiências de um diagnóstico equivocado indicam a necessidade de mais estudos e de ampliação do conhecimento sobre a sialometaplasia necrosante nas várias especialidades odontológicas. Este conhecimento ampliado poderá gerar posturas preventivas e benefícios aos pacientes. 
2 REVISÃO DA LITERATURA 


\section{REVISÃO DA LITERATURA}

Neste capítulo, foram analisados 70 artigos publicados no idioma inglês pertinentes à sialometaplasia necrosante, reunindo uma casuística de 258 relatos de casos clínicos, artigos de revisão ${ }^{1,9,10,45,50,57,66,70,74,75,87,111,113}$, carta ao editor ${ }^{7}$ e um estudo experimental $^{101}$. Alguns trabalhos apresentavam muitos casos $\operatorname{clínicos}^{10,100,108}$, não fornecendo maiores detalhes de cada caso.

Muitas informações amplamente difundidas e constantes na maioria dos trabalhos foram consideradas de conhecimento público e geral, por isso não foram especificadas as referências iniciais.

\subsection{Terminologia e nomenclatura}

\subsubsection{NECROSANTE versus NECROTIZANTE}

1- Necrosante: originária do grego nékrosis e significa mortificação ${ }^{81}$; necrotizante, que provoca necrose $^{80}$; que se apresenta em processo de necrose ${ }^{82}$;

2- Necrotizante: que causa necrotização, necrotizador ${ }^{83}$; que sofreu necrose ${ }^{84}$; necrosante, que produz necrose ${ }^{85}$. 


\subsubsection{ENFARTE versus ENFARTO versus INFARTO}

1- Enfarte: infarto ${ }^{32}$; inchado, fartado, ingurgitado ${ }^{31}$; necrose por coagulação circunscrita de um órgão em conseqüência da obliteração de uma artéria ${ }^{33}$;

2- Enfarto: infarto ${ }^{35}$; enfarte $^{36}$;

3- Infarto: enfarte ${ }^{63}$; entupimento, obstrução ${ }^{62}$; fenômeno patológico em que se produz zona de necrose conseqüiente à hipóxia, na maioria dos casos por trombos ou êmbolos ${ }^{61}$; necrose de uma área devido a uma insuficiência súbita de um vaso arterial ou venoso ${ }^{59}$;

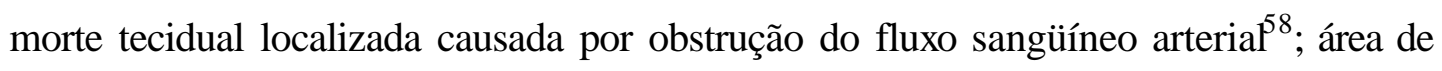
tecido num órgão ou em parte dele que sofreu necrose, seguida de interrupção de suprimento sangüíneo (variante de enfarte e enfarto, mas esta é a melhor forma) ${ }^{65}$.

\subsubsection{DISJUNÇÃO versus DISTRAÇÃO versus EXPANSÃO}

1- Disjunção: ato de disjungir, separar, desunir ${ }^{20}$; segregar $^{21}$; separação dos pares de cromossomos durante a anáfase ${ }^{22}$;

2- Distração: originária do latim distrahere e significa arrastar para diversos $\operatorname{lados}^{27}$; divisão, separação (de algo que se encontra reunido) ${ }^{24}$; rasgar, $\operatorname{romper}^{23}$. É o alongamento de um membro para separar fragmentos ósseos ou superfícies $\operatorname{articulares}^{26}$; localização de dentes ou de outras estruturas maxilares e mandibulares mais afastadas do plano médio do que o normal ${ }^{25}$; 
3- Expansão: originária do latim expansione $e^{40}$ e significa expandir ${ }^{37}$; dilatar ${ }^{39}$; ampliação, crescimento $^{38}$; alargar uma região ${ }^{42}$; processo no qual um volume de massa ou substância é aumentado ${ }^{41}$. Definida como Rapid Maxillary Expansion (Expansão Rápida da Maxila) por OUVÍDIO; FURQUIM ${ }^{11}$, é o alargamento ortopédico das duas metades da maxila geralmente utilizando sistemas de alta carga.

\subsection{Histórico}

Um fato histórico interessante aconteceu com o presidente Stephen Grover Cleveland, o único presidente americano a exercer dois mandatos: o primeiro na década de 1880 (1885-1889) e o segundo na década de 1890 (1893-1897).

Em maio de 1893, os Estados Unidos passavam por uma depressão severa referida como "Pânico de 1893", marcada por dificuldades financeiras. O presidente Cleveland foi chamado ao Congresso para resolver a situação e, associado a estes acontecimentos, descobriu uma irritação no palato $^{78}$.

Passado um mês, a lesão persistia. A preocupação continuava até seu médico Robert Maitland O’Reilly examiná-lo. Intrigado com os seus achados, escreveu uma carta recorrendo ao Dr. Joseph Decatur Bryant.

O presidente tinha 56 anos de idade, era obeso, bebia uísque ocasionalmente e fumava charutos constantemente. Ao exame clínico a lesão apresentavase ulcerada, crateriforme, rugosa, indolor, com exposição óssea e ausência de linfadenopatia regional. As dimensões da lesão atingiam um quarto do palato, com as 
bordas semelhantes à couve-flor e limites envolvendo a gengiva do primeiro molar superior, a linha média e discretamente o palato mole.

Realizada a biópsia, o espécime foi enviado ao Hospital John Hopkins para análise microscópica, aos cuidados de William H. Welch. O espécime também foi examinado por outros patologistas, como Biggs e McAlpin. Conjuntamente, chegaram ao mesmo diagnóstico: "Carcinoma",78.

A equipe médica recomendou a maxilectomia parcial $^{78}$. O procedimento cirúrgico foi realizado secretamente no iate Oneida, partindo da cidade de Nova Iorque com destino a Baía de Buzzards, em Massachusetts, local de uma casa de verão do presidente ${ }^{57}$. O presidente foi operado duas vezes e sobreviveu ao câncer. Morreu 15 anos após as cirurgias, em 1908, de causas não relatadas ${ }^{17}$. Alguns autores sugerem que o presidente foi portador de sialometaplasia necrosante ${ }^{70}$, outros de carcinoma verrucoso ${ }^{17}$.

Após 65 anos da sua morte, ABRAMS; MELROSE; HOWELL ${ }^{2}$, em 1973, relataram na revista Cancer os primeiros casos de sialometaplasia necrosante, uma lesão inflamatória até então diagnosticada equivocadamente como carcinoma mucoepidermóide e carcinoma espinocelular. A partir desta data a lesão ficou esclarecida na literatura e vários casos foram relatados.

\subsection{Etiopatogenia}

A etiologia da sialometaplasia necrosante está relacionada com o

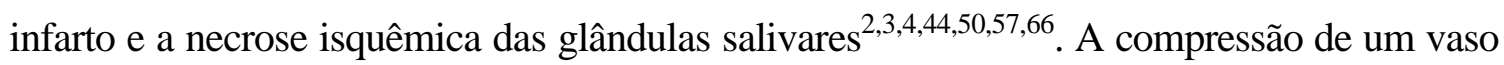


sangüíneo principal como a artéria palatina maior, no palato duro, pode ser a causa principal do infarto ${ }^{4}$, provocada por um fator traumático ${ }^{1,66,89,110}$. Os fatores traumáticos mais comuns são próteses parciais ou totais removíveis mal-adaptadas ou fraturadas $^{3,5,10,47,48,56,67,68,77,79,108}$; agulhas durante as anestesias ${ }^{10,15,47,50,57,69,108}$; traumas e fenômenos vasculares (estenose, trombose ou embolia) após procedimentos cirúrgicos $^{4,9,10,50,75,94,100,108,110}$ e traumas mastigatórios ${ }^{44,47}$.

A sialometaplasia necrosante ainda não foi relacionada ao uso de aparelhos dentomucossuportados. Durante a disjunção palatina ortodôntica, CONSOLARO et al. ${ }^{16}$ relataram haver tempo e força suficientes para o acrílico do aparelho comprimir ou lesar a artéria palatina maior, principal vaso sanguiíneo do palato duro. A isquemia desta artéria e necrose dos tecidos da submucosa palatina e ou infarto das glândulas salivares menores, podem resultar até em sialometaplasia necrosante. Esta conseqüência quase sempre resulta em lesões palatinas necróticas. Os aparelhos disjuntores palatinos são confeccionados independente das particularidades da vascularização palatina. Até o momento, nenhum protocolo de manufatura foi desenvolvido visando evitar a ocorrência dessas lesões, exceto neste trabalho mencionado.

Agressão por fatores físicos, químicos ou infecciosos ${ }^{1,4,29,46,47,50,110}$; pressão digital em pacientes com crises de indução de vômito, provocadas até 50 vezes por semana $^{98}$; ingestão de alimentos muito quente ${ }^{13}$ ou picantes ${ }^{72}$ e pacientes submetidos a tratamento periodontal ${ }^{15,57}$ também são relatados como fatores causais. 
Cinco estádios morfológicos da sialometaplasia necrosante foram descritos por ANNEROTH; HANSEN ${ }^{3}$ e assim caracterizados:

A- Infarto: necrose glandular com alguns ácinos e ductos sobreviventes observados na periferia da lesão;

$B$ - Seqüestro: o tecido necrótico das glândulas salivares necrosadas migra em direção ao epitélio para ser expulso;

C- Ulcerativa: destruição epitelial devido ao tecido necrótico seqüestrado, com exposição do tecido conjuntivo subjacente, formando uma ulceração crateriforme;

D- Reparatória: hiperplasia pseudo-epiteliomatosa e proliferação das projeções epiteliais em direção ao tecido conjuntivo, metaplasia escamosa dos ácinos mucosos e dos ductos das glândulas salivares e reparo da ulceração;

E- Curativa: substituição da estrutura glandular necrosada por tecido conjuntivo fibroso, metaplasia escamosa dos ácinos mucosos e dos ductos, alguns se apresentando dilatados.

Nos espécimes enviados para exame microscópico, estes estádios podem ser observados sobrepostos. Nem sempre estão bem demarcados. As características mais comuns são ulceração, hiperplasia pseudo-epiteliomatosa, necrose dos ácinos mucosos e metaplasia dos ductos, bem como alterações inflamatórias ${ }^{57}$.

O tabagismo e o etilismo são fatores associados a sialometaplasia necrosante ${ }^{30,86,97,99}$. JAINKITTIVONG; SOOKASAM; PHILIPSEN ${ }^{66}$ revisaram 127 casos 
da literatura e encontraram $42 \%$ dos pacientes tabagistas. ABAZA; ABAZA; SEDHOM ${ }^{1}$ apresentaram um caso de sialometaplasia necrosante em paciente tabagista e etilista sofrendo complicações como pancreatite, ascite, hepatite e outras. PHILIPSEN; PETERSON; SIMONSEN ${ }^{88}$ descreveram a sialometaplasia necrosante em um paciente com suspeita de lesão maligna, tabagista e etilista, com características microscópicas de estomatite nicotínica, associando o tabagismo à lesão. Em contraparte, GAHHOS et al. ${ }^{47}$ revisaram a literatura e adicionaram cinco casos de pacientes tabagistas e etilistas, porém sem dados estatisticamente significantes para suportar esta associação com a presença da lesão.

Na laringe, WALKER et al. ${ }^{110}$ encontraram lesões de sialometaplasia necrosante cinco semanas após a manipulação cirúrgica de um aneurisma aterosclerótico localizado na artéria carótida comum. A provável causa da isquemia seria a presença de um êmbolo ateromatoso.

A presença de sialometaplasia necrosante na doença de Buerger, uma tromboangite obliterante, foi relatada por RYE; CALHOUN; REDMAN ${ }^{94}$. Neste caso, o paciente necessitou de amputação parcial dos dedos indicadores e a lesão de sialometaplasia necrosante reparou-se em 17 semanas.

A associação da sialometaplasia necrosante à doenças sistêmicas como diabetes melito ${ }^{56,69,95}$, anemia falciforme ${ }^{71}$, artrite reumatóide ${ }^{112}$ e hipertireiodismo ${ }^{14}$ podem ser achados coincidentes e não relacionados.

A indução experimental de sialometaplasia necrosante em ratos foi objetivo de estudo para SHIGEMATSU et al. ${ }^{101}$. Os autores injetaram solução anestésica no 
palato duro de uma a cinco vezes em cada animal num intervalo de 24 horas. Após as injeções, os animais foram mortos em intervalos estabelecidos e suas glândulas salivares palatinas removidas para análise microscópica e imuno-histoquímica. Os resultados revelaram variados graus de danos às glândulas salivares palatinas, concluindo que a observação da morfologia característica da sialometaplasia necrosante depende do número de injeções anestésicas aplicadas.

\subsection{Características clínicas e radiográficas}

A sialometaplasia necrosante afeta predominantemente o gênero masculino da raça branca na década dos $45 \operatorname{anos}^{10}$. Sua lesão fundamental é a ulceração crateriforme e pode estar situada em localizações variadas. Esta ulceração está circundada por um halo eritematoso, as bordas são levemente elevadas e endurecidas ${ }^{105}$, com dimensões variando de $0,3^{95}$ a $3,5 \mathrm{~cm}^{43}$ de diâmetro e $0,2 \mathrm{~cm}$ de profundidade ${ }^{57,105}$. O osso subjacente à lesão apresenta -se comumente exposto e recoberto por tecido inflamatório e restos necróticos, bem como tecido de granulação na base e na periferia da lesão ${ }^{66}$. Não necessariamente a ulceração é a lesão fundamental da sialometaplasia necrosante. Lesões inicias foram descritas como nódulos eritematosos dando lugar posteriormente às ulcerações típicas ${ }^{1}$.

A lesão pode apresentar sintomatologia dolorosa ou não ${ }^{1,11,29,43,47,57,67,69,87,95,96}$. Nos casos de ulceração ou inchaço de várias semanas, a parestesia do palato precede a lesão $0^{50,66,69,70} \mathrm{e}$, em alguns casos, o paciente pode relatar a "perda" do palato ${ }^{1}$. A dor pode irradiar para o pescoço, olhos, orelha e faringe, bem como 
para a região cervical e nódulos linfáticos, criando ansiedade no paciente em relação à sintomatologia $2,29,50,70,72,78,88,98,111$.

As glândulas salivares do palato duro são as mais comprometidas pela sialometaplasia necrosante ${ }^{66}$, podendo ser afetadas uni ou bilateralmente. As glândulas presentes na junção dos palatos duro e mole podem ser outro local de ocorrência ${ }^{3,68,77,79}$. As glândulas labiais ${ }^{46,73}$, do canal incisivo e da bochecha ${ }^{10}$, do sulco alveolar ${ }^{48}$, do seio maxilar, da região retromolar ${ }^{44}$ e da laringe ${ }^{110}$ também podem ser acometidas, bem como as glândulas salivares maiores e a língua ${ }^{10}$. MARCIANI; SABES ${ }^{72}$ encontraram lesões concomitantes na língua e no palato duro, com diagnósticos respectivos de carcinoma espinocelular e sialometaplasia necrosante.

O primeiro caso de lesões metacrônicas de sialometaplasia necrosante foi relatado por ROSSIE; ALLEN; BURNS ${ }^{93}$. A primeira lesão, ulcerada, lado direito, reparou após quatro semanas. Cinco anos depois, outra lesão, não ulcerada, lado esquerdo, reparou em três semanas.

Alterações hormonais, distúrbios circulatórios e vômitos constantes durante a gravidez são fatores relacionados com a ocorrência das lesões de sialometaplasia necrosante ${ }^{104}$.

O exame radiográfico das lesões de sialometaplasia necrosante apresenta padrões de normalidade, sem apresentar envolvimento ósseo. Contrariamente, CHAKRAVORTY; YONEYAMA; MAKOOI ${ }^{12}$ encontraram reação óssea moderada no processo palatino da maxila esquerda, embora este dado seja insignificante para confirmar o diagnóstico. Para BELL; LOUKOTA ${ }^{6}$, os exames radiográficos revelaram imagens 
radiopacas e radiolúcidas no soalho do seio maxilar e diagnóstico microscópico de pólipo sinusal associado à sialometaplasia necrosante.

Em dois casos apresentados por ABRAMS; MELROSE; HOWELL ${ }^{2}$, os autores observaram discreta imagem radiolúcida. Um outro caso descrito por DAUDIA; MURTY $^{19}$ apresentava ulceração bilateral no palato duro, comunicação com a cavidade nasal e reparação completa em seis meses. Os autores afirmam ser o primeiro caso relatado com envolvimento ósseo do palato.

As três maiores casuísticas de características clínicas e radiográficas da sialometaplasia necrosante estão descritas nos trabalhos a seguir.

\section{Em 1989, JAINKITTIVONG; SOOKASAM; PHILIPSEN ${ }^{66}$} revisaram 127 casos de sialometaplasia necrosante a partir da literatura. A predominância foi em pacientes do gênero masculino e da raça branca, com idades variando de 14 a 83 anos. As apresentações clínicas variavam de áreas eritematosas pouco elevadas a profundas ulcerações de 0,5 a $4 \mathrm{~cm}$ de diâmetro, situadas uni ou bilateralmente ao palato duro ou próximo às junções dos palatos duro e mole. Freqüentemente estendiam-se ao osso subjacente e estavam recobertas por exsudato inflamatório ou debris necróticos. Os sintomas variavam de um leve desconforto a dores irradiadas ao ouvido do mesmo lado da lesão ou à faringe. Dos 127 casos, 96 estavam localizados no palato duro e 31 em outras localidades, como glândulas salivares maiores e cavidade nasal. Na maioria dos casos, a lesão fundamental foi a ulceração. As características radiográficas não foram relatadas pelos autores. 
Em 1991, BRANNON; FOWLER; HARTMAN ${ }^{10}$ revisaram 69 casos a partir dos arquivos de Patologia Cirúrgica do Instituto de Patologia das Forças Armadas (AFIP). Observaram predominância em pacientes do gênero masculino, raça branca e 45 anos de idade em média. Sua localização mais comum foi o palato duro, seguido do lábio inferior, região retromolar, glândulas salivares maiores e outras localidades, com duração de 18 dias em média. A lesão fundamental mais comum foi a ulceração, com predominância de sintomatologia dolorosa. Apesar do envolvimento ósseo não ser representativo, em um caso ocorreu imagem radiolúcida circunscrita nas glândulas do canal incisivo.

Em 1992, SEIFERT ${ }^{100}$ revisou uma casuística de 75 casos, reunidas em 24 anos, a partir do Registro de Glândulas Salivares da Universidade de Hamburgo. Observou não haver predileção pelo gênero e o pico de idade abrangia os 60 anos em média e localizava-se mais comumente na glândula parótida, seguida pelo palato.

\subsection{Características microscópicas}

A maior contribuição referente às características microscópicas típicas da sialometaplasia necrosante foi descrita em 1973 por ABRAMS; MELROSE; HOWELL $^{2}$. Os autores enumeraram-nas da seguinte forma:

1- infarto ou necrose dos lóbulos das glândulas salivares;

2- morfologia nuclear das células escamosas discretamente preservada;

3- metaplasia escamosa acinar e ductal; 
4- tecidos de granulação e inflamatório proeminentes;

5- manutenção da arquitetura geral dos lóbulos das glândulas salivares.

A manutenção da arquitetura geral das glândulas salivares é uma das características mais relevantes para diferenciar a sialometaplasia necrosante de lesões malignas. O epitélio predominante é do tipo pavimentoso estratificado escamoso. A hiperplasia pseudo-epiteliomatosa e a acantose apresentam-se comumente ${ }^{2}$.

No tecido conjuntivo, observa-se infarto das glândulas salivares mucosas com os ácinos preenchidos por material mucóide e circundados por delicados septos fibrosos. Os ductos são compostos por células ora escamosas, ora basais, com alterações da sua espessura. Alguns ácinos e ductos apresentam metaplasia escamosa. Outros ácinos e ductos encontram-se com transformação aparente em massas sólidas e cordões de componentes celulares similares ${ }^{2}$.

As áreas adjacentes são caracterizadas por material mucóide e organização semelhante ao cisto de retenção mucoso ${ }^{90}$. O infiltrado inflamatório predominante é do tipo polimorfonuclear, com eventuais células pseudoxantomatosas ${ }^{2}$.

O tecido de granulação se apresenta proeminente em muitas áreas, particularmente próximo às ulcerações. Algumas áreas contêm acúmulos de células escamosas arredondadas ou ovóides apresentando núcleos uniformes e discretos, com abundante citoplasma eosinofílico ${ }^{2}$.

Em algumas ilhotas predominam células epiteliais basais escamosas com regiões completamente hipercromáticas e mitoses típicas. Alguns dos grupos 
metaplásicos estão dentro da coleção mucóide e adjacentes aos componentes glandulares necróticos. Os microcistos com conteúdo mucóide podem ser eventuais ${ }^{2}$. A presença de vasculite, trombose, granulomas ou microorganismos ${ }^{103}$ são achados incomuns.

\subsection{Diagnóstico diferencial}

Os diagnósticos equivocados mais comuns de sialometaplasia necrosante são com as lesões malignas, como os carcinomas mucoepidermóide ${ }^{106}$ e espinocelular ${ }^{28}$ e neoplasias de glândulas salivares ${ }^{18,107}$. Outra lesão, porém inflamatória, é a sialoadenite necrosante subaguda ${ }^{45}$.

A sialoadenite necrosante subaguda apresenta semelhanças clínicas e microscópicas com a sialometaplasia necrosante e foi revisada por FOWLER; $\mathrm{BRANNON}^{45}$. Afeta as glândulas salivares do palato duro, mede até $2,5 \mathrm{~cm}$ de diâmetro, é indolor e não ulcerada. Acomete em maior proporção o gênero masculino nas idades entre 15 e 45 anos. A microscopia óptica revela necrose e perda das células acinares, atrofia das células ductais, presença de infiltrado inflamatório e, ultra-estruturalmente, partículas virais. Sua etiologia é desconhecida e os autores sugeriram ser a representação de um processo infeccioso ou de uma resposta imune a alérgenos. Contrariamente, outros autores incluíram esta entidade no espectro da sialometaplasia necrosante.

A metaplasia escamosa adjacente às áreas necróticas das neop lasias das glândulas salivares é comum e deve ser distinguida das encontradas em outras lesões. A maior dificuldade para o diagnóstico encontra-se na periferia da necrose tumoral. No carcinoma espinocelular, a metaplasia escamosa representa uma reação à proliferação 
epitelial com extensão pseudo-invasiva circundando os tecidos; os eventuais focos de células caliciformes podem confundila com carcinoma mucoepidermóide. Na sialometaplasia necrosante, a metaplasia escamosa ocorre nos ácinos e ductos devido à necrose isquêmica das glândulas salivares ${ }^{28}$. A sialometaplasia necrosante pode apresentar relação morfológica com a metaplasia escamosa ou mucinosa observada nos tumores oncocíticos, sendo úteis para excluir o diagnóstico de carcinoma de glândula salivar ${ }^{107}$.

Um caso de sialometaplasia necrosante com ulceração no palato duro e inicialmente diagnosticada como carcinoma espinocelular invasivo foi apresentado por BIRKHOLZ; BROWND ${ }^{8}$. A biópsia foi indispensável, evitando cirurgias radicais desnecessárias devido ao reparo aparente da lesão.

Aproximadamente dez mil espécimes enviados ao Serviço de Patologia da Faculdade de Medicina e Odontologia de Nova Jersey durante dez anos (19661975) foram revisados por MESA; GERTLER; SCHNEIDER ${ }^{76}$. Os autores estavam preocupados com o diagnóstico equivocado da lesão antes da sua descoberta em 1973. Encontraram três casos de sialometaplasia necrosante, não havendo diagnóstico anterior de lesão maligna.

Um caso com suspeita de carcinoma basocelular no lábio superior foi relatado por GRANICK et al. ${ }^{49}$. Os autores realizaram biópsia e a análise microscópica confirmou carcinoma basocelular. Ao retornar para reconstrução labial, havia surgido uma reação eczematosa na pele do paciente; esta foi biopsiada e diagnosticada como sialometaplasia necrosante. 
A sugestão de sialometaplasia necrosante em uma paciente chinesa de 48 anos de idade foi relatada por CORRELL; WESCOTT; PIERCE ${ }^{18}$. Há um ano apresentava um inchaço indolor sem aumento das dimensões, firme à palpação, não flutuante e sem envolvimento ósseo. Após a biópsia, o diagnóstico foi de adenoma pleomorfo.

Um dos casos relatados por SUCKIEL et al. ${ }^{106}$ foi diagnosticado equivocadamente como carcinoma mucoepidermóide pelo patologista médico, sem apresentar evolução condizente. Após a revisão do exame microscópico, o diagnóstico de sialometaplasia necrosante foi estabelecido.

A história médica e de traumas anteriores, o aspecto clínico e morfológico, o tempo de evolução, bem como de reparo, são dados importantes para eliminar os diagnósticos de malignidade. É importante salientar que a sialometaplasia necrosante pode obscurecer o diagnóstico de lesões malignas ${ }^{89}$.

Em 2001, VELLOSO ${ }^{109}$ analisou os arquivos do Serviço de Anatomia Patológica da FOB-USP, de 1963 a 2000, com o intuito de estudar sua evolução e características, realizando uma revisão e atualização dos seus arquivos e métodos. Observou-se um aumento crescente e significativo da demanda dos serviços prestados, bem como um aperfeiçoamento destes. Revisou laudos, blocos e lâminas, avaliando se a nomenclatura das lesões condizia com a atual. Observou o reconhecimento de entidades clínicas novas e os erros de diagnóstico. Um caso diagnosticado previamente como carcinoma mucoepidermóide foi reavaliado e diagnosticado como sialometaplasia necrosante. Discutiu-se sobre as prováveis razões para as diferenças encontradas e 
concluiu-se da necessidade de atualização constante no trabalho em grupo, bem como do estímulo constante à análise crítica dos conceitos e critérios diagnósticos em todos os momentos na prática da Patologia Bucal como especialidade odontológica.

\subsection{Tratamento}

A evolução natural da sialometaplasia necrosante é a reparação espontânea por segunda intenção incluída no período de uma ${ }^{87}$ a de $z^{29,43,57,79}$ semanas, dependendo da extensão da lesão. A reparação é lenta devido à necessidade de grande quantidade de tecido para recobrir a área ulcerada.

A remoção do trauma é uma alternativa de tratamento. Caso não seja possível determinar uma relação causa-efeito, a biópsia incisional ou excisional torna-se indispensável.

A antibioticoterapia constitui um aliado importante para evitar as infecções oportunistas. Analgésicos e antiinflamatórios podem ser de grande utilidade para controlar a dor e modular o processo inflamatório localizado.

Os exames laboratoriais não revelam alterações decorrentes da sialometaplasia necrosante. Quando o paciente apresenta história de doenças infecciosas ou sistêmicas deve ser encaminhado para um especialista.

Não há relatos de recidiva após a confirmação microscópica de sialometaplasia necrosante. A lesão pode deixar cicatrizes pouco visíveis depois de reparado o local. 
3 PROPOSIÇÃO 


\section{PROPOSIÇÃO}

Com base na literatura pertinente, a partir de fichas de envio de peças cirúrgicas ao Serviço de Anatomia Patológica, dos cortes microscópicos dos arquivos de lâminas do Serviço de Anatomia Patológica Bucal da Faculdade de Odontologia de Bauru, Universidade de São Paulo e de um caso clínico, propusemo-nos a:

3.1 Estudar e rever os aspectos microscópicos da sialometaplasia necrosante;

3.2 Estudar os aspectos particulares de sua prevalência quanto aos locais e demais formas clínicas correlacionando seus possíveis agentes etiopatogênicos;

3.3 Apresentar uma hipótese sobre a etiopatogenia da sialometaplasia necrosante induzida por aparelhos disjuntores palatinos. 
4 MATERIAL E MÉTODOS 


\section{MATERIAL E MÉTODOS}

\subsection{Obtenção, seleção e caracterização da amostragem}

A amostra constituiu-se de lâminas e blocos pertencentes aos arquivos do Laboratório de Anatomia Patológica da Faculdade de Odontologia de Bauru, Universidade de São Paulo. As peças cirúrgicas foram provenientes das diferentes clínicas da FOB-USP, de outras Faculdades de Odontologia do Brasil e de consultórios particulares.

Os critérios para seleção da amostra analisada microscopicamente obedeceram à ordem cronológica de entrada nos registros até a obtenção de todos os espécimes de Sialometaplasia Necrosante. Resgatou-se todos os casos cadastrados desde 1963 até 2002, a partir de seus respectivos laudos histopatológicos, descrevendo inclusive as características registradas na clínica e na análise microscópica óptica, totalizando 17 casos.

Os cortes observados com coloração de hematoxilina e eosina (H.E.) deveriam estar preservados e não apresentar artefatos de técnica, favorecendo uma análise morfológica criteriosa. Quando necessário, novos cortes microscópicos foram confeccionados.

\subsection{Distribuição da amostragem}

A amostragem foi distribuída de acordo com o diagnóstico conclusivo, compatível ou sugestivo de sialometaplasia necrosante e ou lesões associadas. 
Os casos diagnosticados como Carcinoma Mucoepidermóide e Espinocelular, antes de 1987, foram reavaliados para verificar a ocorrência de diagnóstico equivocado.

Foram adotados os seguintes critérios de inclusão:

a) laudos com diagnóstico microscópico conclusivo, compatível ou sugestivo de sialometaplasia necrosante, podendo associar-se à outra lesão;

b) laudos com presença ou ausência de relato clínico e ou radiográfico.

As lâminas foram acondicionadas em caixas apropriadas.

\subsection{Caracterização da amostra}

A amostra foi caracterizada e disposta em tabelas, de 1 a 7 , conforme apresentadas no capítulo dos resultados, de acordo com a distribuição de parâmetros estabelecidos, como a época do diagnóstico microscópico ao longo dos 40 anos de evolução do Serviço de Anatomia Patológica da FOB-USP, gênero, raça e idade dos pacientes, localização e lesão fundamental, etiologia associada, sintomatologia relatada pelo paciente e o tempo de evolução da lesão no momento do diagnóstico clínico. 


\subsection{Análise microscópica descritiva}

A avaliação microscópica das lesões baseourse nos aspectos registrados em tabelas elaboradas previamente, como no modelo abaixo:

\begin{tabular}{|c|c|c|c|c|c|c|c|c|c|c|c|c|}
\hline & & & & & & & & $\overline{\operatorname{Re}}$ & tro & & & \\
\hline & & onst & ção dos D & Tecidos & $\overline{1}$ & 2 & 3 & $\overline{4}$ & $\overline{5}$ & 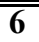 & 7 & $\overline{88}$ \\
\hline & & & pitélio & Atrófico & & & & & & & & \\
\hline & & & ratificado & Normal & & & & & & & & \\
\hline ฮี & 0. & & imentoso & Hiperplásico & & & & & & & & \\
\hline 徥 & 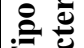 & & & & & & & & & & & \\
\hline 言 & $F \underset{\pi}{=}$ & & Iiperplasia & epiteliomatosa & & & & & & & & \\
\hline & & & & & & & & & & & & \\
\hline & & & & & & & & & & & & \\
\hline & & & & & & & & & & & & \\
\hline & & & $\mathbf{V a}$ & í́neos & & & & & & & & \\
\hline & $\Xi$ & Fen & enos & Trombose & & & & & & & & \\
\hline & 恶 & Vas & lares & Embolia & & & & & & & & \\
\hline & & & & Necrose & & & & & & & & \\
\hline & & & & lo de Granulação & & & & & & & & \\
\hline 㫣 & & & & Discreto & & & & & & & & \\
\hline$\tilde{\theta}$ & & Sev & dade & Moderado & & & & & & & & \\
\hline 으를 & & & & Intenso & & & & & & & & \\
\hline 兑 & 刍 & & & Neutrófilo & & & & & & & & \\
\hline & $\ddot{\Xi}$ & i్ల్ల్ & PMN & Eosinófilo & & & & & & & & \\
\hline & 常 & $\overline{0}$ & & Basófilo & & & & & & & & \\
\hline & & है & MN & $\begin{array}{c}\text { Linfócito } \\
\text { Plas mócito }\end{array}$ & & & & & & & & \\
\hline & & & & Macrófago & & & & & & & & \\
\hline & & & & & & & & & & & & \\
\hline & & & $\mathbf{C a}$ & ientes & & & & & & & & \\
\hline & E & & Biofil & obianos & & & & & & & & \\
\hline 0 & 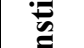 & & & Osteócito & & & & & & & & \\
\hline & نे & & & Osteoblasto & & & & & & & & \\
\hline & & & & Osteoclasto & & & & & & & & \\
\hline & Alte & со̃es & & $\begin{array}{l}\text { la Escamosa } \\
\text { crose }\end{array}$ & & & & & & & & \\
\hline & & & Ilhot: & dlas Mioepiteliais & & & & & & & & \\
\hline & & & & & & & & & & & & \\
\hline & 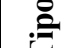 & & & & & & & & & & & \\
\hline E. & & & & & & & & & & & & \\
\hline 节 & & & & & & & & & & & & \\
\hline & & & & & & & & & & & & \\
\hline & है & & & & & & & & & & & \\
\hline & $\tilde{a}$ & & 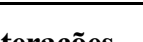 & Dilatado & & & & & & & & \\
\hline & & & ter açoes & Muco no Interior & & & & & & & & \\
\hline & $\mathbf{F a}$ & $\overline{\text { de } E}$ & ução (ANI & $\overline{\text {; HANSEN }^{3} \text { ) }}$ & & & & & & & & \\
\hline
\end{tabular}


A observação das diversas características microscópicas nas lesões foi descritiva registrando-se a ausência ou presença de estruturas e de determinados fenômenos, como exemplo, a inflamação.

O epitélio foi classificado como atrófico, estratificado pavimentoso normal ou hiperplásico. Eventualmente poderia estar ausente, desorganizado, com exocitose, com hiperplasia pseudo-epiteliomatosa, displásico ou ulcerado.

A submucosa e o tecido conjuntivo foram analisados quanto à presença ou ausência de vasos sangüíneos e nervos. Eventualmente poderiam apresentar fenômenos vasculares como trombose e embolia, bem como necrose e tecido de granulação.

O infiltrado inflamatório foi analisado quanto à sua severidade como discreto, moderado e intenso. O infiltrado inflamatório foi analisado ainda quanto à sua composição e tipo celular.

As glândulas salivares foram classificadas como mucosas, serosas e mistas. Os ductos foram analisados como intercalares, estriados e excretores. Foram incluídas alterações glandulares como metaplasia escamosa, necrose, dilatação e presença de muco no interior dos ductos, bem como a presença de ilhotas de células mioepiteliais.

O tecido ósseo foi analisado quanto à presença de periósteo, canais de Havers e Volkmann e células como osteócitos, osteoblastos e osteoclastos. Eventualmente o tecido ósseo, bem como algumas destas estruturas, poderiam estar ausentes ou desorganizadas. 
A fase de evolução da sialometaplasia necrosante foi classificada, de acordo com ANNEROTH; HANSEN ${ }^{3}$ (FIGURA 1), como A ou de infarto; B ou de seqüestro; C ou ulcerativa; D ou reparatória; E ou curativa. Eventualmente ocorreu associação entre as fases. A descrição minuciosa dessas fases já foi descrita no capítulo da Revisão da Literatura, item 2.3, página 11.

Utilizoutse para a análise microscópica um aparelho binocular Olympus CHK-B145 e um microscópio de luz transmitida Carl Zeiss, West German. As fotomicrografias foram obtidas a partir de um aparelho Zeiss com lente optovar 1,25x e lente de projeção 3,2x, pertencentes ao Serviço de Anatomia Patológica da Faculdade de Odontologia de Ba uru, Universidade de São Paulo.

\subsection{Caso clínico}

Um caso clínico de lesão necrótica no palato duro induzida por aparelho disjuntor palatino foi explorado quanto à sua evolução, relações etiopatogênicas e conduta terapêutica, conforme descrito no capítulo dos resultados. 


\subsection{Análise estatística}

\subsubsection{Análise intra-examinador}

Após 21 dias, todos os casos foram reavaliados para aplicação do índice Kappa, no intuito de avaliar a confiabilidade do método de análise, bem como o nível de concordância de um mesmo examinador.

Foram escolhidos para este teste os seguintes critérios, considerados mais relevantes:
a) Característica do epitélio estratificado pavimentoso de revestimento;
b) Severidade do infiltrado inflamatório;
c) Metaplasia escamosa do tecido glandular salivar;
d) Ilhotas de células mioepiteliais no tecido glandular salivar. 

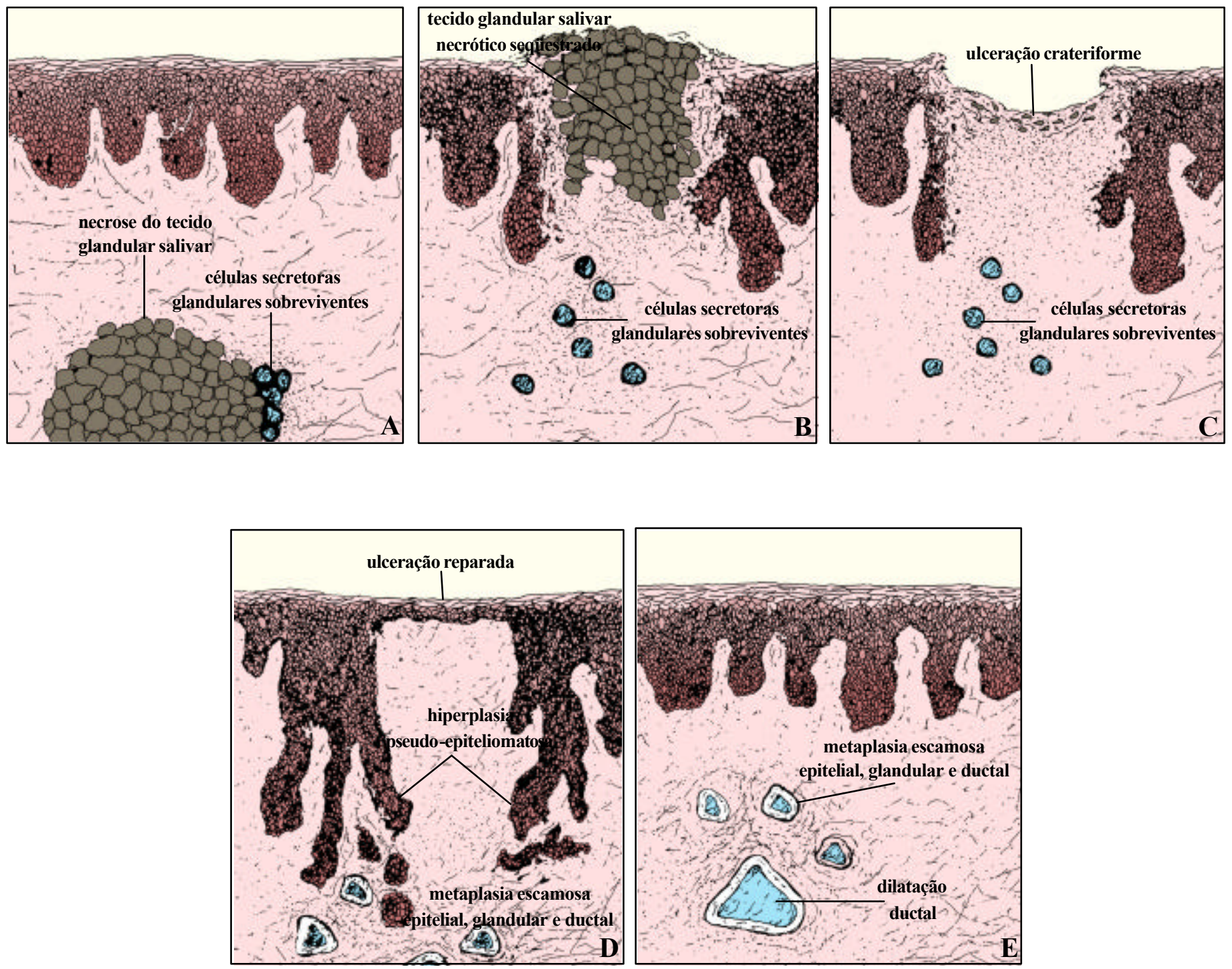

FIGURA 1 - Desenho esquemático e representativo dos cinco estádios morfológicos da sialometaplasia necrosante, de acordo com ANNEROTH; HANSEN ${ }^{3}$ : A=Infarto; $\mathrm{B}=$ Sequiestro; $\mathrm{C}=$ Ulcerativa; $\mathrm{D}=$ Reparatória; $\mathrm{E}=$ Curativa. Este foi um dos critérios utilizados para análise microscópica 


\section{RESULTADOS}

\subsection{Caracterização da amostra}

\subsubsection{Quanto à época do diagnóstico do Serviço de Anatomia Patológica da FOB-USP}

As sialometaplasias necrosantes foram diagnosticadas ao longo dos 40 anos do Serviço de Anatomia Patológica da FOB-USP (1963-2003), desde 1989. Um caso diagnosticado anteriormente a esta data, em 1969, também se tratava de Sialometaplasia Necrosante, conforme demonstrado no trabalho de VELLOSO ${ }^{109}$. Os casos e sua distribuição no tempo estão representados na TABELA 1.

TABELA 1 - Diagnósticos de Sialometaplasia Necrosante ao longo dos 40 anos do Serviço de Anatomia Patológica da FOB-USP ( $n=17$ )

\begin{tabular}{c||c||c}
\hline \multicolumn{1}{c||}{ Anos } & Diagnóstico Estabelecido & n \\
\hline \hline $\mathbf{1 9 6 3 - 1 9 6 8}$ & - & - \\
\hline $\mathbf{1 9 6 9}$ & Sialometaplasia Necrosante* & 1 \\
\hline $\mathbf{1 9 7 0}-\mathbf{1 9 8 8}$ & - & - \\
\hline $\mathbf{1 9 8 9}$ & Sialometaplasia Necrosante & 1 \\
\hline $\mathbf{1 9 9 0}-\mathbf{1 9 9 4}$ & - & - \\
\hline $\mathbf{1 9 9 5}$ & Sialometaplasia Necrosante & 3 \\
\hline $\mathbf{1 9 9 6}$ & Sialometaplasia Necrosante & 2 \\
\hline $\mathbf{1 9 9 7}$ & Sialometaplasia Necrosante & 2 \\
\hline $\mathbf{1 9 9 8}$ & & - \\
\hline $\mathbf{1 9 9 9}$ & Sialometaplasia Necrosante & 2 \\
\hline $\mathbf{2 0 0 0}$ & Sialometaplasia Necrosante & 3 \\
\hline $\mathbf{2 0 0 1}$ & Sialometaplasia Necrosante & 2 \\
\hline $\mathbf{2 0 0 2}$ & Sialometaplasia Necrosante & 1 \\
\hline \hline
\end{tabular}

* Diagnóstico anterior de Carcinoma Mucoepidermóide ${ }^{109}$ 


\subsubsection{Quanto às características pessoais dos pacientes}

\subsubsection{Quanto ao gênero}

Não houve significante predileção pelo gênero. A distribuição dos casos está demonstrada na TABELA 2.

\subsubsection{Quanto à raça}

A raça branca totalizou $100 \%$ dos casos examinados. Em um caso não houve relato da raça do paciente. Sua distribuição está demonstrada na TABELA 2.

\subsubsection{Quanto à idade}

Ocorreu variação entre 7 e 72 anos de idade. Em três casos não houve relato da idade do paciente. A distribuição dos casos está demonstrada na TABELA 2.

TABELA 2 - Distribuição dos casos de Sialometaplasia Necrosante de acordo com o gênero, raça e idade $(\mathrm{n}=14 *)$

\begin{tabular}{|c|c|c|c|c|c|c|c|c|c|c|c|c|c|c|}
\hline \multicolumn{2}{|c|}{$\begin{array}{l}\text { Idade } \\
\text { (anos) }\end{array}$} & $0-5$ & $6-10$ & $11-15$ & $16-20$ & 21-25 & $26-30$ & $31-35$ & $36-40$ & $41-45$ & $46-50$ & $51-55$ & $\geq 56$ & Total \\
\hline \multirow{2}{*}{ 苞 } & $\mathbf{M}$ & - & - & - & - & 1 & - & 1 & - & 1 & - & 1 & 3 & 7 \\
\hline & $\mathbf{F}$ & - & 2 & - & 1 & - & 1 & - & - & - & - & 2 & 1 & 7 \\
\hline \multirow{3}{*}{ 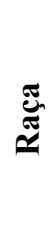 } & B & - & 2 & - & 1 & 1 & 1 & 1 & - & 1 & - & 3 & 4 & \multirow{3}{*}{14} \\
\hline & $\mathbf{N}$ & - & - & - & - & - & - & - & - & - & - & - & - & \\
\hline & $\mathbf{A}$ & - & - & - & - & - & - & - & - & - & - & - & - & \\
\hline
\end{tabular}

* Em três casos não houve relato de idade e em um caso não houve relato de raça 


\subsubsection{Quanto às características clínicas relatadas pelos profissionais}

As características clínicas resgatadas a partir das fichas clínicas foram tabuladas e apresentadas em tabelas.

\subsubsection{Quanto à localização da lesão}

$\mathrm{Na}$ casuística analisada, a localização predominante foi no soalho bucal. Destacamos ainda que em quatro casos a sialometaplasia necrosante ocorreu no palato duro, um na junção dos palatos duro e mole e outro no palato mole (TABELA 3).

TABELA 3 - Distribuição dos casos de Sialometaplasia Necrosante de acordo com a localização da lesão $(\mathrm{n}=17)$

\begin{tabular}{l|l||c}
\hline \hline \multicolumn{2}{c||}{ Dados Clínicos } & Total \\
\hline \hline \multirow{4}{*}{ Localização } & Soalho Bucal & 5 \\
\cline { 2 - 3 } & Palato Duro & 4 \\
\cline { 2 - 3 } & Palato Mole & 1 \\
\cline { 2 - 3 } & Junção dos Palatos Duro e Mole & 1 \\
\cline { 2 - 3 } & Lábio Inferior & 3 \\
\cline { 2 - 3 } & Bochecha & 1 \\
\cline { 2 - 3 } & N/E* & 2 \\
\hline
\end{tabular}

$* \mathrm{~N} / \mathrm{E}=$ Não Especificado

\subsubsection{Quanto à lesão fundamental apresentada}

A maior parte dos casos (sete) apresentava-se descrita como nódulo. Destacamos ainda que em quatro, a lesão fundamental foi descrita como ulceração (TABELA 4). 
TABELA 4 - Distribuição dos casos de Sialometaplasia Necrosante de acordo com a lesão fundamental $(\mathrm{n}=17)$

\begin{tabular}{l|l||c||}
\hline \hline \multicolumn{2}{c|}{ Dados Clínicos } & Total \\
\hline \hline \multirow{4}{*}{ Lesão Fundamental } & & 7 \\
& Nódulo & 4 \\
\cline { 2 - 3 } & Ulceração & 17 \\
\cline { 2 - 3 } & Bolha & 5 \\
\cline { 2 - 3 } & N/E & \\
\hline
\end{tabular}

$* \mathrm{~N} / \mathrm{E}=$ Não Especificado

\subsubsection{Quanto ao momento do diagnóstico e causas relacionadas}

Neste item, classificamos as lesões como primárias quando com diagnóstico exclusivo de sialometaplasia necrosante, e em secundárias quando com diagnóstico de sialometaplasia necrosante associada a outras lesões. Entre as primárias, a causa mais comum foi algum fator relacionado à alimentação (TABELA 5).

Quanto às secundárias, a situação primária preexistente mais comum foi o mucocele. De forma intrigante e ao mesmo tempo esclarecedora, um dos casos mais extremos na caracterização da sialometaplasia necrosante ocorreu em conseqüência de uma cirurgia de lábio inferior para remoção de um carcinoma espinocelular em área com queilite actínica (FIGURAS 7 e 8). 
TABELA 5 - Distribuição dos casos de Sialometaplasia Necrosante de acordo com as causas primárias e secundárias $(\mathrm{n}=17)$

\begin{tabular}{l|c||c|c|c||c||c}
\hline \hline \multicolumn{1}{c|}{ Causas } & Alimentação & $\begin{array}{c}\text { Trauma por } \\
\text { PPR* }^{*}\end{array}$ & $\begin{array}{c}\text { Trauma por } \\
\text { Cirurgia }\end{array}$ & $\begin{array}{c}\text { Trauma por } \\
\text { Mordida }\end{array}$ & N/E** & Total \\
\hline \hline Primárias & 2 & 1 & - & - & \\
\hline \hline Secundárias & 1 & - & 1 & 1 & 11 \\
\hline \hline
\end{tabular}

* PPR $=$ Prótese Parcial Removível

$* * \mathrm{~N} / \mathrm{E}=$ Não Especificado

\subsubsection{Quanto à sintoma tologia clínica}

Nos casos em que esta informação foi apresentada, o sintoma mais freqüente foi a dor (TABELA 6).

TABELA 6 - Distribuição dos casos de Sialometaplasia Necrosante de acordo com a presença ou ausência de sintomatologia dolorosa $(n=17)$

\begin{tabular}{l||l||c}
\hline \hline \multicolumn{1}{c|}{ Sint omatologia Dolorosa } & n & Total \\
\hline \hline Presença & 6 & \multirow{2}{*}{17} \\
\hline Ausência & 6 & \\
\hline N/E $^{*}$ & 5 & \\
\hline \hline
\end{tabular}

$* \mathrm{~N} / \mathrm{E}=$ Não Especificado

\subsubsection{Quanto ao tempo de evolução da lesão no momento do diagnóstico}

Nos casos em que esta informação foi apresentada, o tempo de evolução variou de 10 a 365 dias (TABELA 7). 
TABELA 7 - Distribuição dos casos de Sialometaplasia Necrosante de acordo com o tempo de evolução da lesão no momento do diagnóstico $(n=17)$

\begin{tabular}{c|c||c||c||c||c||c||c|c}
\hline \hline $\begin{array}{c}\text { Evolução } \\
\text { (dias) }\end{array}$ & $\mathbf{1 0}$ & $\mathbf{1 5}$ & $\mathbf{4 5}$ & $\mathbf{9 0}$ & $\mathbf{1 2 0}$ & $\mathbf{3 6 5}$ & $\mathbf{N} / \mathbf{E}^{*}$ & Total \\
\hline \hline $\begin{array}{c}\mathbf{N}^{\mathbf{0}} \mathrm{de} \\
\text { Casos }\end{array}$ & 1 & 1 & 1 & 2 & 1 & 1 & 10 & $\mathbf{1 7}$ \\
\hline \hline
\end{tabular}

$* \mathrm{~N} / \mathrm{E}=$ Não Especificado

\subsection{Análise das características microscópicas: resultados}

As características microscópicas serão descritas por tópicos. No apêndice encontra-se a descrição detalhada dos 17 casos, se houver interesse por uma visão integrada das características gerais de cada caso.

\subsubsection{Características do epitélio de revestimento}

As características da mucosa bucal quanto ao tipo e situação do epitélio estão demonstradas na TABELA 8. Nessa tabela, destacamos que a ulceração ocorreu em cinco casos e em nenhum deles detectamos displasia epitelial. A hiperplasia pseudo-epiteliomatosa (FIGURA 2) foi observada em apenas um dos casos. Na maioria dos casos, o epitélio estava preservado, mas hiperplásico. 
TABELA 8 - Características microscópicas dos casos de Sialometaplasia Necrosante de acordo com o epitélio de revestimento $(n=17)$

\begin{tabular}{|c|c|c|c|c|}
\hline \multirow{2}{*}{\multicolumn{4}{|c|}{ Constituição }} & Total \\
\hline & & & & $\overline{\mathbf{n}}$ \\
\hline \multirow{7}{*}{ 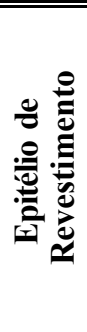 } & \multirow{7}{*}{ 记 } & \multirow{3}{*}{$\begin{array}{c}\text { Epitélio } \\
\text { Estratificado } \\
\text { Pavimentoso }\end{array}$} & Atrófico & 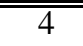 \\
\hline & & & Normal & 4 \\
\hline & & & Hiperplásico & 13 \\
\hline & & \multicolumn{2}{|c|}{ Exocitose } & 8 \\
\hline & & \multicolumn{2}{|c|}{ Hiperplasia Pseudo-epiteliomatosa } & 1 \\
\hline & & \multicolumn{2}{|c|}{ Displasia } & - \\
\hline & & \multicolumn{2}{|c|}{ Ulceração } & 5 \\
\hline
\end{tabular}

\subsubsection{Características do tecido conjuntivo submucoso}

Os dados relativos aos achados microscópicos estão na TABELA 9. O que mais chamou atenção foi o intenso infiltrado inflamatório misto distribuído de forma difusa, ora predominando polimorfonucleares do tipo neutrófilo, ora predominando mononucleares do tipo macrófago, linfócito e plasmócito (FIGURAS 3, 15 e 16). Um tecido de granulação bem organizado foi encontrado em cinco dos 17 casos. Áreas de necrose foram encontradas em dois casos. Em um caso, por uma coincidência feliz, o vaso trombosado responsável pela sialometaplasia necrosante apresentava-se observável nos cortes examinados (FIGURAS 9, 10, 15, 18 e 19). 
TABELA 9 - Características microscópicas dos casos de Sialometaplasia Necrosante de acordo com o tecido conjuntivo submucoso $(n=17)$

\begin{tabular}{|c|c|c|c|c|c|}
\hline \multirow{2}{*}{\multicolumn{5}{|c|}{ Constituição }} & Total \\
\hline & & & & & $\overline{\mathrm{nn}}$ \\
\hline \multirow{15}{*}{ 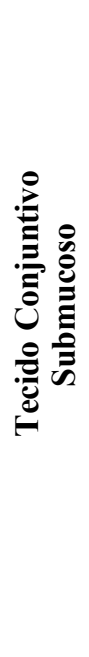 } & \multirow{6}{*}{ 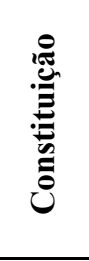 } & \multicolumn{3}{|c|}{ Nervos } & $\overline{13}$ \\
\hline & & \multicolumn{3}{|c|}{ Vasos Sangüíneos } & 17 \\
\hline & & \multirow{2}{*}{\multicolumn{2}{|c|}{$\begin{array}{l}\text { Fenômenos } \\
\text { Vasculares }\end{array}$}} & Trombose & 2 \\
\hline & & & & Embolia & - \\
\hline & & \multirow{2}{*}{\multicolumn{2}{|c|}{ Outras }} & Necrose & 2 \\
\hline & & & & Tecido de Granulação & 5 \\
\hline & \multirow{9}{*}{ 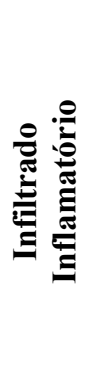 } & \multirow{3}{*}{\multicolumn{2}{|c|}{ Severidade }} & Discreto & 3 \\
\hline & & & & Moderado & 2 \\
\hline & & & & Intenso & 11 \\
\hline & & \multirow{6}{*}{ 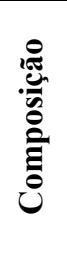 } & \multirow{3}{*}{ PMN } & Neutrófilo & 15 \\
\hline & & & & Eosinófilo & 7 \\
\hline & & & & Basófilo & - \\
\hline & & & \multirow{3}{*}{ MN } & Linfócito & 16 \\
\hline & & & & Plasmócito & 16 \\
\hline & & & & Macrófago & 16 \\
\hline
\end{tabular}

\subsubsection{Características do tecido ósseo}

Quanto às características do tecido ósseo, os fragmentos não apresentavam tecido duro. Em um caso apenas encontroutse grande número de osteoclastos, mas sem tecido mineralizado presente (TABELA 10).

TABELA 10 - Características microscópicas dos casos de Sialometaplasia Necrosante de acordo com o tecido ósseo $(\mathrm{n}=1 *)$

\begin{tabular}{|c|c|c|c|c|}
\hline \multirow{2}{*}{\multicolumn{4}{|c|}{ Constituição }} & Total \\
\hline & & & & $\overline{\mathbf{n}}$ \\
\hline \multirow{6}{*}{ 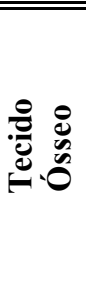 } & \multirow{6}{*}{ 异 } & \multicolumn{2}{|c|}{ Periósteo } & - \\
\hline & & \multicolumn{2}{|c|}{ Canais Nutrientes } & - \\
\hline & & \multicolumn{2}{|c|}{ Biofilmes Microbianos } & - \\
\hline & & \multirow{3}{*}{ Células } & Osteócito & - \\
\hline & & & Osteoblasto & - \\
\hline & & & Osteoclasto & 1 \\
\hline
\end{tabular}

* Em apenas um caso foram encontradas células ósseas, mais especificamente osteoclastos 


\subsubsection{Características das glândulas salivares}

Estas características estão representadas na TABELA 11. As glândulas salivares apresentadas nos cortes foram predominantemente mucosas (FIGURAS $4,5,6,12,14,20,21,24$ e 25$)$ e apenas eventualmente serosa. O padrão misto foi bem mais comum do que o seroso. Os ductos apresentavam-se com freqüência, mas em muitos casos sem os ácinos correspondentes.

A metaplasia escamosa foi observada em 15 dos 17 casos. Este fenômeno é tardio em relação à necrose (FIGURAS 3, 6, 15, 17, 20, 21, 22, 23,24 e 25).

Eventuais ilhotas de células mioepiteliais (FIGURA 24) e de células escamosas (FIGURAS 5, 9, 11, 12, 13, 14 e 16) foram freqüentemente observadas.

No interior do lume ductal, com ou sem metaplasia escamosa, havia associação com dilatação e muco no seu interior (FIGURAS 24 e 25).

TABELA 11 - Características microscópicas dos casos de Sialometaplasia Necrosante de acordo com as glândulas salivares $(n=17)$

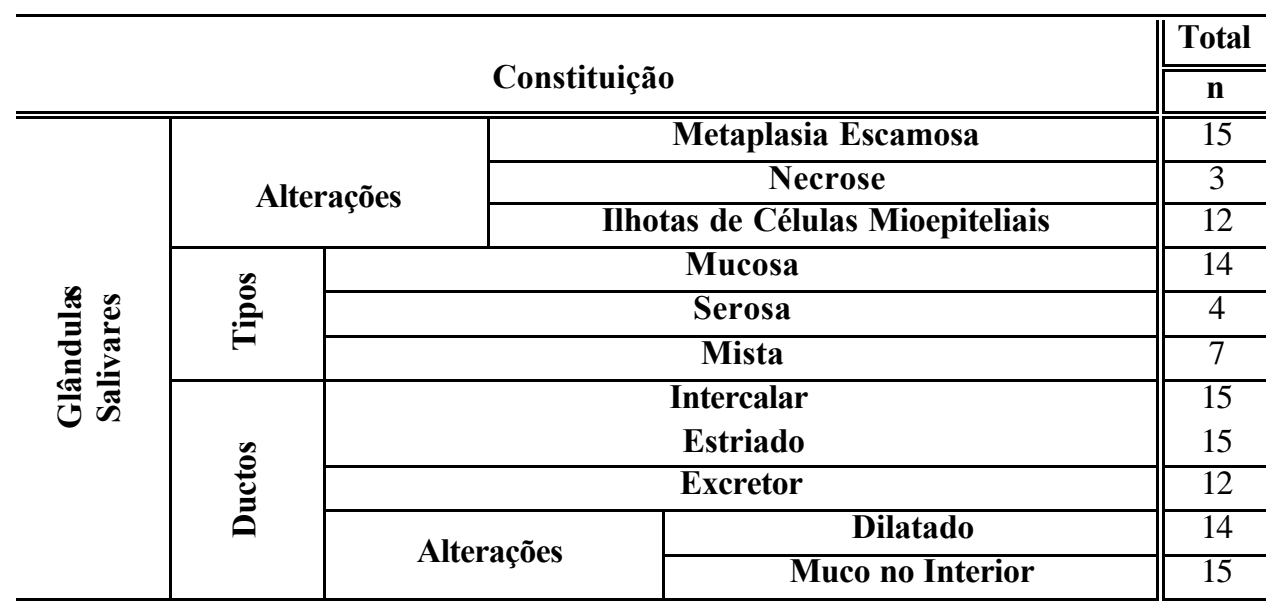




\subsection{Caracterização do quadro microscópico de acordo com as fases evolutivas propostas por ANNEROTH; HANSEN ${ }^{3}$}

Como podemos observar na TABELA 12, as fases predominantes em que as lesões de sialometaplasia necrosante foram biopsiadas são as fases associadas C/D ou ulcerativa/reparatória. Um pouco menos freqüentes foram as fases A ou de infarto e D ou reparatória. Em apenas um caso a fase B ou de seqüestro estava presente e, também em um caso, não foi possível classificar a fase evolutiva por não possuir tecido glandular salivar.

TABELA 12 - Características microscópicas dos casos de Sialometaplasia Necrosante de acordo com as fases evolutivas propostas por ANNEROTH; HANSEN ${ }^{3}$ $\left(\mathrm{n}=16^{*}\right)$

\begin{tabular}{|c|c|c|}
\hline \multirow{2}{*}{\multicolumn{2}{|c|}{ Fase de Evolução (ANNEROTH; HANSEN ${ }^{3}$ ) }} & Total \\
\hline & & $\overline{\mathbf{n}}$ \\
\hline \multicolumn{2}{|c|}{ A ou Infarto } & 3 \\
\hline \multicolumn{2}{|c|}{ B ou Seqüestro } & 1 \\
\hline \multicolumn{2}{|c|}{ C ou Ulcerativa } & 1 \\
\hline \multicolumn{2}{|c|}{ D ou Reparatória } & 2 \\
\hline \multicolumn{2}{|c|}{ E ou Curativa } & 1 \\
\hline \multirow{3}{*}{ Associadas } & $\mathbf{A} / \mathbf{D}$ & 1 \\
\hline & C/D & 5 \\
\hline & $\mathbf{D} / \mathbf{E}$ & 2 \\
\hline
\end{tabular}

* Um caso não apresentava tecido glandular salivar para classificar-se a fase de evolução 


\section{Ilustrações}



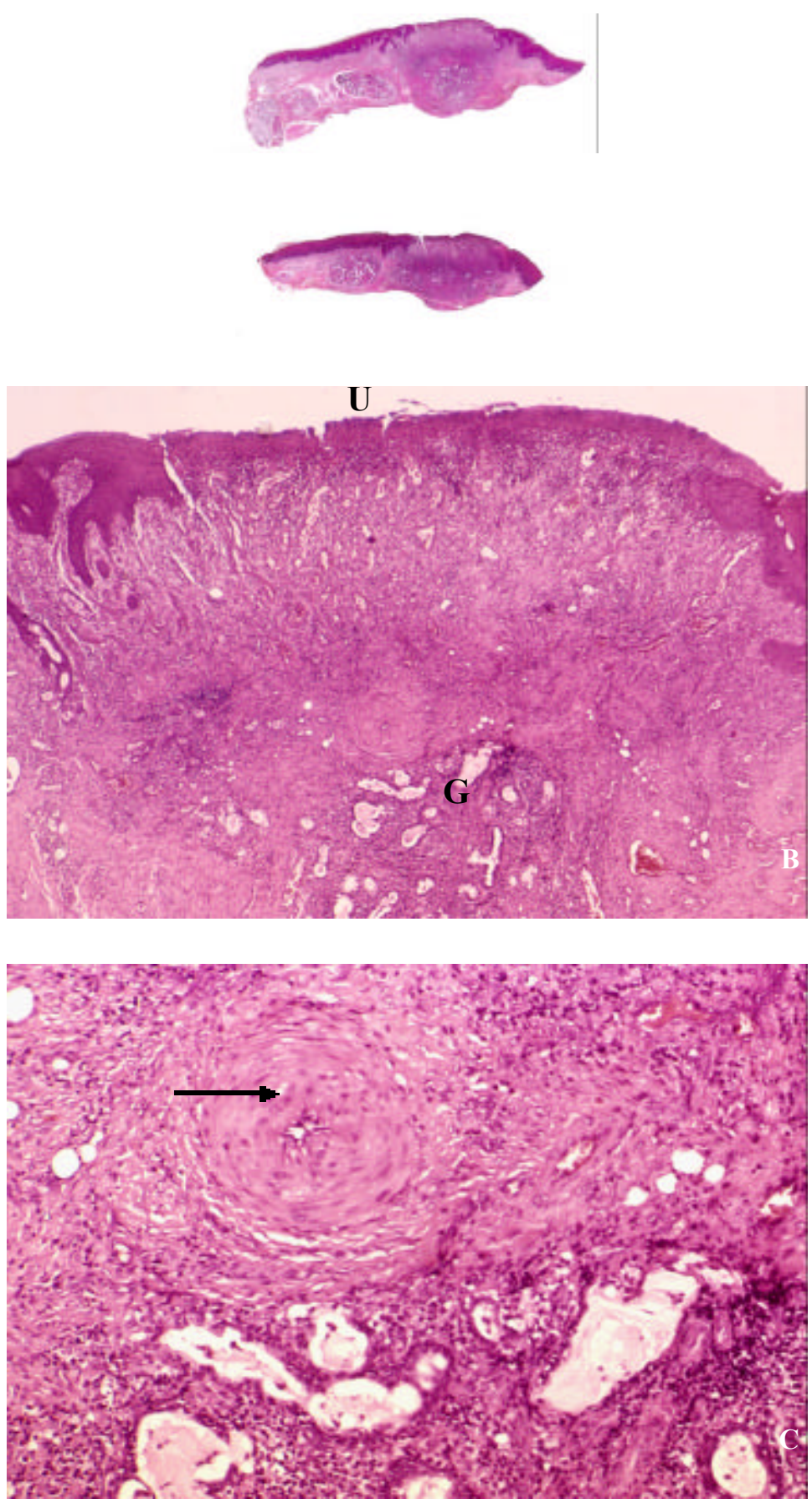

FIGURA 2 - Caso 11 de sialometaplasia necrosante localizada no palato duro com 10 dias de evolução e apresentando-se como lesão ulcerada. Destaca-se a hiperplasia pseudo-epiteliomatosa nas margens da ulceração. Subjacente à glândula salivar (G) revelam-se ácinos e ductos de permeio a intenso infiltrado inflamatório mononuclear. Logo acima da glândula, observa-se uma artéria com obstrução luminar (seta), provavelmente associada a etiopatogenia da lesão. (H.E.; a umento original: $\mathrm{A}=4 \mathrm{x} ; \mathrm{B}=10 \mathrm{x} ; \mathrm{C}=40 \mathrm{x}$ ) 

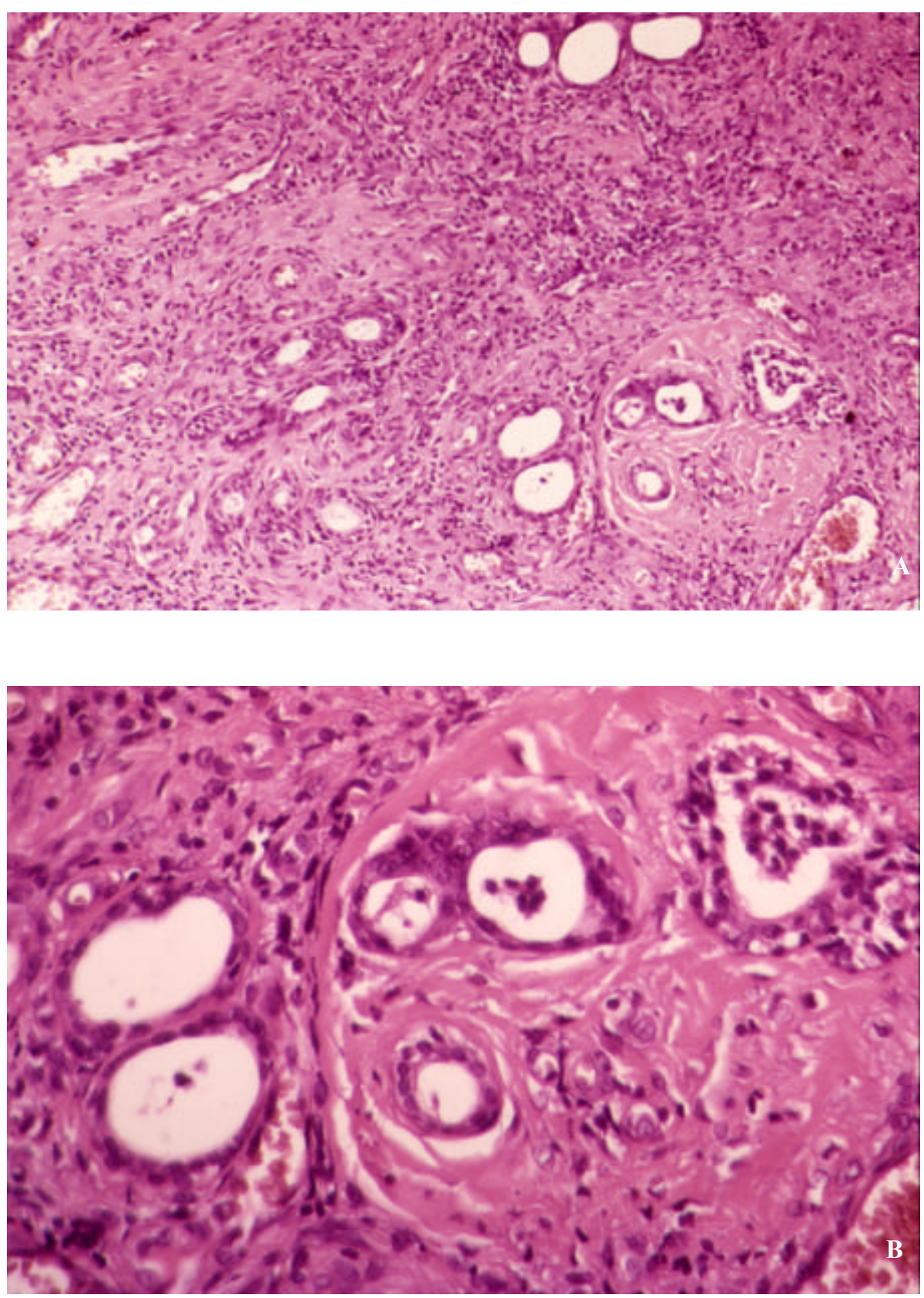

FIGURA 3 - Destaca-se, em outros campos e aumentos, a glândula salivar com ácinos e ductos com metaplasia escamosa de permeio a intenso infiltrado inflamatório mononuclear. (Caso 11; H.E.; aumento original: $\mathrm{A}=40 \mathrm{x}$; $\mathrm{B}=100 \mathrm{x})$ 

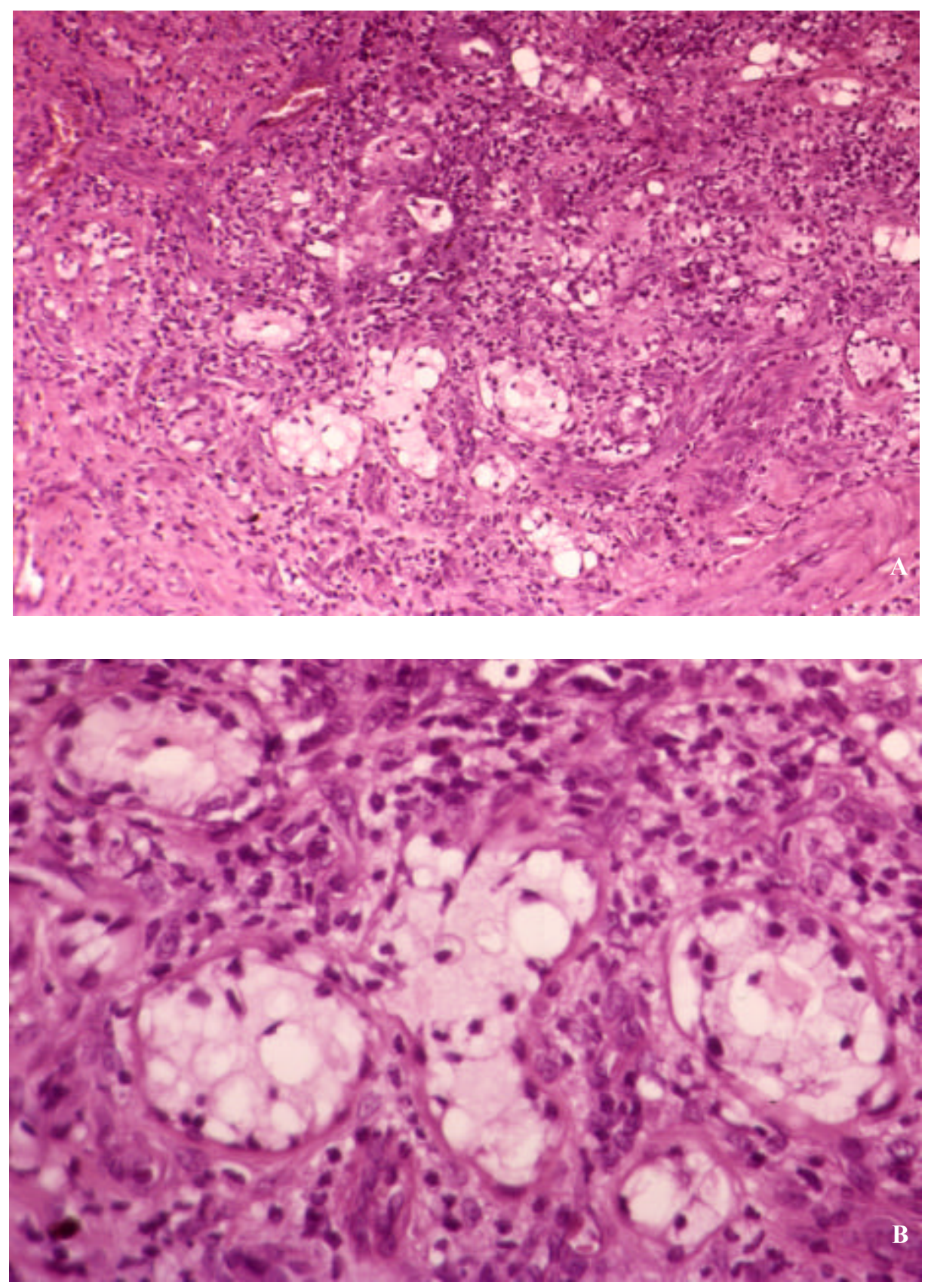

FIGURA 4 - Destaca-se neste campo que a glândula salivar revela ácinos com glândulas mucosas persistentes ou remanescentes, podendo levar a um diagnóstico equivocado de carcinoma mucoepidermóide. (Caso 11; H.E.; aumento original: $\mathrm{A}=40 \mathrm{x} ; \mathrm{B}=100 \mathrm{x}$ ) 

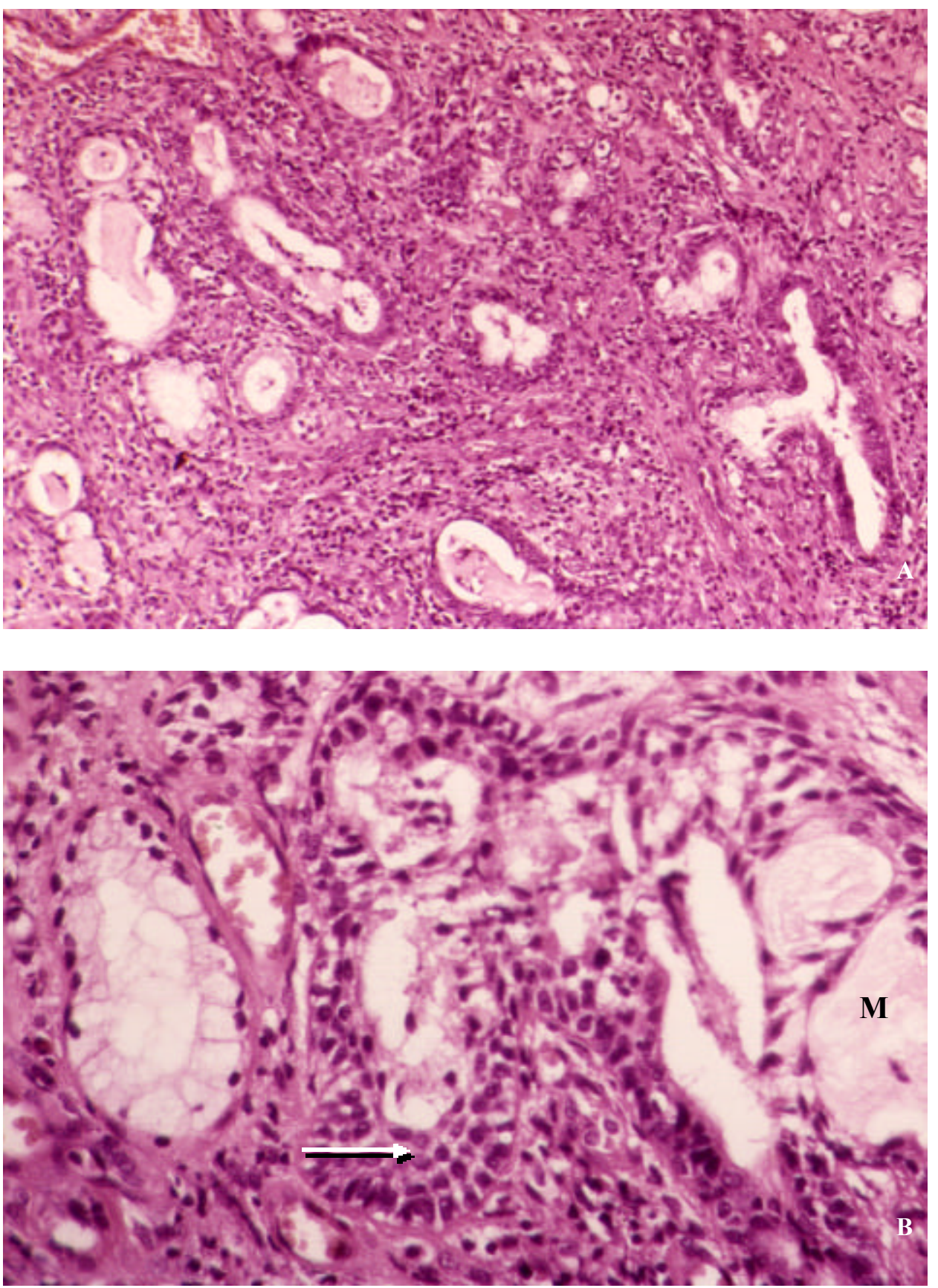

FIGURA 5 - Destaca-se neste campo a glândula salivar com ácinos e células mucosas persistentes ou remanescentes associadas a ilhotas de epitélio escamoso (seta), podendo levar a um quadro muito semelhante ao carcinoma mucoepidermó ide, inclusive com acúmulos de material mucóide $(\mathrm{M})$ em pequenas cavidades. (Caso 11; H.E.; aumento original: $\mathrm{A}=40 \mathrm{x} ; \mathrm{B}=100 \mathrm{x}$ ) 


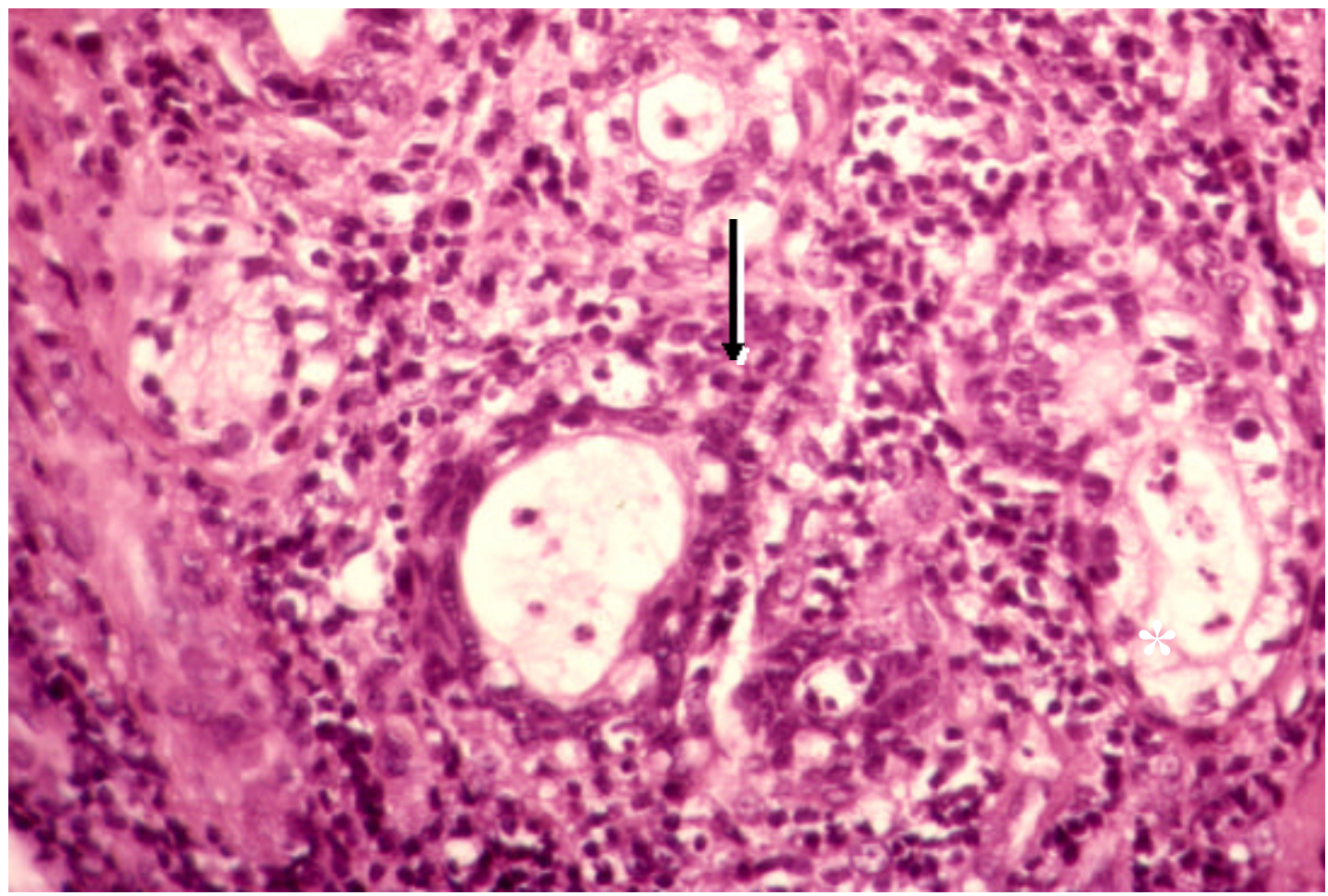

FIGURA 6 - Neste campo o quadro microscópico se assemelha muito com o carcinoma mucoepidermóide pelas áreas de metaplasia escamosa (seta) e persistência de células mucosas (*) associadas a um infiltrado inflamatório mononuclear. (Caso 11; H.E.; aumento original=100x) 

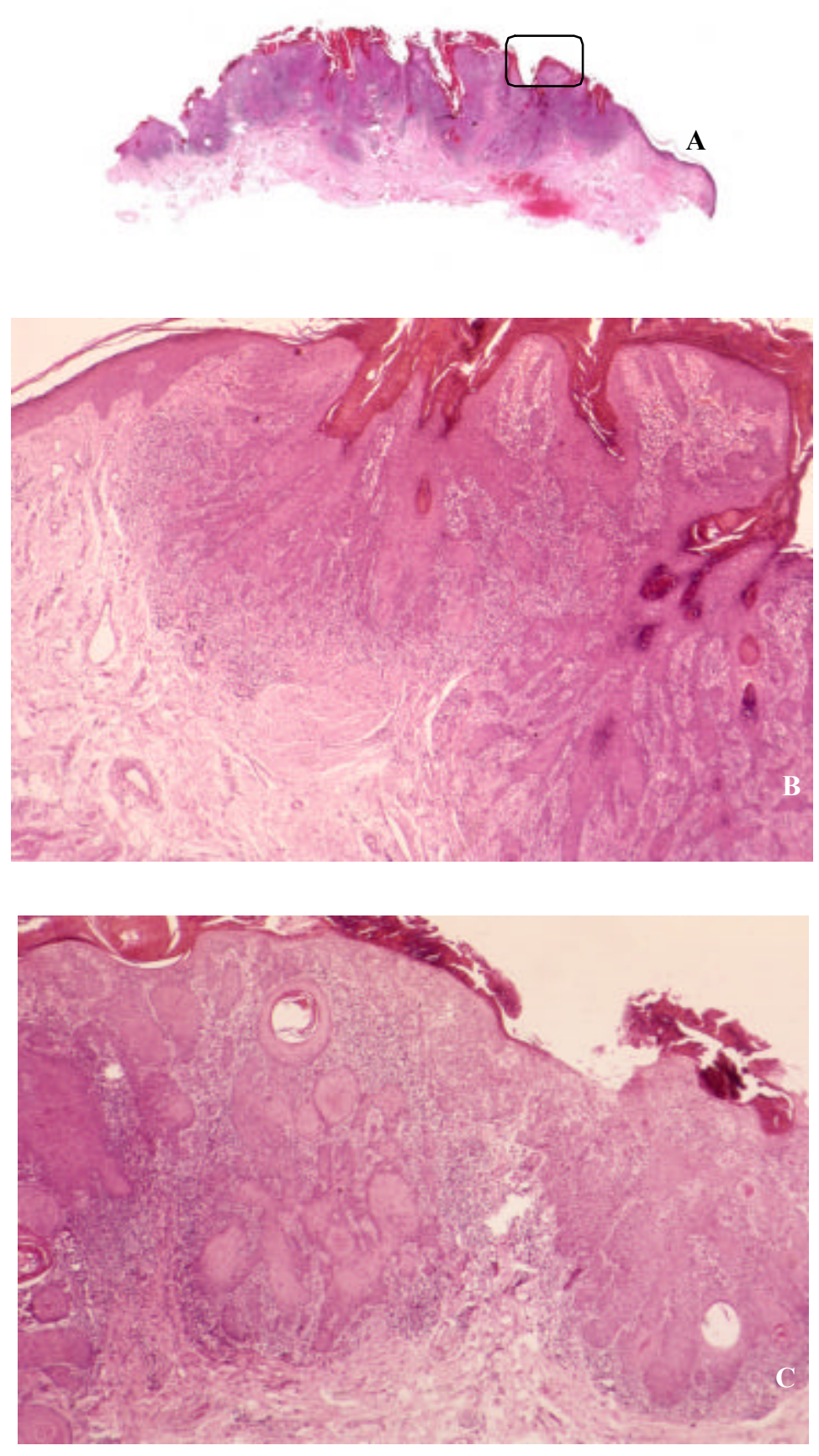

FIGURA 7 - Carcinoma espinocelular bem diferenciado em semimucosa labial inferior com queilite actínica. Em seguida, neste paciente, instalourse uma sialometaplasia necrosante em conseqüência acidental de obstrução vascular pós-operatória (caso 13). (H.E.; aumento original: A=4x; $\mathrm{B}$ e $\mathrm{C}=10 \mathrm{x}$ ) 

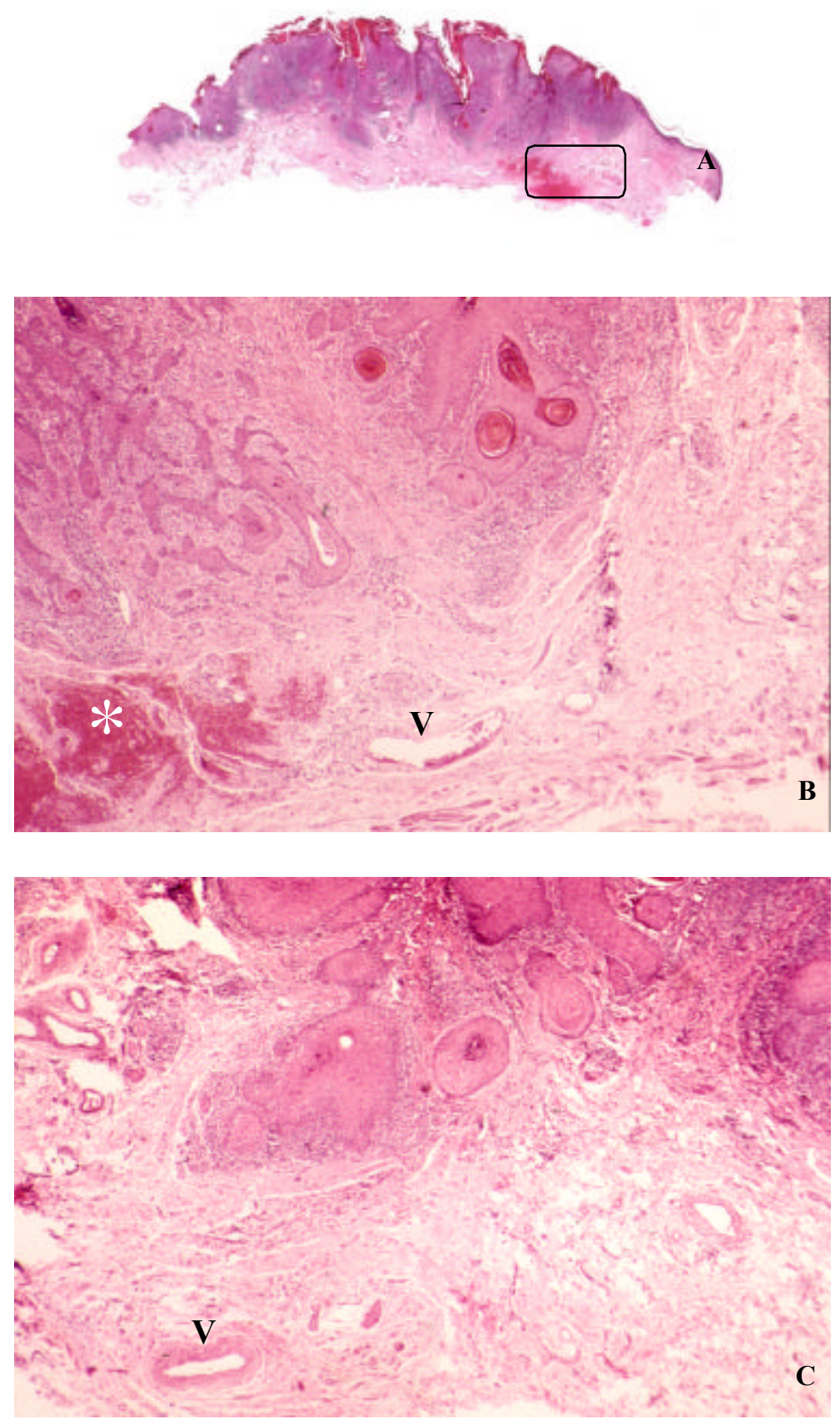

FIGURA 8 - Na peça cirúrgica do caso apresentado na figura anterior, logo abaixo do carcinoma espinocelular, observam-se vasos calibrosos (V) e áreas hemorrágicas (*). Em seguida, neste paciente, instalourse uma sialometaplasia necrosante em conseqüência de obstrução vascular pósoperatória (caso 13). (H.E.; aumento original: $\mathrm{A}=4 \mathrm{x}$; $\mathrm{B}$ e $\mathrm{C}=10 \mathrm{x}$ ) 

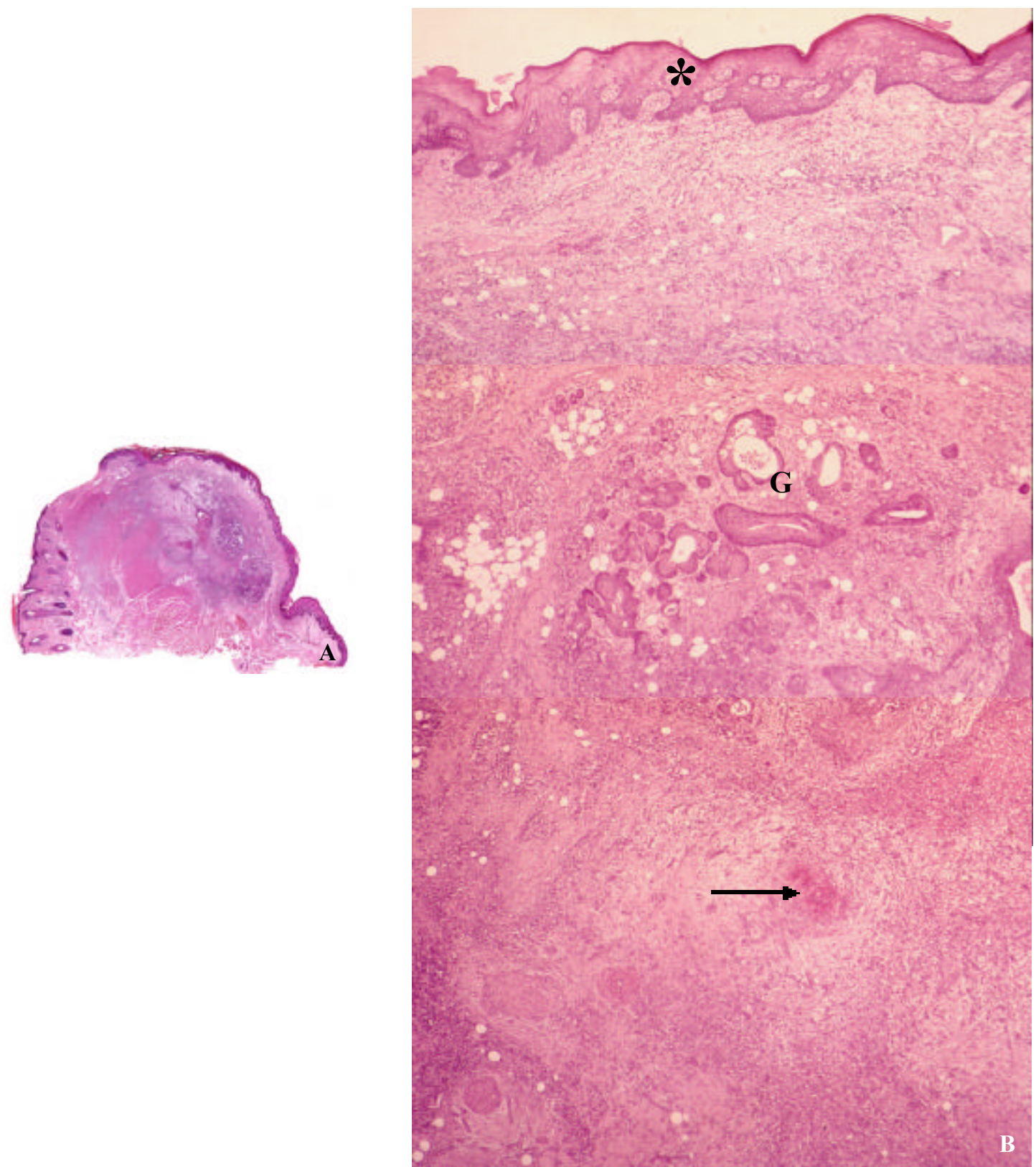

FIGURA 9 - Caso 13 de sialometaplasia necrosante diagnosticada após uma segunda cirurgia. Na peça cirúrgica, a glândula salivar $(\mathrm{G})$ subjacente à mucosa bucal (*) apresenta ilhotas de epitélio escamoso, ácinos em desorganização e desestruturação com ductos metaplásicos associados. No plano mais profundo, observa-se um vaso calibroso com trombose (seta). (H.E.; aumento original: $\mathrm{A}=4 \mathrm{x} ; \mathrm{B}=10 \mathrm{x}$ ) 

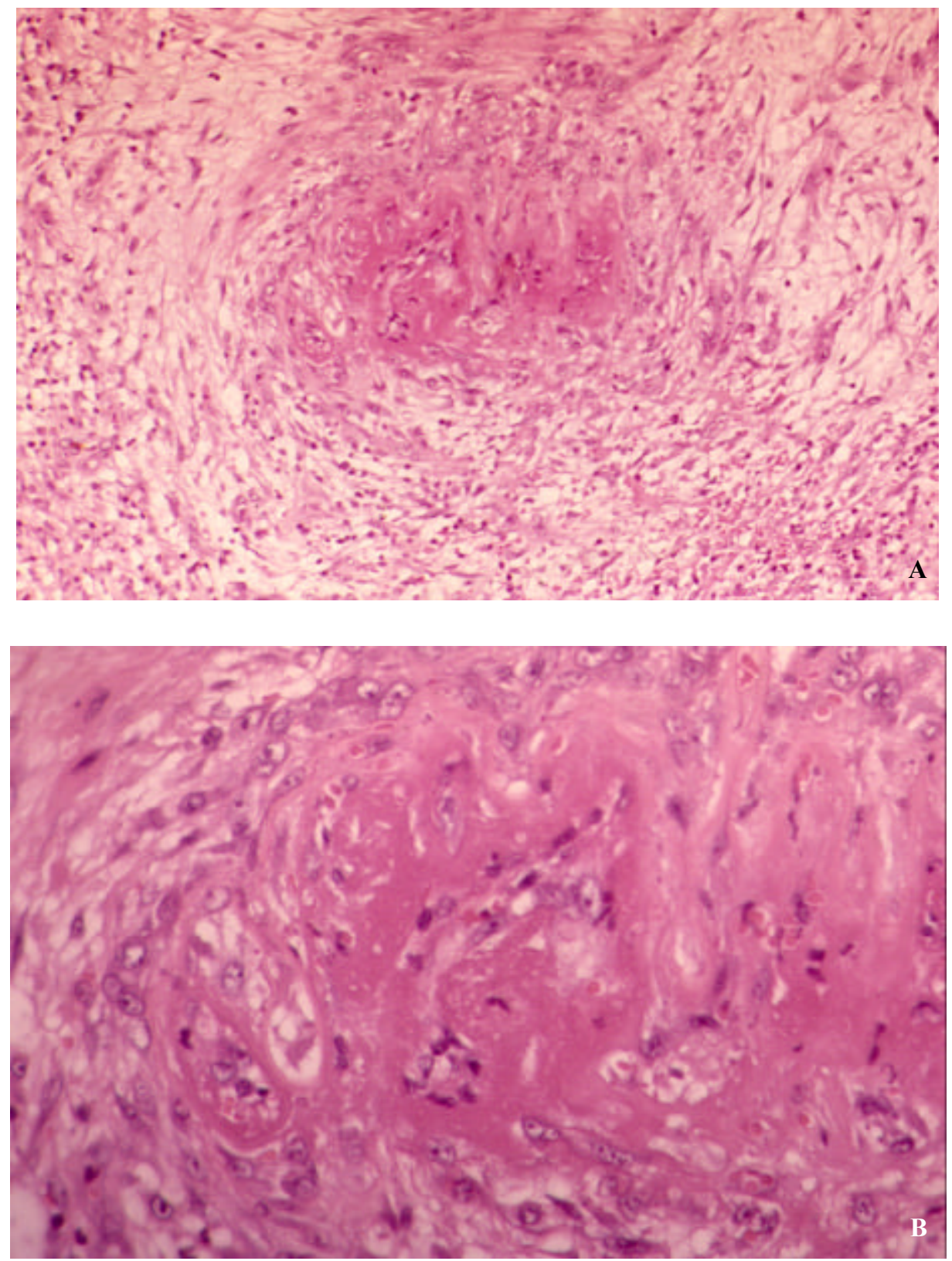

FIGURA 10 - Aspectos microscópicos da trombose em organização presente em um vaso associado à lesão de sialometaplasia necrosante diagnosticada após uma segunda cirurgia, mostrada na figura anterior. (Caso 13; H.E.; aumento original: $\mathrm{A}=40 \mathrm{x} ; \mathrm{B}=100 \mathrm{x}$ ) 

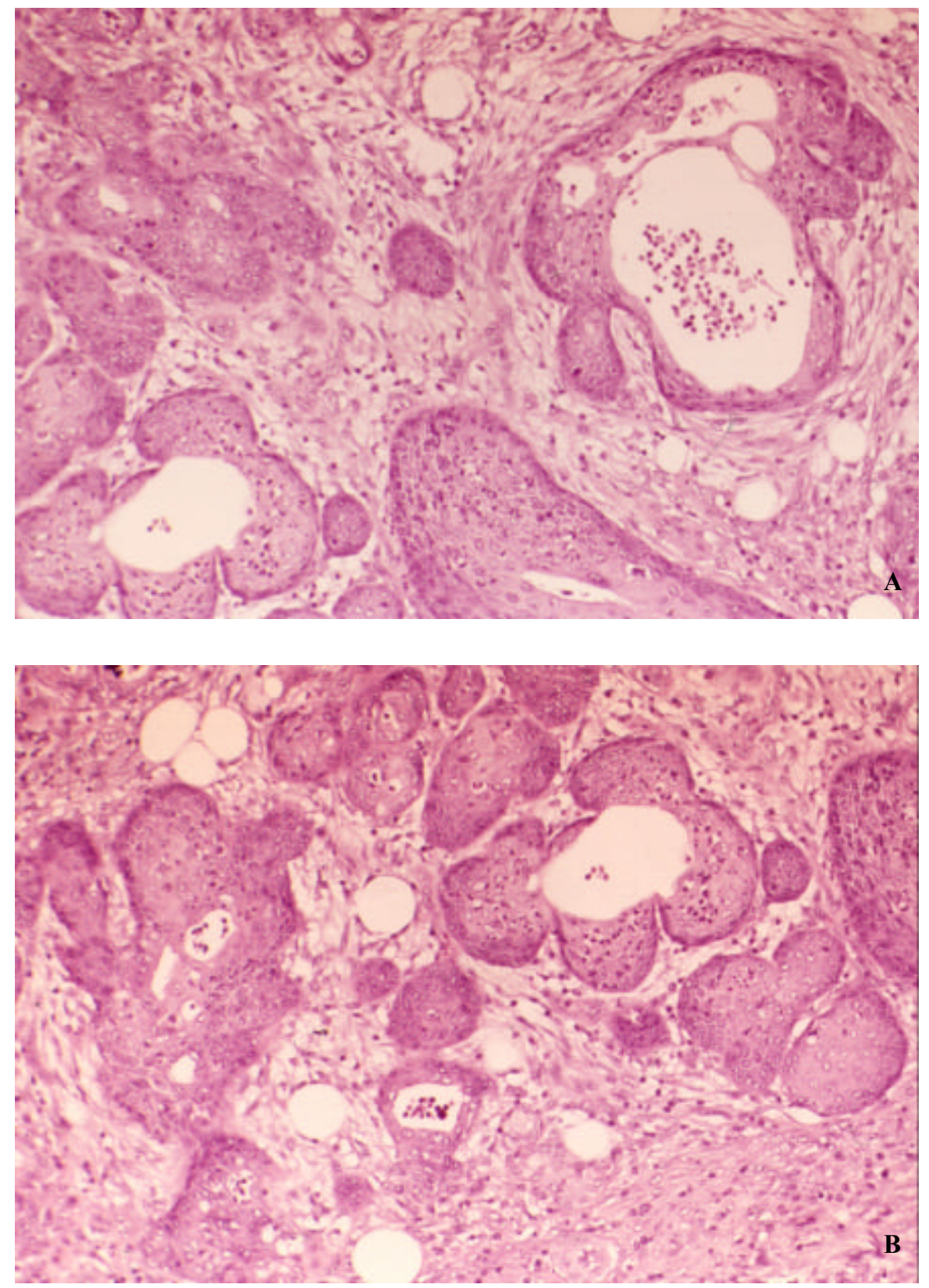

FIGURA 11 - Destaca-se a presença de ilhotas de epitélio escamoso dispostas ao acaso gerando um quadro muito semelhante ao carcinoma espinocelular. Em algumas ilhotas observam-se microcavidades. (Caso 13; H.E.; aumento original: $\mathrm{A}$ e $\mathrm{B}=40 \mathrm{x}$ ) 

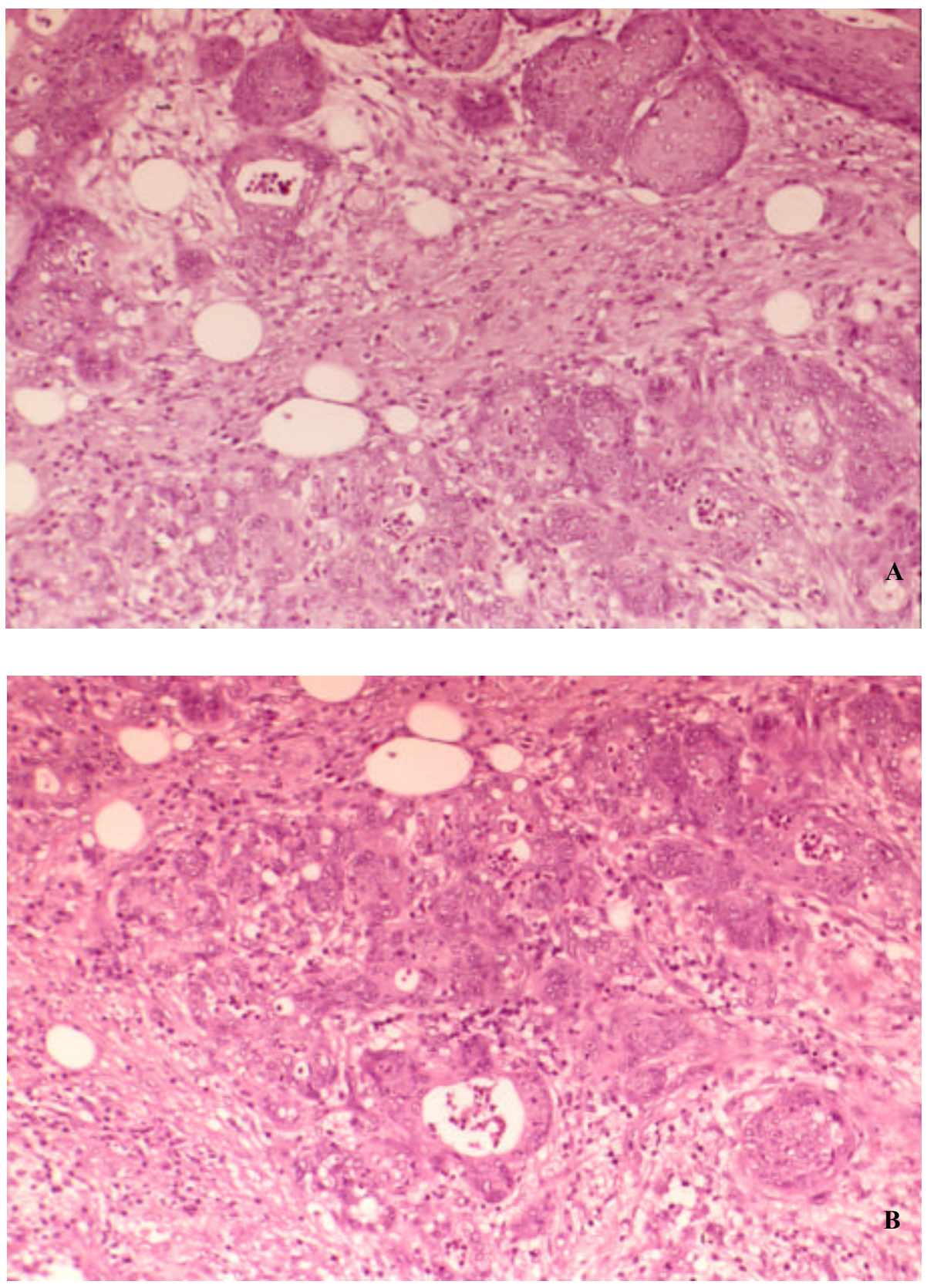

FIGURA 12 - Neste campo, a presença de ilhotas de epitélio escamoso dispostas ao acaso está associada a presença de células acinares e ductais organizadas, de aspecto mucoso, gerando um quadro muito semelhante ao carcinoma mucoepidermóide. (Caso 13; H.E.; aumento original: A e $\mathrm{B}=40 \mathrm{x}$ ) 

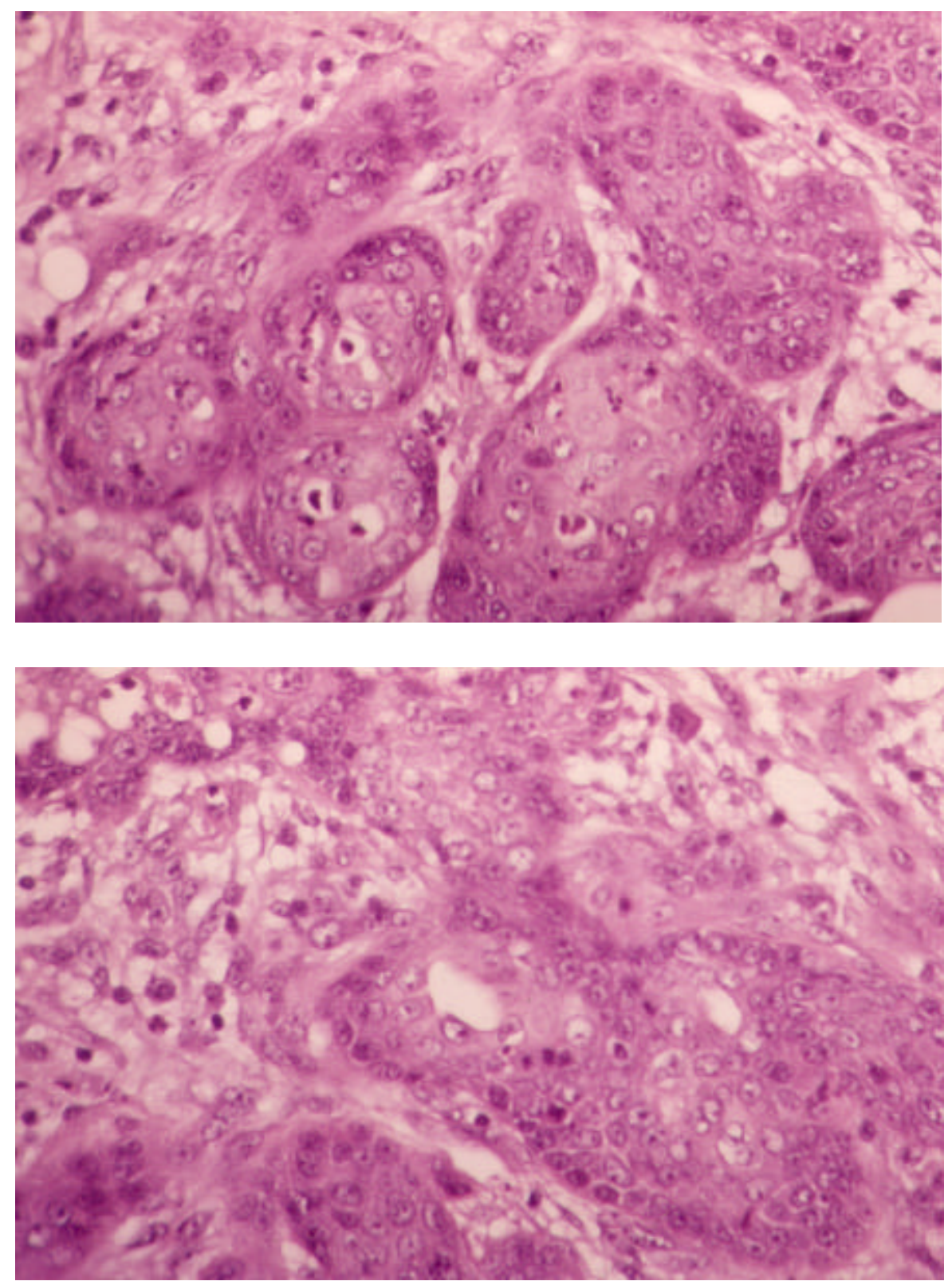

FIGURA 13 - Em outra glândula salivar menor do mesmo caso, as ilhotas de epitélio escamoso irregulares constituindo um quadro muito semelhante ao carcinoma espinocelular. Em algumas ilhotas as células epiteliais apresentam pleomorfismo, hipercromatismo e mitoses pela associação com processos inflamatório e reparatório próprios da sialometaplasia necrosante. (Caso 13; H.E.; aumento original: A e $\mathrm{B}=100 \mathrm{x}$ ) 

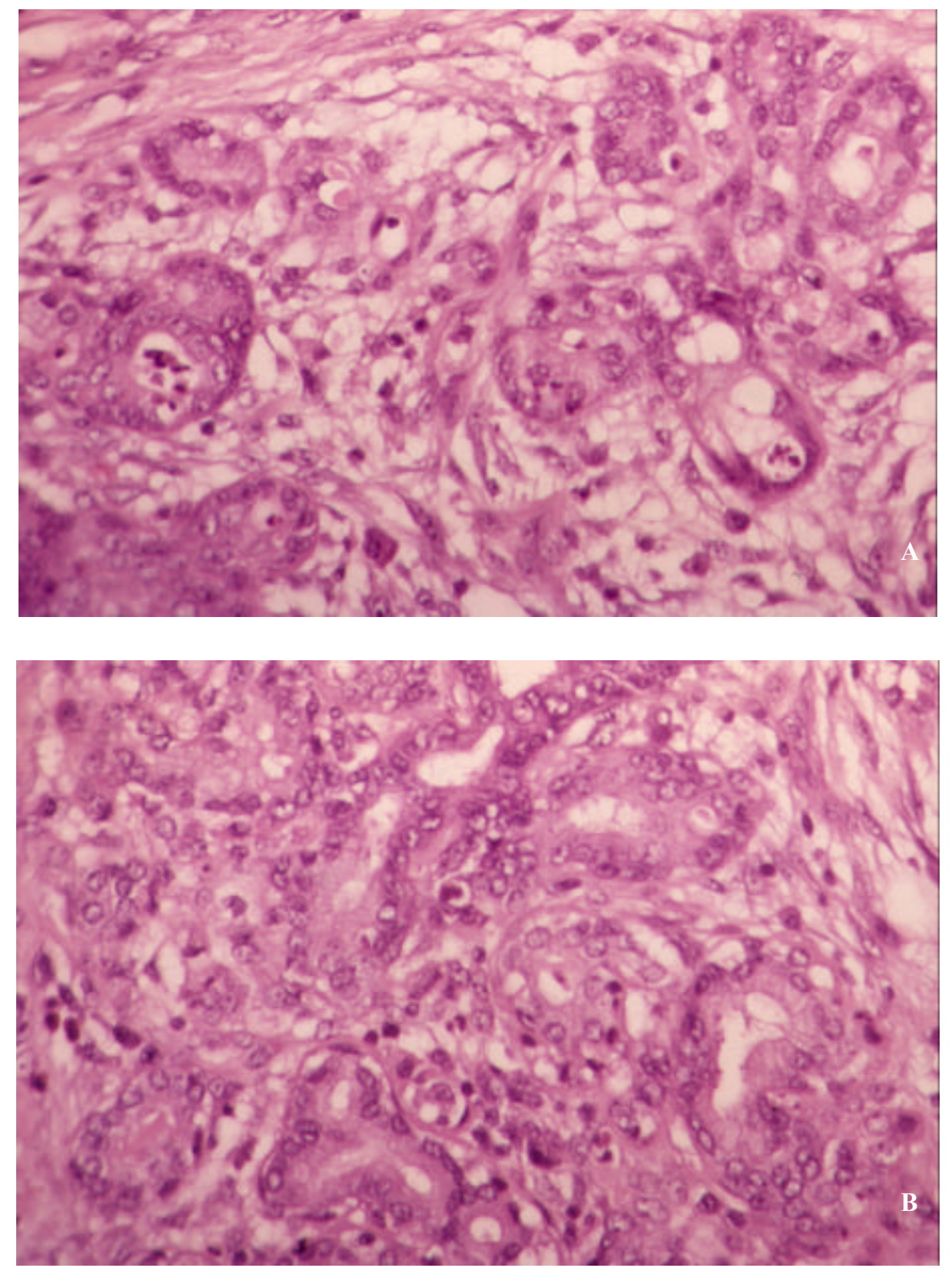

FIGURA 14 - De permeio às ilhotas de epitélio escamoso irregulares, têm-se ainda células mucosas e aspectos semelhantes a ducto; este quadro pode sugerir carcinoma mucoepidermóide. (Caso 13; H.E.; aumento original: A e $\mathrm{B}=100 \mathrm{x})$ 

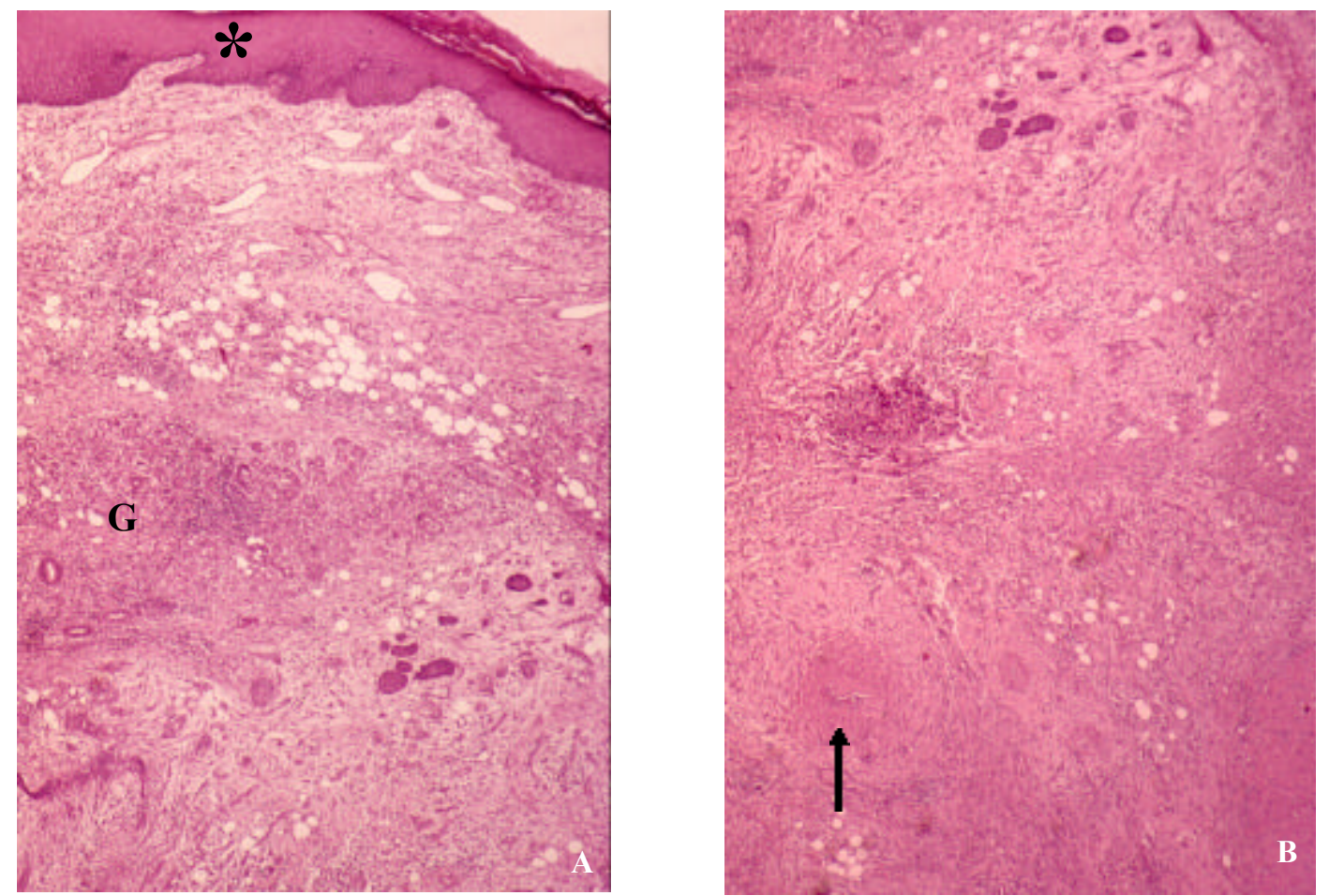

FIGURA 15 - Sialometaplasia necrosante localizada no lábio inferior com a presença de trombose em um vaso associado ao quadro diagnosticado nas glândulas salivares. Subjacente à mucosa bucal $(*)$, a glândula salivar $(\mathrm{G})$ revela ácinos e ductos de permeio a intenso infiltrado inflamatório, bem como evidentes ilhotas de epitélio com metaplasia escamosa. Logo abaixo da glândula, apresenta-se uma artéria com obstrução luminar por trombose em organização (seta), provavelmente associada a etiopatogenia da lesão. (Caso 13; H.E.; aumento original: A e $\mathrm{B}=10 \mathrm{x}$ ) 

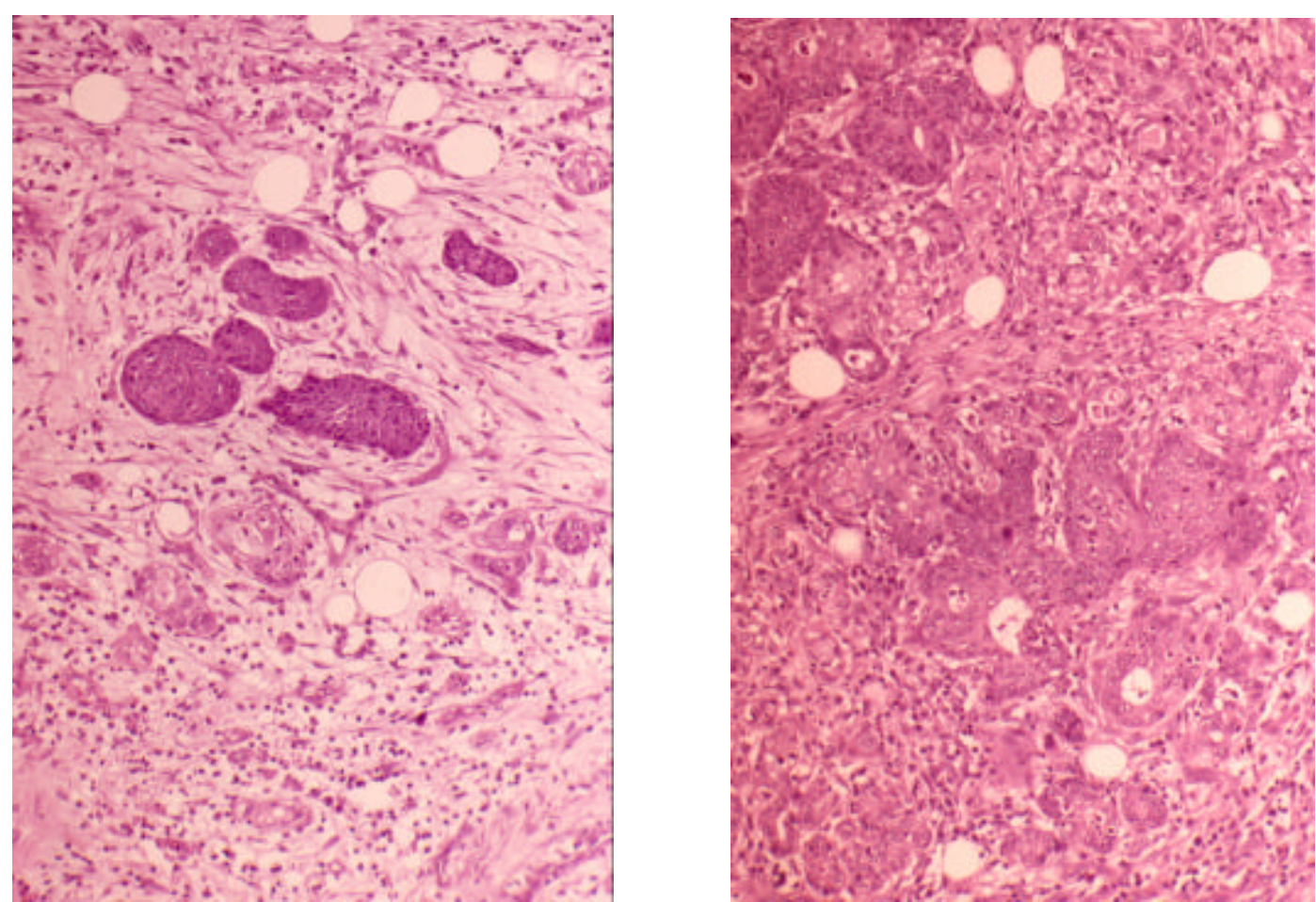

FIGURA 16 - Destaca-se, neste aumento, a presença de ilhotas de epitélio escamoso dispostas ao acaso. Em algumas ilhotas, observam se microcavidades e formações ductiformes. De permeio, observa-se infiltrado inflamatório predominantemente mononuclear. (Caso 13; H.E.; aumento original: A e $\mathrm{B}=40 \mathrm{x})$ 

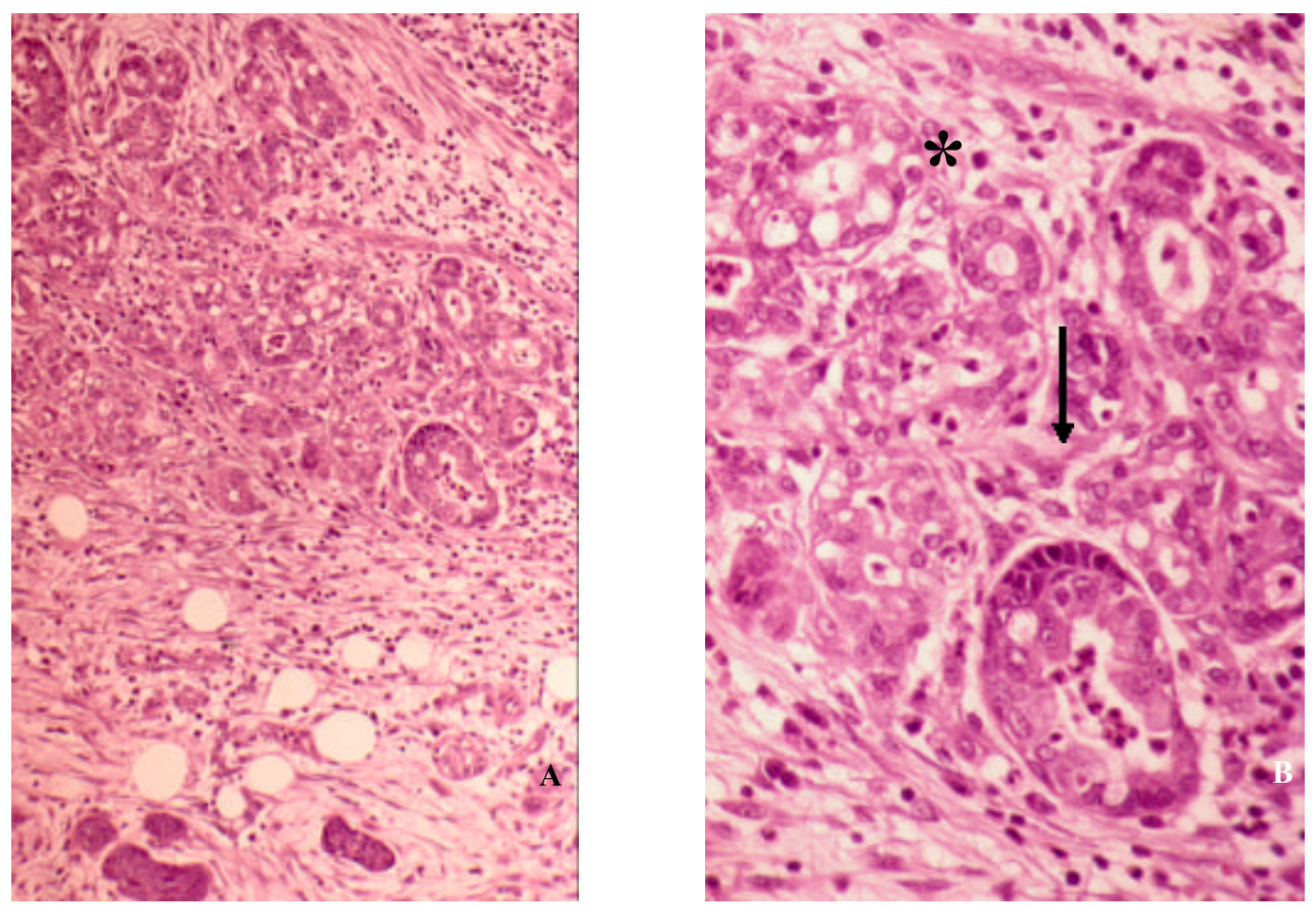

FIGURA 17 - Nesta região, em uma das ilhotas de epitélio, revela-se uma típica transformação metaplásica escamosa (seta). Em algumas ilhotas observamse formações ductiformes (*). De permeio, observa-se um discreto infiltrado inflamatório mononuclear. (Caso 13; H.E.; aumento original: $\mathrm{A}=40 \mathrm{x} ; \mathrm{B}=100 \mathrm{x}$ ) 


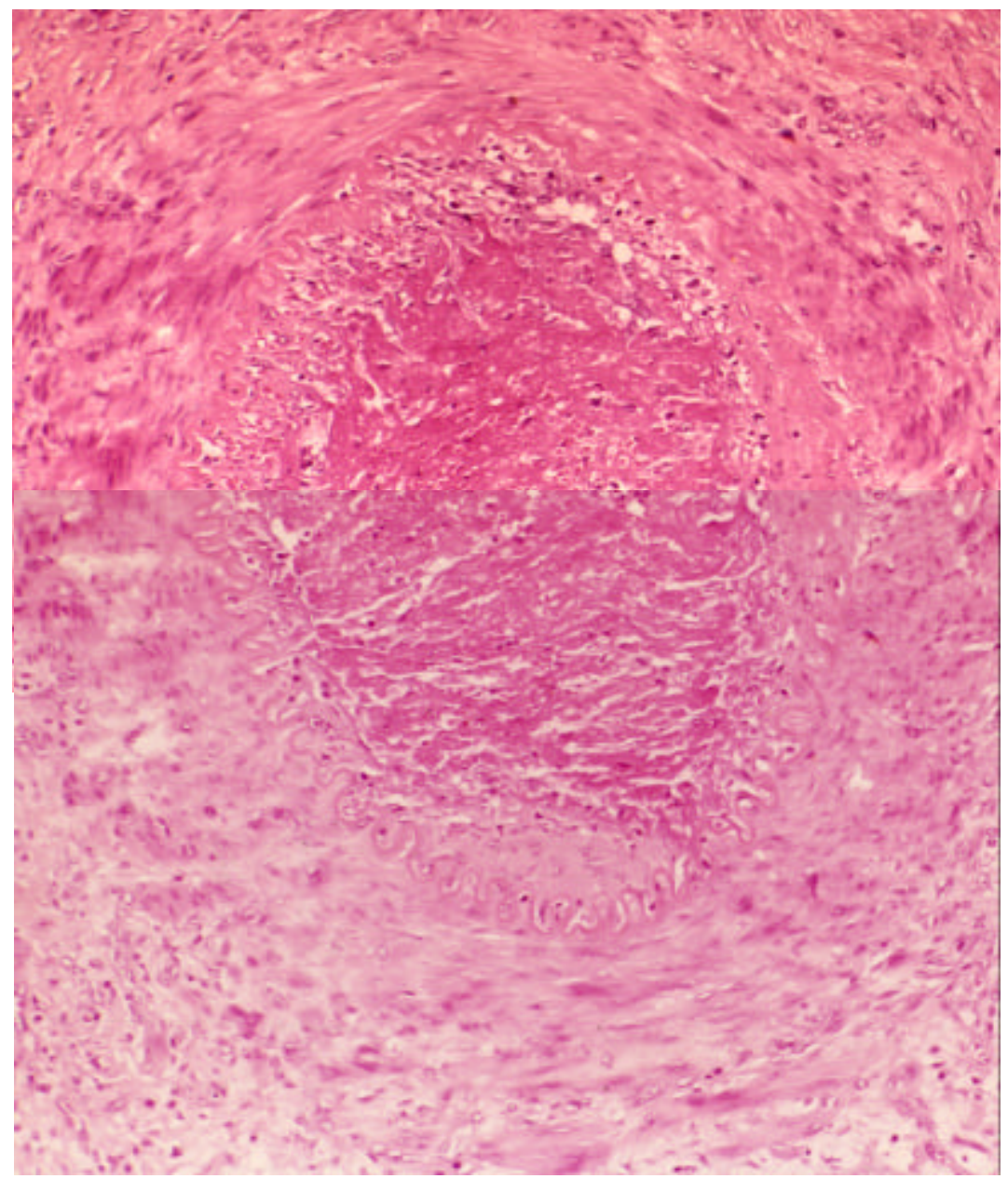

FIGURA 18 - Aspectos microscópicos da trombose em organização diagnosticada nos vasos associados à lesão de sialometaplasia necrosante. As estruturas da parede vascular estão preservadas, podendo sugerir uma compressão, não uma ruptura do vaso. (Caso 13; H.E.; aumento original=40x) 

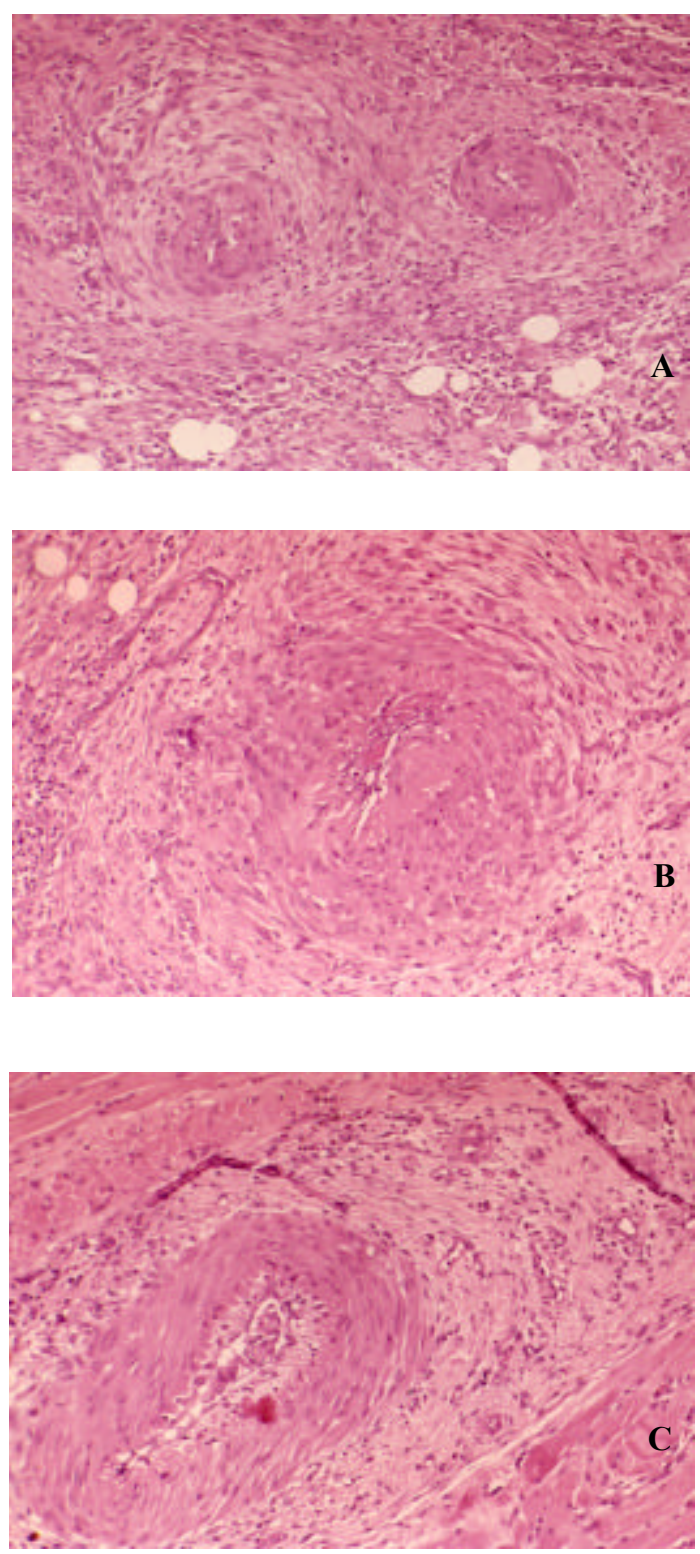

FIGURA 19 - Aspectos microscópicos das alterações vasculares encontradas nos cortes microscópicos de sialometaplasia necrosante. Os vasos afetados são de calibres variados e a trombose diagnosticada revela uma fase avançada do processo quando da realização da biópsia. As estruturas da parede vascular estão preservadas. Isto pode sugerir uma compressão e não uma ruptura do vaso. (Caso 13; H.E.; aumento original: $\mathrm{A}, \mathrm{B}$ e $\mathrm{C}=40 \mathrm{x}$ ) 


\section{$*$}
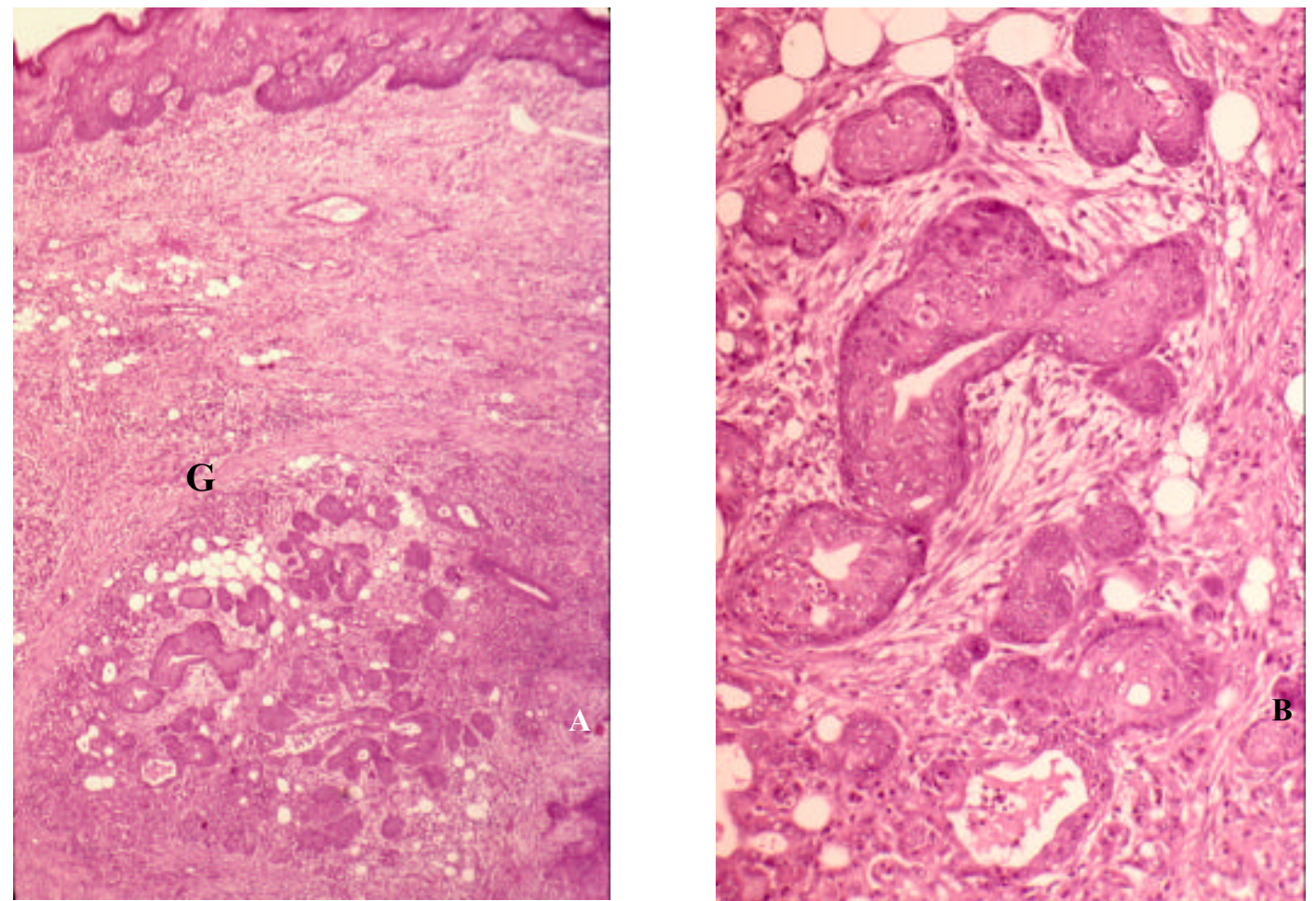

FIGURA 20 - Subjacente à mucosa bucal (*) as glândulas salivares $(\mathrm{G})$ revelam intensa e extensa metaplasia escamosa de suas estruturas epiteliais, sugerindo tratarse de uma neoplasia de origem epitelial com formações cistos-like, acúmulo de material mucóide e presença de células mucosas. Este quadro microscópico pode levar ao diagnóstico equivocado de carcinoma mucoepidermóide. (Caso 13; H.E.; aumento original: $\mathrm{A}=10 \mathrm{x} ; \mathrm{B}=40 \mathrm{x}$ ) 

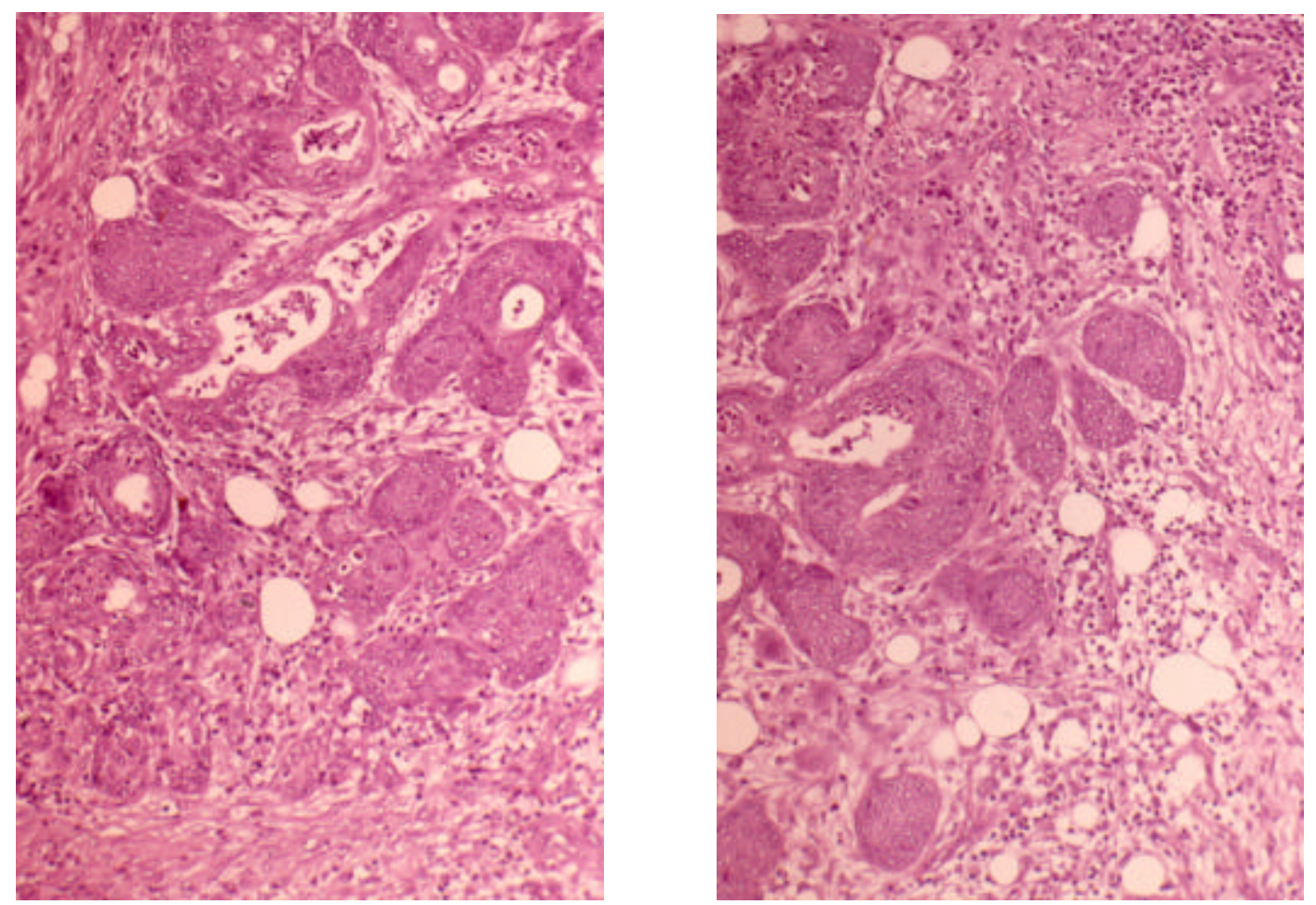

FIGURA 21 - Nota-se em outros campos dos cortes examinados, a mesma intensa e extensa metaplasia escamosa das estruturas epiteliais com formações cistoslike, acúmulo de material mucóide e presença de células mucosas. (Caso 13; H.E.; aumento original: $\mathrm{A}$ e $\mathrm{B}=40 \mathrm{x}$ ) 

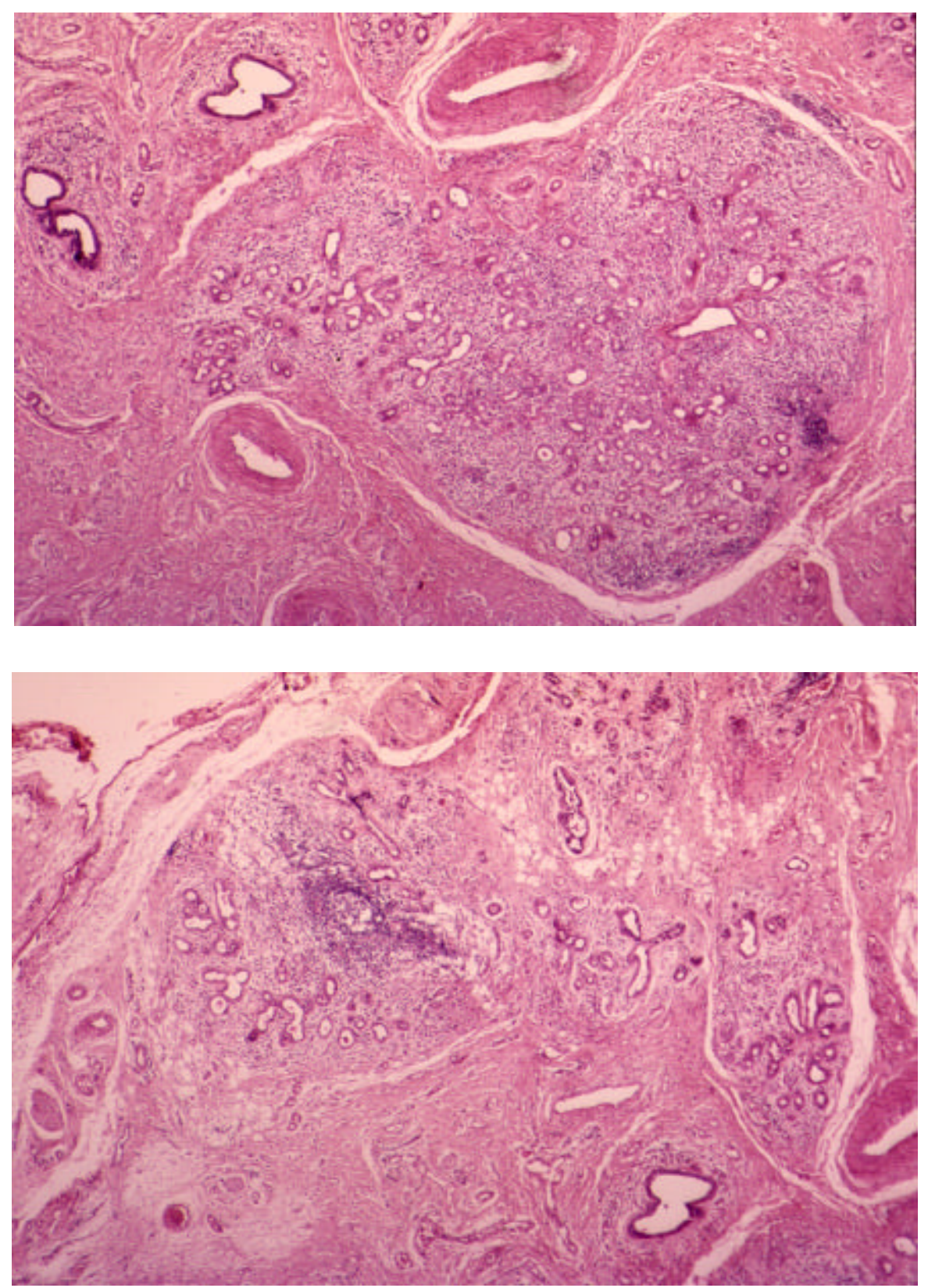

FIGURA 22 - Caso 7 de sialometaplasia necrosante localizada no soalho bucal com três meses de evolução. Subjacente à mucosa bucal, as glândulas salivares $(\mathrm{G})$ revelam desaparecimento dos ácinos e persistência dos ductos. O epitélio ductal e acinar remanescente sofre metaplasia escamosa. $\mathrm{O}$ quadro revela atrofia acinar generalizada e persistência da árvore ductal. (H.E.; aumento original: $\mathrm{A}$ e $\mathrm{B}=10 \mathrm{x}$ ) 

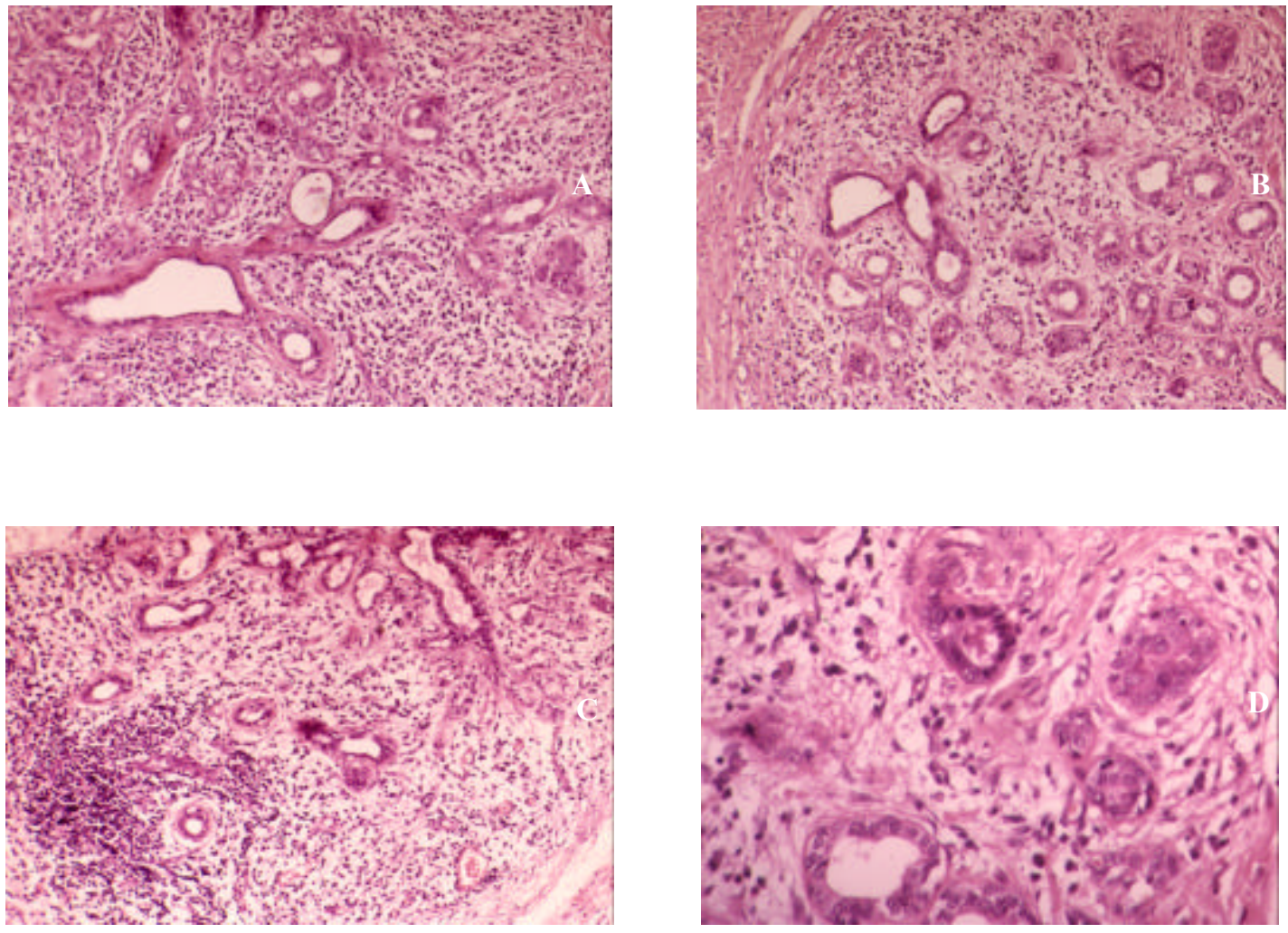

FIGURA 23 - As glândulas salivares revelam desaparecimento dos ácinos e persistência dos ductos. O epitélio ductal e acinar remanescente sofre metaplasia escamosa ainda discreta. $\mathrm{O}$ quadro apresenta atrofia acinar generalizada e persistência da árvore ductal, com moderado infiltrado mononuclear intersticial. (Caso 7; H.E.; aumento original: A, B e C=40x; D=100x) 

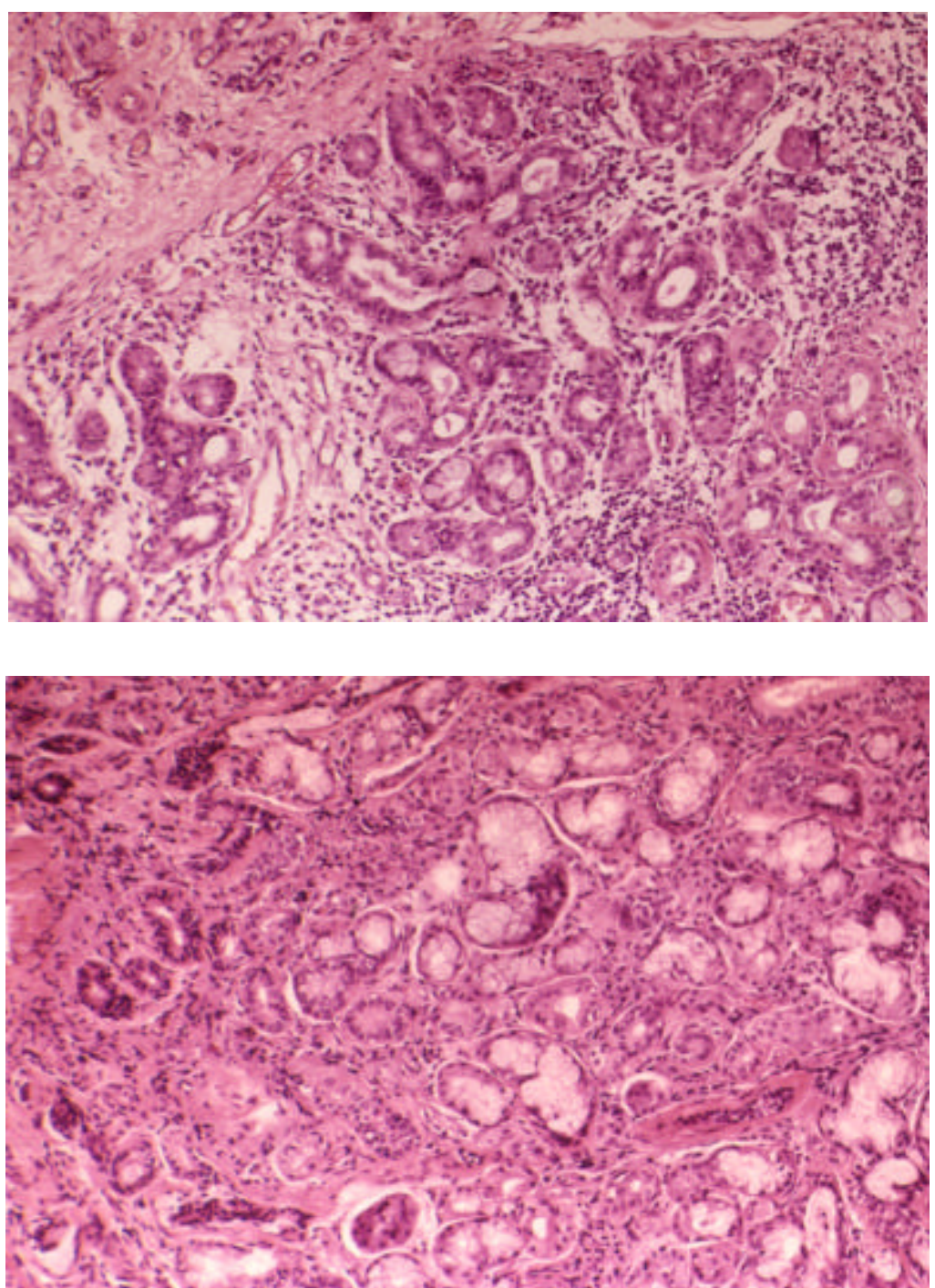

FIGURA 24 - Caso 1 de sialometaplasia necrosante diagnosticada como carcinoma mucoepidermóide localizada no soalho bucal. Subjacente à mucosa bucal, as glândulas salivares revelam metaplasia escamosa de suas estruturas epiteliais, sugerindo tratar-se de uma neoplasia de origem epitelial com formações ductiformes e tipo cistos-like, acúmulo de material mucóide no seu interior e presença de células mucosas formando ácinos de aspecto rudimentar. Observa-se ainda ilhotas de células mioepiteliais (seta). Este quadro microscópico pode levar ao diagnóstico equivocado de carcinoma mucoepidermóide. Na época do diagnóstico, a sialometaplasia necrosante não havia sido descrita ainda como uma entidade clínica definida. (H.E.; aumento original: $\mathrm{A}$ e $\mathrm{B}=40 \mathrm{x}$ ) 

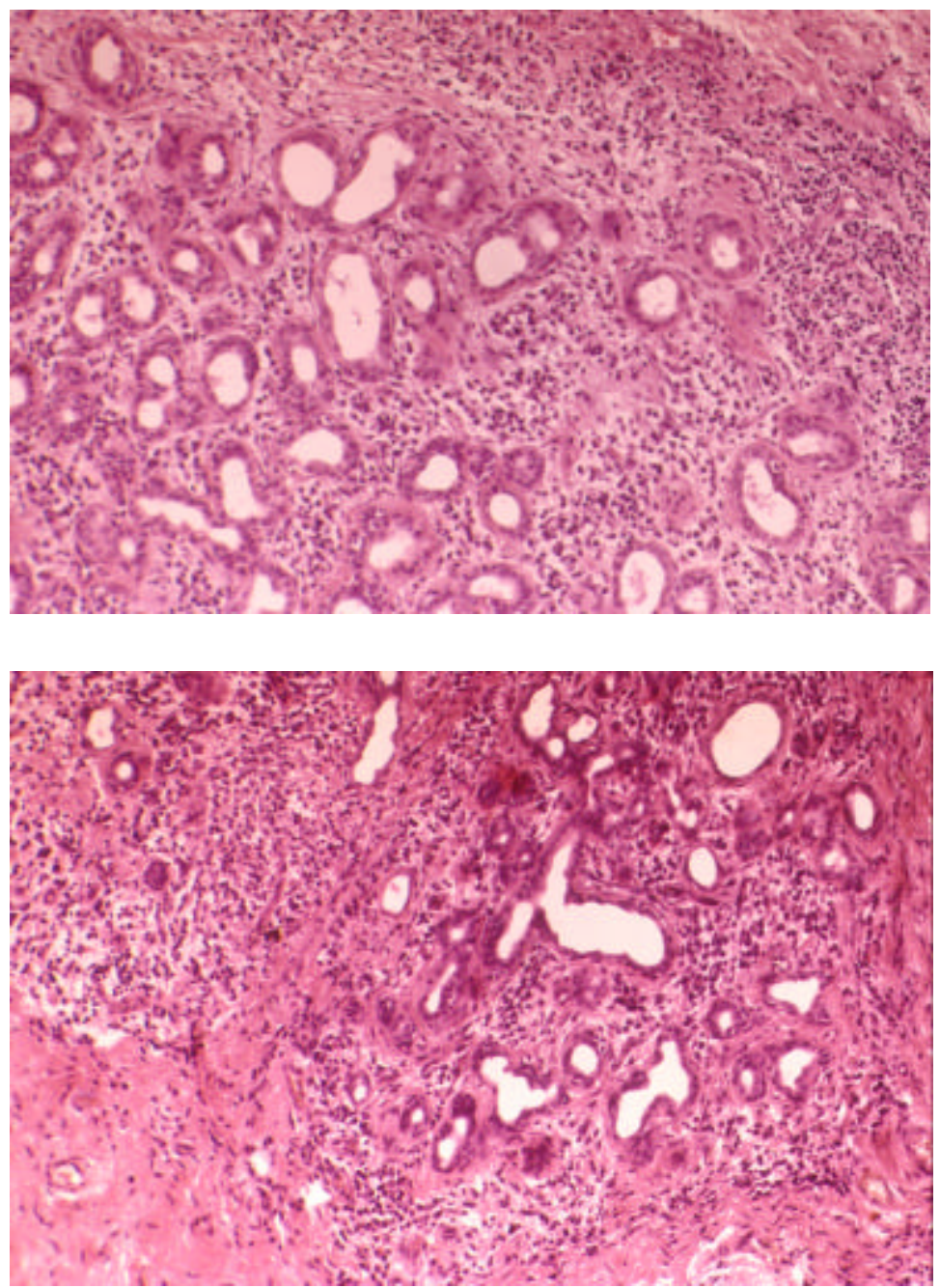

FIGURA 25 - Em outros campos as glândulas salivares também revelam metaplasia escamosa de suas estruturas epiteliais, com formações ductiformes, acúmulo de material mucóide e presença de células mucosas formando ácinos de aspecto rudimentar. Este quadro microscópico da sialometaplasia necrosante pode levar ao diagnóstico equivocado de carcinoma mucoepidermóide. Na época deste diagnóstico, a sialometaplasia necrosante não havia sido descrita ainda como uma entidade clínica definida. (Caso 1; H.E.; aumento original: $\mathrm{A}$ e $\mathrm{B}=40 \mathrm{x}$ ) 


\subsection{Caso clínico suplementar}

Um paciente de 21 anos de idade, gênero masculino, procurou tratamento para lesão ulcerada e necrótica no palato duro após procedimento de disjunção palatina com o aparelho tipo Haas (FIGURA 26). O ortodontista relatou ao clínico o protocolo de ativação do aparelho e a sintomatologia do paciente. Depois de instalado, o paciente ativava o aparelho duas vezes pela manhã (meia volta do parafuso do aparelho) e duas vezes à tarde (mais meia volta), para completar o total de uma volta/dia. A dor relatada pelo paciente se deu a partir do quinto dia. Frente a esta sintomatologia, reduziu-se o número de ativações para um quarto de volta/dia, com término das ativações no sétimo dia. Após quatro dias, tentoutse retomar as ativações. Não se obteve sucesso pela dor intensa relatada. Prescreveu-se diclofenaco potássico. Controlada a dor, as ativações continuaram. Após três dias a sintomatologia era intensa e o paciente foi indicado para tratamento da lesão palatina, com queixas de gosto ruim e odor fétido intra-bucal.

Ao remover o aparelho, observou-se necrose na região posterior do palato, lado direito, com exposição de superfície óssea (FIGURA 27). As radiografias oclusais (FIGURAS 28 e 29) revelaram a não abertura da sutura palatina mediana, provavelmente pelo tempo insuficiente de ação do aparelho ou pela ossificação precoce da sutura.

O diagnóstico estabelecido foi lesão ulcerada por sialometaplasia necrosante. O plano de tratamento objetivou remover a causa, promover debridamento da área, evitar infecção secundária, aliviar sintomatologia e promover condições para o reparo. O tecido necrosado foi removido facilmente com pinça. Para proteger a lesão, aplicou-se uma fina camada de cimento cirúrgico. Indicourse anti-séptico bucal à base de clorexidina, 
diclofenaco potássico e cefalexina por 15 dias. A biópsia não foi realizada pela evidente relação causa-efeito. A lesão regrediu em quatro semanas (FIGURA 30).

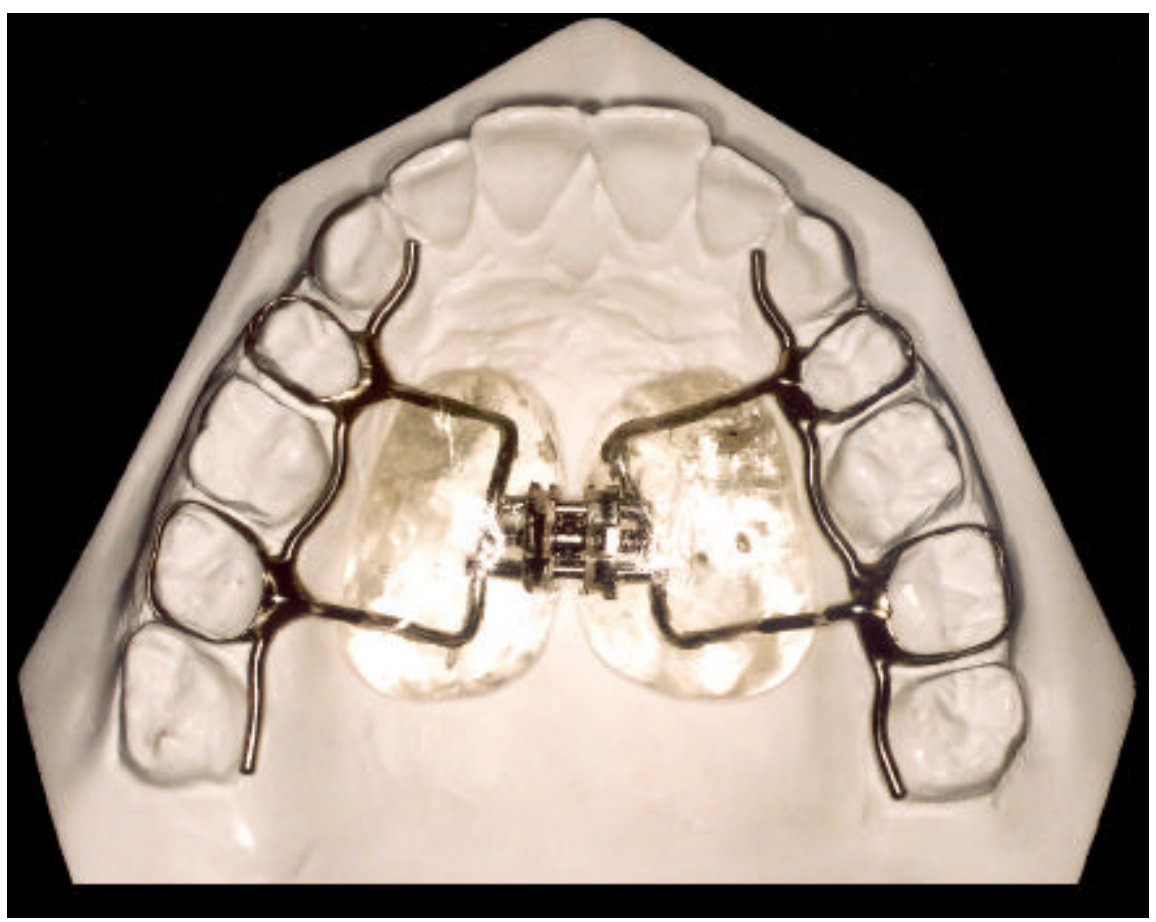

FIGURA 26 - Aparelho disjuntor tipo Haas adaptado no modelo de gesso, do mesmo tipo utilizado no caso clínico apresentado 


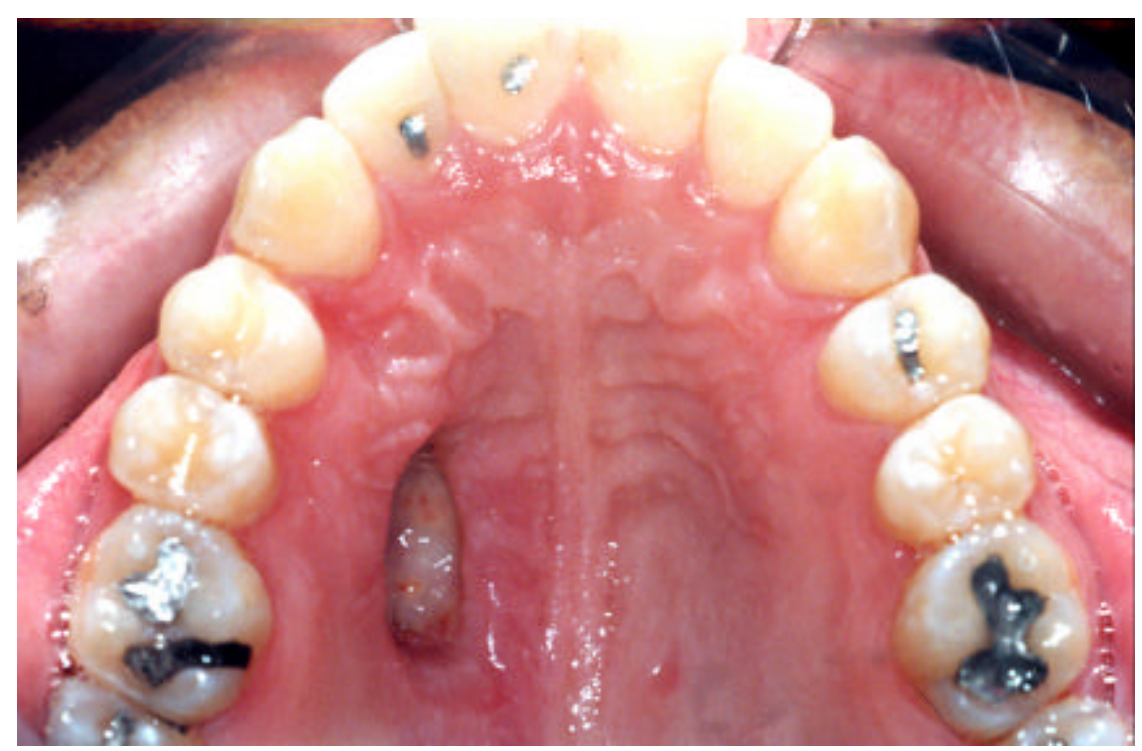

FIGURA 27 - Ulceração na mucosa palatina com exposição de superfície óssea

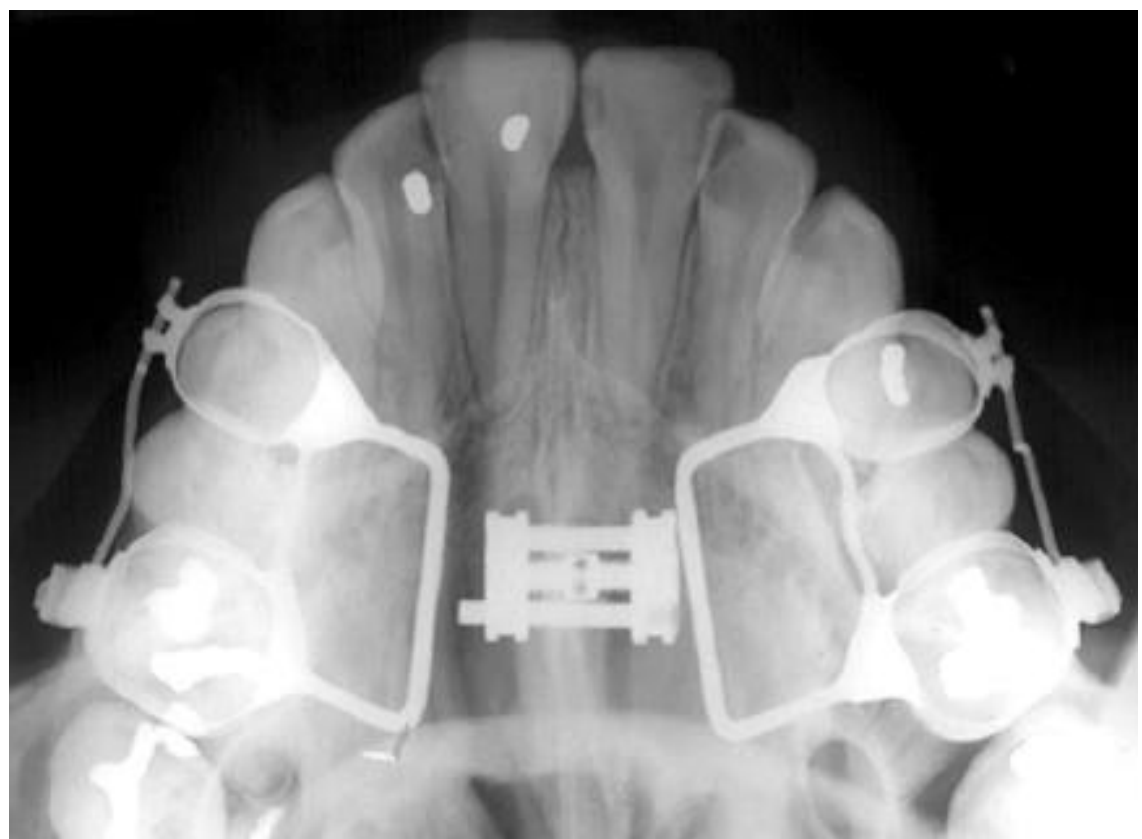

FIGURA 28 - Radiografia oclusal após as ativações do aparelho disjuntor tipo Haas. Observa-se a ausência do diastema entre os incisivos centrais e a sutura palatina mediana 


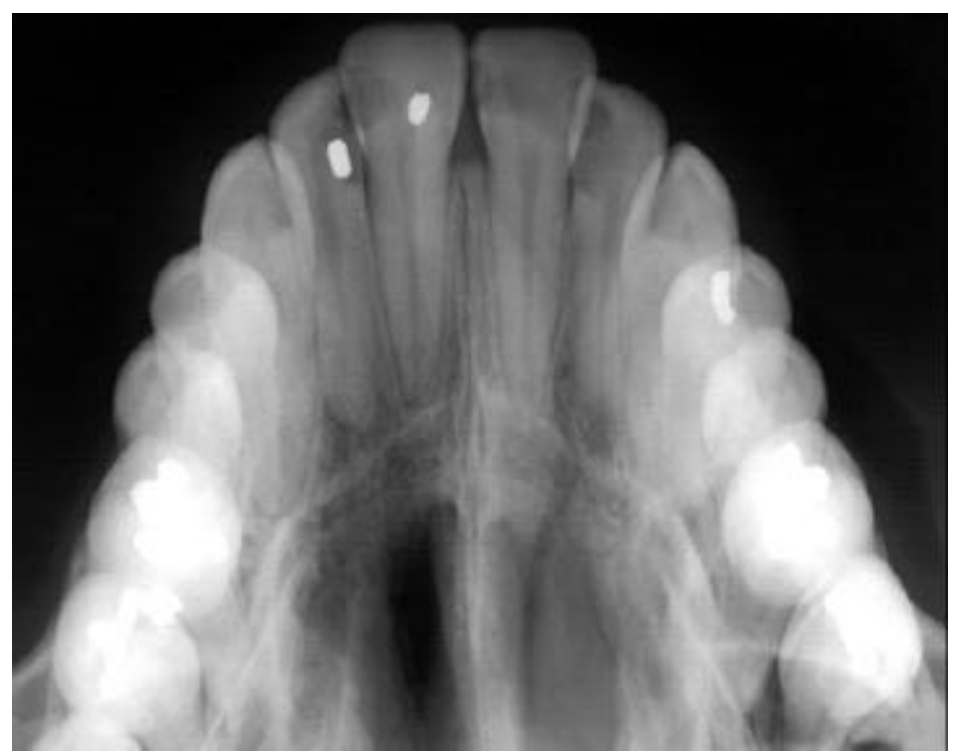

FIGURA 29 - Radiografia oclusal após a remoção do aparelho disjuntor tipo Haas. No lado direito da sutura palatina mediana, observa-se uma imagem radiolúcida representativa do local da lesão de sialometaplasia necrosante

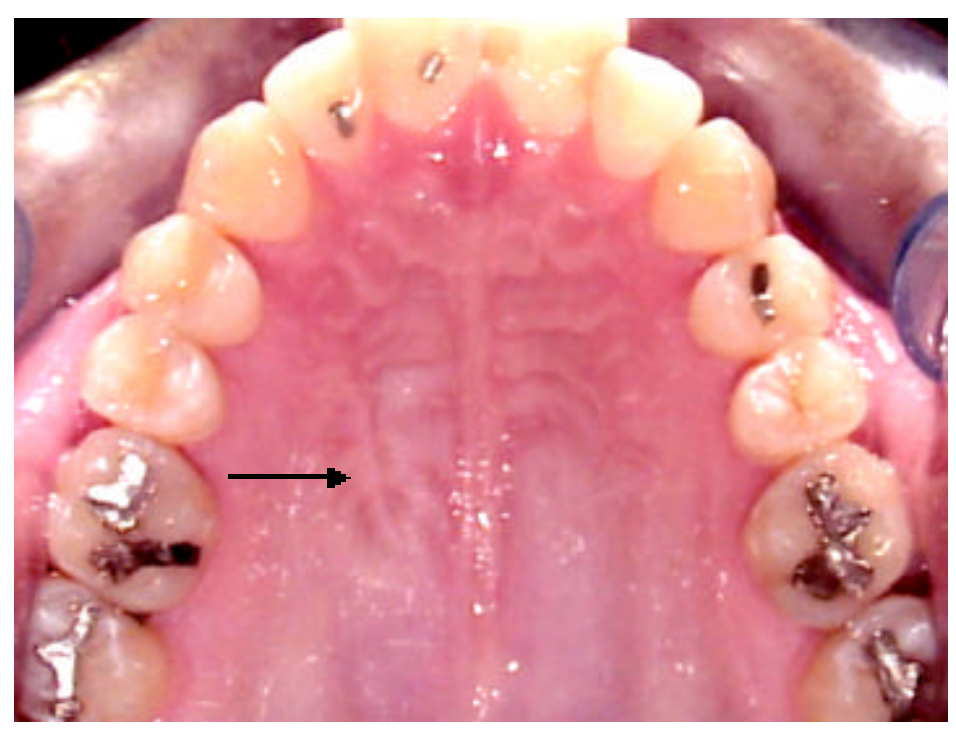

FIGURA 30 - Vista oclusal da mucosa palatina um ano após a reparação do local por segunda intenção (seta) 


\subsection{Da análise estatística}

\subsubsection{Teste intra-examinador}

A interpretação dos resultados do índice Kappa* deve ser realizada de acordo com o quadro abaixo.

\begin{tabular}{|c||c||}
\hline Coeficiente Kappa & Nivel de Concordância \\
\hline \hline$<0,00$ & - \\
\hline $0,00-0,20$ & Baixo \\
\hline $0,21-0,40$ & Médio \\
\hline $0,41-0,60$ & Moderado \\
\hline $0,61-0,80$ & Substancial \\
\hline $0,81-1,00$ & Quase Perfeito \\
\hline
\end{tabular}

\subsubsection{Característica do epitélio estratificado pavimentoso de revestimento}

Para este critério, o índice Kappa resultou em 0,85, com nível de concordância classificado como quase perfeito (TABELA 13).

TABELA 13 - Representação dos dados para a realização do índice Kappa, de acordo com as características do epitélio estratificado pavimentoso de revestimento

\begin{tabular}{|c|c|c|c|c|}
\hline & Atrófico & "Normal & "Hiperplásico & Total \\
\hline Atrófico & $\overline{44}$ & $\overline{0}$ & 0 & $\overline{4}$ \\
\hline Normal & 0 & 0 & 1 & 1 \\
\hline Hiperplásico & 0 & 0 & 12 & 12 \\
\hline $\begin{array}{l}\text { Total } \\
\end{array}$ & 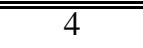 & $\overline{00}$ & $\overline{13}$ & $\overline{177}$ \\
\hline
\end{tabular}

\footnotetext{
* LANDIS, J.R.; KOCH, G.G. The measurement of observer agreement for categorical data. Biometrics, v.33, n.1, p.159-74, Mar. 1977.
} 


\subsubsection{Severidade do infiltrado inflamatório}

Para este critério, o índice Kappa resultou em 1,00, com nível de concordância classificado como quase perfeito a perfeito (TABELA 14).

TABELA 14 - Representação dos dados para a realização do índice Kappa, de acordo com a severidade do infiltrado inflamatório

\begin{tabular}{|c|c|c|c|c|}
\hline & " Discreto & "Moderado & Intenso & Total \\
\hline Discreto & 4 & 0 & 0 & 4 \\
\hline Moderado & 0 & 2 & 0 & 2 \\
\hline Intenso & 0 & 0 & 11 & 11 \\
\hline Total & 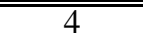 & 2 & 11 & 17 \\
\hline
\end{tabular}

\subsubsection{Metaplasia escamosa do tecido glandular salivar}

Para este critério, o índice Kappa resultou em 0,76, com nível de concordância classificado como substancial (TABELA 15).

TABELA 15 - Representação dos dados para a realização do índice Kappa, de acordo com a metaplasia escamosa do tecido glandular salivar

\begin{tabular}{l||c||c|c}
\cline { 2 - 4 } \multicolumn{1}{c||}{} & Presente & Ausente & Total \\
\hline \hline Presente & 14 & 1 & 15 \\
\hline Ausente & 0 & 2 & 2 \\
\hline \hline Total & 14 & 3 & $\mathbf{1 7}$ \\
\hline
\end{tabular}




\subsubsection{Ilhotas de células mioepiteliais no tecido glandular salivar}

Para este critério, o índice Kappa resultou em 0,74, com nível de concordância classificado como substancial (TABELA 16).

TABELA 16 - Representação dos dados para a realização do índice Kappa, de acordo com as ilhotas de células mioepiteliais no tecido glandular salivar

\begin{tabular}{l|c||c||c}
\cline { 2 - 4 } \multicolumn{1}{c||}{} & Presente & Ausente & Total \\
\hline \hline Presente & 10 & 2 & 12 \\
\hline Ausente & 0 & 5 & 5 \\
\hline \hline Total & 10 & 7 & $\mathbf{1 7}$ \\
\hline
\end{tabular}




\section{DISCUSSÃO}

\subsection{Da concepção do trabalho*}

A idéia original do trabalho adveio de um caso clínico enviado para a Disciplina de Patologia da FOB-USP. Um clínico solicitou consultoria para o diagnóstico de uma lesão palatina associada ao tratamento ortodôntico e ortopédico, mais especificamente com o uso de disjuntor palatino dentomucossuportado, também conhecido como aparelho de Haas (FIGURA 26). Consultamos a literatura pertinente e não encontramos relatos de casos clínicos, tampouco a definição de um diagnóstico associando a presença de lesões palatinas com o uso de aparelhos ortodônticos dentomucossuportados. Em comunicações verbais, com certa freqüência se descreve a ocorrência de necrose da mucosa palatina relacionada à disjunção palatina.

O surgimento desta lesão é pouco freqüente, mas talvez pouco descrita, relatada ou admitida. Quando ela ocorre, a conduta a ser adotada é a remoção do trauma. Após reparada a área, retoma-se o tratamento ortodôntico e ou ortopédico, podendo ou não se alterar o plano de tratamento, sem um diagnóstico preciso estabelecido da lesão e sem esclarecimento da sua etiopatogenia. Se a lesão ainda estiver presente e for examinada por um outro clínico, sem conhecimento prévio da utilização de aparelhos

\footnotetext{
* Nota do orientador: este subtópico consta nas nossas orientações de dissertações e teses para mostrar o surgimento da idéia e os raciocínios inicia is estabelecidos. Desta forma, outros mestrandos e doutorandos, além de outros leitores, terão à disposição os mecanismos pessoais pelos quais no dia-a-dia possamos ter idéias para investigar pontos inquietantes ou ainda obscuros da ciência odontológica. Nos trabalhos resultantes a serem enviados para publicação, em geral, este tópico é retirado da discussão. Consideramos este tópico como um exercício acadêmico muito importante.
} 
dentomucossuportados, este pode ser induzido a um diagnóstico que vai desde a úlcera traumática até lesões malignas, passando-se pela sialometaplasia necrosante.

Entre as particularidades da sialometaplasia necrosante, tem-se a obstrução dos vasos sanguiíneos com infarto e necrose isquêmica das glândulas salivares, resultando geralmente em lesões ulceradas localizadas também no palato duro. Suas características clínicas são suficientes para induzir preocupações com possíveis equívocos diagnósticos quanto a lesões malignas; muitos casos de carcinomas foram realizados em casos de sialometaplasia necrosante. Muitas dessas ocorrências podem ser detectadas no dia-a-dia de um serviço de diagnóstico e quase sempre advêm da falta de informação para discernir com segurança e precisão as diferenças existentes entre sialometaplasia necrosante e lesões malignas.

A partir desta percepção foi desenvolvida uma linha de raciocínio da qual surgiu este trabalho: caracterizar os aspectos microscópicos da sialometaplasia necrosante como um primeiro passo. Posteriormente, estudar os aspectos particulares de sua prevalência quanto aos locais e demais formas clínicas, correlacionando-as em seus possíveis agentes etiopatogênicos, bem como apresentar uma hipótese sobre a sua etiopatogenia considerando a indução por aparelhos disjuntores palatinos.

Aliado a estes objetivos, na concepção deste trabalho, também se procurou difundir de que é importante distinguir clínica e microscopicamente a sialometaplasia necrosante de lesões malignas, ressaltando que a possibilidade de sua ocorrência nas várias especialidades odontológicas é grande. Quanto maior esta difusão, menor será os riscos de equívocos diagnósticos. 
Em suma, o questionamento inicial foi: as lesões necróticas da mucosa palatina relacionadas ao uso de aparelhos disjuntores da maxila poderiam ser sialometaplasias necrosantes iatrogenicamente induzidas?

\subsection{Da metodologia utilizada}

A metodologia adotada procurou ser condizente com os objetivos do trabalho: chamar a atenção dos patologistas, dos clínicos das demais especialidades odontológicas, em especial dos ortodontistas, para refinar ainda mais o seu diagnóstico diferencial de lesões palatinas ulceradas, aumentando sua precisão e segurança quanto ao prognóstico. A metodologia se baseou nos arquivos, fichas e cortes microscópicos preparados e utilizados de forma rotineira nos serviços de diagnósticos microscópicos. Assim foram analisados os dados, os registros e os cortes microscópicos corados pela técnica da hematoxilina e eosina de Harris.

Os casos que apresentavam epitélios com ulceração e hiperplasia pseudo-epiteliomatosa foram considerados ulcerados por representar uma evolução do processo (FIGURA 2). Considerando que a análise dos espécimes é qualitativa, optourse por avaliar o critério de observação e a calibração do examinador para verificar a confiabilidade de ambos.

Quando uma lesão palatina for biopsiada, é importante que o clínico forneça o maior número de dados clínicos possíveis, para auxiliar o patologista a diagnosticar com mais segurança. Para atingir tal objetivo devemos incluir: a) dados pessoais do paciente como gênero, raça e idade; b) aspectos clínicos como localização da 
lesão e o tempo de evolução no momento do diagnóstico; c) os possíveis agentes etiopatogênicos; d) o tipo de lesão fundamental e a sintomatologia; e) exames laboratoriais e imaginológicos; f) associação com outras lesões. Assim que o patologista estabelece o diagnóstico e envia o laudo ao clínico, torna-se ainda mais importante a manutenção da comunicação entre clínico e patologista para acompanhar a evolução dos casos, pois microscopicamente a sialometaplasia necrosante também pode simular outras lesões.

A sialometaplasia necrosante apresenta-se em fases. Neste trabalho achamos interessante estabelecer a fase clínica em que se encontravam os casos e relacionar, quando possível, se eram microscopicamente condizentes os aspectos evolutivos da lesão. Estudos dos cortes teciduais por imuno-histoquímica e microscopia eletrônica foram descartados, pois as colorações em H.E., analisadas pela microscopia óptica, foram suficientes para estabelecer o diagnóstico. Não há marcadores imuno-histoquímicos que permitam um diagnóstico específico de sialometaplasia necrosante.

Uma vez obtidos os dados, procurourse comparar situações clínicas e verificar a possibilidade de existir um quadro característico, que pudesse identificá-la com segurança, apenas do ponto de vista microscópico e acreditamos que isto ocorreu. O tipo de epitélio presente ou ausente, desorganizado ou ulcerado; o tipo de infiltrado inflamatório presente quanto à sua severidade e composição; a presença de glândulas salivares dos variados tipos com preservação da arquitetura lobular geral, apesar das alterações como metaplasia escamosa e número de mitoses aumentado, tal como nas fases evolutivas sugeridas por ANNEROTH; HANSEN ${ }^{3}$ favorecem a distinção das lesões malignas de forma segura e precisa, especialmente quando associadas a informações clínicas detalhadas. A sonegação de informação, por comodidade ou intencionalmente, pode prejudicar o paciente. 
Em alguns casos as informações radiográficas e ou clínicas foram omitidas. A conjunção das análises microscópicas com as informações clínicas e radiográficas, explicitadas na ficha de envio das peças cirúrgicas, resulta no diagnóstico definitivo e em maior benefício clínico ao paciente.

Quanto ao número de casos, se considerarmos a raridade da oportunidade de seu diagnóstico microscópico, a confusão e equívocos realizados em sua identificação com a do carcinoma mucoepidermóide e espinocelular, o número de casos publicados por apenas um serviço de diagnóstico, 17 casos correspondem a uma casuística considerável para estudar a sialometaplasia necrosante. Ainda mais se aproveitarmos a oportunidade para a difusão deste conhecimento aos patologistas e aos ortodontistas.

Como um dado evidenciador dos estudos e hipóteses descritas, apresentamos também o caso clínico que nos presenteou com a concepção original do trabalho, de interesse voltado à Ortodontia, referente a um paciente tratado com aparelho disjuntor tipo Haas, sofrendo de necrose do palato duro devido à ação traumática do acrílico do aparelho sobre a mucosa palatina. Não somente os aparelhos dentomucossuportados, mas qualquer outro tipo de aparelho protético que traumatize as mucosas, bem como as suturas após procedimentos cirúrgicos, apresentam potencial para provocar lesões necróticas, não apenas no palato duro, mas em qualquer outra região das mucosas. A vascularização do palato duro é arboriforme e terminal. Se ocorrer compressão da artéria palatina maior, não há vasos sangüíneos suficientes para suprir a oxigenação tecidual e, conseqüentemente, ocorre a necrose do palato. Mas, quando ela será comprimida? Estes aspectos e questionamentos induziram o desenvolvimento deste trabalho. 


\subsection{Da terminologia e nomenclatura}

\subsubsection{NECROSANTE versus NECROTIZANTE}

A nomenclatura empregada para as lesões de sialometaplasia necrosante, do ponto de vista do idioma português, apresenta-se de forma condizente com a terminologia empregada ao idioma inglês. Elas representam a mesma entidade e apresentam o mesmo significado, porém com ressalvas.

Os termos necrosante e necrotizante são derivados da palavra necrose, originária do grego nékrosis ${ }^{81}$ e significa mortificação. Ambas terminologias são utilizadas pelo idioma português. No idioma inglês pode-se utilizar necrotizing ${ }^{85}$ ou necrosing ${ }^{82}$. Usualmente, quando consultamos a literatura inglesa, encontramos necrotizing.

Não haveria uma falha de comunicação ao utilizar-se necrosante ou necrotizante, de qualquer forma far-se-ia entender, mas a partir dos trabalhos consultados em nossa revisão, preferimos utilizar para este trabalho o termo necrosante.

\subsubsection{ENFARTE versus ENFARTO versus INFARTO}

Este termo refere-se ao distúrbio circulatório causador das lesões de sialometaplasia necrosante e pode ser denominado de várias formas. Descrevemos estas formas no capítulo da revisão da literatura encontradas em alguns dicionários da língua portuguesa e inglesa, assim como nos dicionários de terminologia científica. Os significados mais comuns encontrados são entupimento, obstrução ${ }^{62}$; inchado, fartado e ingurgitado $^{31}$. Na Medicina, segundo STEDMAN ${ }^{59}$, infarto significa a necrose de uma área devido à insuficiência súbita de um vaso arterial ou venoso. 
Ao utilizarmos o termo enfarte e enfarto nos referimos a este distúrbio circulatório de forma leiga e equivocada. Do nosso ponto de vista e de acordo com SACCONI ${ }^{65}$, cientificamente seria infarto a melhor forma a ser utilizada, mesmo porque nos dicionários de termos científicos e da área médica, como MCGRAW-HILL ${ }^{58}$ e STEDMAN $^{59}$ respectivamente, quando se busca a definição deste distúrbio circulatório encontramos apenas infarto.

BECKER $^{60}$ em 1968 e REZENDE ${ }^{64}$ em 1992, ao referir o termo infarto afirmam: área necrosada de um tecido por falta de circulação. REZENDE ${ }^{34}$ destaca por sua vez que o termo enfarte denota ingurgitamento ou inchação, o mesmo significado de enfartação e enfartamento. Para ele o termo enfarte tem uso muito antigo em português, mas sempre com a conotação de aumento de volume, enchimento, repleção e tumefação.

\subsubsection{DISJUNÇÃO versus DISTRAÇÃO versus EXPANSÃO}

Em nossa revisão da literatura definimos estes termos de acordo com alguns dicionários da língua portuguesa e inglesa, da área médica, bem como um dicionário específico de Ortodontia.

Disjunção significa, de acordo com STEDMAN $^{22}$, a separação dos pares de cromossomos durante a anáfase. Para HOUAISS ${ }^{20}$ e MICHAELIS ${ }^{21}$ significa desunião, separação, segregação.

Distração é originária do latim distrahere e significa arrastar para diversos $\operatorname{lados}^{27}$; também significa a divisão ou separação de algo que estava reunido ${ }^{24}$; rasgar, romper ${ }^{23}$. De acordo com GALVÃO FILHO ${ }^{25}$, significa a localização de dentes ou 
de outras estruturas maxilares e mandibulares mais afastadas do plano médio do que o normal.

Expansão, originária do latim expansione ${ }^{40}$, significa expandir ${ }^{37}$; ampliação, crescimento ou alargamento de uma região ${ }^{38,42}$. Este termo é muito utilizado pelo ortodontista e ou odontopediatra quando, segundo OUVÍDIO; FURQUIM ${ }^{91}$, realiza-se o alargamento ortopédico das duas metades da maxila geralmente utilizando-se sistemas de alta carga.

Quando questionamos qual a terminologia empregada ao procedimento, devemos refletir da seguinte forma: a) ao utilizar disjunção, significa que estamos tratando da separação das maxilas; b) para a distração também significa que tratamos da separação das maxilas, mas ressaltamos que também podemos nos referir a uma pessoa distraída, despercebida ou desatenta, dando uma estranha conotação às pessoas não familiarizadas ao procedimento; e c) para a expansão como dependente do crescimento facial.

A partir das reflexões obtidas desta terminologia nos parece mais coerente utilizar disjunção ao ato de separar as duas metades da maxila e expansão ao resultado obtido a partir da disjunção. Em outras palavras, disjunção refere-se ao início e expansão ao término do procedimento.

\subsection{Dos resultados}

Os resultados revelam a possibilidade de um diagnóstico preciso e seguro da sialometaplasia necrosante. Apesar da taxativa afirmação anterior, ela não deve 
ser levada em consideração como uma conclusão definitiva em uma prática clínica com razoável grau de padronização de seus procedimentos. Na rotina laboratorial, quase sempre o diagnóstico pode ser conclusivo e definitivo com base em dados exclusivamente microscópicos. Nos casos duvidosos, a interação clínica e radiográfica é indispensável.

Percebe-se que ao longo dos 37 anos do Serviço de Anatomia Patológica da FOB-USP, como mostrado no trabalho de VELLOSO $^{109}$, houve muitas mudanças desde a nomenclatura das diversas lesões até diagnósticos equivocados. Para o nosso trabalho, por exemplo, teve grande importância a revelação de um caso anterior de sialometaplasia necrosante diagnosticado anteriormente como carcinoma mucoepidermóide (FIGURAS 24 e 25). Na época deste diagnóstico, em 1969, ainda não havia na literatura a descrição da sialometaplasia necrosante relatada por ABRAMS; MELROSE; HOWELL ${ }^{2}$ em 1973. A partir daí, outros trabalhos de revisão de arquivos dos laboratórios de anatomia patológica foram publicados para detectar equívocos diagnósticos, como o de MESA; GERTLER; SCHNEIDER ${ }^{76}$, em 1984, encontrando três casos de sialometaplasia necrosante diagnosticados equivocadamente, sem diagnóstico anterior de lesões malignas.

Desta forma, buscamos, revisando os laudos diagnosticados como carcinomas mucoepidermóide e espinocelular, todos os casos diagnosticados como sialometaplasia necrosante ao longo dos 40 anos de existência do Serviço de Anatomia Patológica da FOB-USP. Enfatizamos a revisão dos casos nos anos anteriores a 1987 por serem, desta data adiante, sempre diagnosticados e ou revisados pelo mesmo examinador.

Características como gênero e raça não são relevantes para diagnosticar as lesões de sialometaplasia necrosante. Tornam-se importantes apenas para 
identificar de uma forma mais completa as características pessoais dos pacientes. Nos casos revisados em nosso trabalho não houve predomínio pelo gênero, como na revisão de casos de SEIFERT ${ }^{100}$. Os resultados encontrados por JAINKITTIVONG; SOOKASAM; PHILIPSEN ${ }^{66}$ ao revisarem 127 casos a partir da literatura detectaram um predomínio no gênero masculino, como também foi detectado em 69 casos descritos por BRANNON; FOWLER; HARTMAN ${ }^{10}$.

Em nosso trabalho, os pacientes da raça branca foram identificados em $100 \%$ dos casos. Os trabalhos de JAINKITTIVONG; SOOKASAM; PHILIPSEN ${ }^{66}$ e de BRANNON; FOWLER; HARTMAN ${ }^{10}$ estão de acordo com nossos achados, porém não tão discrepantes como mostrado em nosso trabalho. Revisando a literatura japonesa, YOSHIMURA et al. ${ }^{113}$ relataram os únicos casos acometendo a raça amarela.

Se seguirmos os dados encontrados na literatura, a idade acima dos 40 anos predispõe ao surgimento de lesões malignas. Esta afirmação pode ser verdadeira, mas vai depender da história clínica e das causas associadas. O caso do paciente que recebeu o diagnóstico de carcinoma mucoepidermóide equivocado com a sialometaplasia necrosante, em 1969, tinha apenas 44 anos de idade. No soalho bucal, o paciente apresentava uma tumoração sangrante na altura do ducto submandibular. Informações como o tempo de evolução da lesão no momento do diagnóstico, exame radiográfico e dimensão da lesão foram sonegadas. $\mathrm{Na}$ época deste diagnóstico, nem sequer conhecia-se a sialometaplasia necrosante, nem mesmo podia-se deduzir com os dados fornecidos que aquela lesão poderia ser de natureza inflamatória. Foi esperado o insucesso para localizar o paciente e ou o cirurgião que realizou o exame na época do diagnóstico para notificarmos a evolução do caso. De acordo com os achados de BRANNON; FOWLER; HARTMAN ${ }^{10}$, nosso trabalho 
revelou variação de idade entre 7 e 72 anos com predomínio na faixa dos 45 anos. Em contraparte, os achados de SEIFERT ${ }^{100}$ e YOSHIMURA et al. ${ }^{113}$ atingiram a faixa dos 60 anos de idade.

Em nossos resultados a localização predominante da lesão foi no soalho bucal (cinco casos), seguida do palato duro (quatro casos) e lábio inferior (três casos). Em dois casos foram sonegadas informações referentes à localização da lesão. $\mathrm{O}$ carcinoma mucoepidermóide como uma neoplasia maligna das glândulas salivares pode ocorrer em qualquer localização da mucosa bucal, se considerarmos a ampla distribuição glandular.

Quanto à lesão fundamental, os nossos resultados revelaram predomínio de lesões nodulares, seguida de lesões ulceradas e bolhosas. Em uma parte das fichas enviadas (cinco) não foi especificado o tipo de lesão fundamental apresentada no momento do diagnóstico. A importância da lesão fundamental constitui-se no fato dos carcinomas geralmente se apresentarem como úlceras sem tendência ao reparo, já na sialometaplasia necrosante as lesões iniciais são nodulares e quando necrosam o epitélio subjacente, em uma fase subseqüente, se apresentam como ulcerações com tendência ao reparo após a remoção da possível causa, geralmente um agente traumático.

A carência de dados clínicos dificultou os resultados em relação às causas de sialometaplasia necrosante. Dos 17 casos analisados em nosso trabalho, 11 deles não estava especificada uma causa provável. Dos seis casos onde houve relatos de causa, a primária mais comum foi o trauma durante alimentação, por coincidência, ambas localizadas no soalho bucal. As associações com fenômenos de retenção de mico ou 
mucocele foram as causas secundárias mais comuns. Um dos casos, ao mesmo tempo intrigante e esclarecedor, ocorreu em conseqüência de uma cirurgia de lábio inferior para remoção de carcinoma espinocelular em área com queilite actínica (FIGURAS 7 e 8). A pressão excessiva durante a sutura pode ter sido a provável causa da ocorrência de sialometaplasia necrosante no local com retenção de muco associada. Neste caso, não se pode ainda descartar a possibilidade de associação da causa ao procedimento e efeitos anestésicos. Semelhante a esta situação, GRANICK et al. ${ }^{49}$ relataram um caso em um paciente com suspeita de carcinoma basocelular no lábio superior. Os autores realizaram biópsia e a análise microscópica confirmou carcinoma basocelular. Ao retornar para reconstrução labial, havia surgido uma reação eczematosa na pele do paciente; esta foi biopsiada e diagnosticada como sialometaplasia necrosante. Uma outra situação revelada por nosso trabalho ocorreu no lábio inferior em função de um trauma de prótese parcial removível.

A sintomatologia dolorosa apresenta-se comumente, porém não contribui de forma significante para o diagnóstico da sialometaplasia necrosante. Em muitos casos a dor pode ocorrer de forma espontânea ou provocada, bem como difusa ou localizada. Em nossos resultados, ela esteve presente em $50 \%$ dos casos onde havia o relato da sua presença. Cinco casos não apresentavam dados referentes à sintomatologia dolorosa.

O tempo de evolução das lesões no momento do diagnóstico é uma referência muito importante a ser fornecida pelo clínico. Dos resultados revelados pelo nosso trabalho, os casos onde o tempo de evolução foi relatado variaram de dez dias a um ano. Em quase $60 \%$ dos casos não houve relatos referentes ao tempo de evolução da lesão no momento do diagnóstico. Destaca-se que a história médica e de traumas anteriores, o 
aspecto clínico e morfológico das lesões, o tempo de evolução no momento do diagnóstico, bem como de reparo, são dados relevantes para descartar os diagnósticos de malignidade.

As características microscópicas da sialometaplasia necrosante reveladas por nosso trabalho estão de acordo com ABRAMS; MELROSE; HOWELL²: a) infarto ou necrose dos lóbulos das glândulas salivares; b) morfologia nuclear das células escamosas discretamente preservada; c) metaplasia escamosa acinar e ductal (FIGURAS 3, 22 e 23); d) tecido de granulação, infiltrado e exsudato inflamatórios proeminentes (FIGURAS 3, 15 e 16); e) manutenção da arquitetura geral dos lóbulos das glândulas salivares (FIGURAS 2, 9, 20 e 22).

O epitélio de revestimento do tipo estratificado pavimentoso hiperplásico apresentou-se de forma predominante com exocitose. A associação destas características representa uma resposta a prováveis antígenos advindos da superfície epitelial. A hiperplasia provavelmente serve para obter-se mais camadas como se fossem barreiras para dificultar a entrada de antígenos; o infiltrado inflamatório adentra ao epitélio para combater estes antígenos que conseguiram penetrar no epitélio.

Em lesões com presença de ulceração, encontrada em cinco dos nossos casos, era de se esperar a presença de epitélio aparentemente atrófico em lesões mais evoluídas, representando uma evolução ao reparo. A fase de evolução de ANNEROTH; HANSEN ${ }^{3}$, nestes mesmos casos, se encontravam nas fases C e D, ou ulcerativa e reparatória, respectivamente. No tecido conjuntivo logo abaixo da área ulcerada, há a presença de infiltrado inflamatório polimorfonuclear e mononuclear, na maioria dos casos com intensa severidade, bem como de tecido de granulação, também 
indicativo de reparo. A presença de ulceração geralmente vem acompanhada de sintomatologia dolorosa e nossos achados suportaram esta hipótese, exceto em um dos casos. Nos casos apresentados pela literatura, esta correlação está presente, embora também haja casos com presença de ulceração e ausência de sintomatologia dolorosa.

O infiltrado inflamatório apresentou-se com distribuição e tipos celulares variáveis: neutrófilos, eosinófilos, macrófagos, linfócitos e plasmócitos. A sua severidade, na maioria dos casos, apresentou-se intensa, suportando a natureza inflamatória da lesão.

O envolvimento do tecido ósseo é pouco freqüente e nem a lesão, mesmo apresentando envolvimento ósseo, apresenta imagem radiográfica significante. Em apenas um dos mossos casos, os clastos estavam presentes, embora o clínico remetente da biópsia não relatou a presença de imagem radiográfica, nem enviou a radiografia para comprovação do envolvimento ósseo.

Como a própria definição de sialometaplasia necrosante já indica o envolvimento das glândulas salivares, seria imprescindível a presença deste tecido para identifica- la. Nos casos examinados ocorreu o envolvimento de glândulas salivares, exceto em um dos casos. Neste, após o diagnóstico microscópico compatível com carcinoma mucoepidermóide, sugerimos tratar-se de sialometaplasia necrosante, pois a área biopsiada pelo clínico envolvia o palato duro e não apresentava tecido glandular à microscopia. Ao acompanharmos sua evolução, o clínico relatou que nova biópsia foi realizada e o diagnóstico de carcinoma mucoepidermóide confirmourse. Este dado nos parece esclarecer que, nem sempre, nos carcinomas é imprescindível a presença de tecido glandular. Para o 
diagnóstico ser definitivo de sialometaplasia necrosante, a presença de tecido glandular é imprescindível e independe da glândula salivar atingida.

Anatomicamente, as glândulas salivares são formadas por lobos e lóbulos constituídos por ácinos e ductos suportados por estroma de trabéculas conjuntivas. No interior dos lóbulos, saindo dos ácinos, encontramrse os ductos intercalares e estriados que desembocam no ducto excretor principal. As células mioepiteliais abraçam os ácinos e são responsáveis pela sua compressão para a secreção da saliva sintetizada. As células mais diferenciadas, como as acinares, necrosam-se com a hipóxia ou a anoxia, mas as células epiteliais ductais e mioepiteliais resistem e sofrem metaplasia escamosa, formando ilhotas e cordões celulares que, misturadas a algumas células acinares persistentes e, à necrose, enganam o patologista com o diagnóstico equivocado de carcinoma ${ }^{2,3,16}$. Eventuais hiperplasias pseudo-epiteliomatosas podem estar presentes, apenas uma em nossos resultados (FIGURA 2), indicando uma hiperplasia epitelial exagerada com mitoses típicas, podendo também confundir o patologista.

As fases de evolução propostas por ANNEROTH; HANSEN ${ }^{3}$ tentam explicar a etiopatogenia da lesão. É importante ao patologista conhecer estas fases para informar ao clínico se a lesão se apresenta em uma fase inicial ou até curativa. Nossos resultados revelam o predomínio das fases ulcerativa e reparatória. Seria difícil prever clinicamente a presença de sialometaplasia necrosante na fase inicial ou de infarto, porém as fases ulcerativa e ou reparatória, normalmente estão associadas e clinicamente visíveis. Semelhante a ANNEROTH; HANSEN ${ }^{3}$, o trabalho de IMBERY; EDWARDS ${ }^{57}$ tenta explicar as mesmas fases de evolução, ambos trabalhos baseados nos moldes propostos por ABRAMS; MELROSE; HOWELL ${ }^{2}$. Nosso trabalho revela que a preservação da 
arquitetura geral dos lóbulos das glândulas salivares constitui a principal característica microscópica para descartar o diagnóstico de carcinoma mucoepidermóide, bem como a carência de atipia celular, identificada equivocadamente como hiperplasia pseudoepiteliomatosa ou em áreas de regeneração epitelial.

\subsubsection{Dos resultados estatísticos}

Como a avaliação morfológica trata-se de uma análise qualitativa, optou-se por um teste estatístico que evidenciasse a confiabilidade do método utilizado na padronização da observação das lâminas, bem como que verificasse a calibração do examinador.

Deste modo, empregou-se o índice Kappa na avaliação dos critérios selecionados, de acordo com a sua relevância para o diagnóstico da lesão, como as características do epitélio estratificado pavimentoso de revestimento, a severidade do infiltrado inflamatório, a presença de metaplasia escamosa e de ilhotas de células mioepiteliais do tecido glandular salivar.

O índice Kappa apresentou níveis de concordância quase pe rfeito a perfeito para dois dos critérios analisados: o epitélio e o infiltrado inflamatório. Este resultado constata que estes aspectos observados apresentavamse bastante claros e evidentes, podendo-se considerá-los bons critérios de diagnóstico, não deixando quaisquer dúvidas ou demonstrando exímia calibração do examinador, o que seria menos provável. 
Os demais critérios avaliados pela aplicação do índice foram os únicos aspectos onde ocorreu discordância entre a primeira e segunda análise intra-examinador. Optou-se pela realização do índice Kappa para estes critérios, mesmo que não fossem de primordial importância diagnóstica, para demonstrar que mesmo quando ocorreu discordância no exame das lâminas, estes foram apenas em um ou dois casos apenas e conforme o indicado pela interpretação do índice: não foram estatisticamente significantes (os índices apresentaram-se com valor acima do considerado crítico, ou seja, 0,6). Pode-se considerar, portanto, que o método de análise foi eficiente e verificourse a calibração bastante satisfatória do examinador, mesmo quando houve maior dificuldade na identificação da metaplasia escamosa e das ilhotas de células mioepiteliais.

\subsection{Do caso clínico e das implicações clínicas}

O caso clínico ilustrativo deste trabalho mostrou como pode ser freqüente a ocorrência de lesões ulceradas e necróticas no palato duro advindas de disjunções palatinas com aparelhos dentomucossuportados. A conduta realizada frente a este caso foi descrita no capítulo dos resultados.

Quantos casos de ulcerações na mucosa palatina, advindas de disjunção palatina já ocorreram sem notificação e destaque na literatura? Do ponto de vista literário não há relatos de casos clínicos, porém é eventual a sua frequiência. Muitos clínicos, após a exposição da situação, bem como em comunicações pessoais, revelam já ter passado por essa experiência e ainda ressaltam que após a remoção do aparelho a lesão 
repara em três semanas aproximadamente. O planejamento do tratamento pode ou não ser modificado após o alívio dos sintomas.

Como revelado também por nossos estudos, com interesse ao ortodontista e odontopediatra, nenhuma associação de lesões necróticas no palato duro à disjunção palatina foi relacionada nos trabalhos consultados, muito menos o diagnóstico destas lesões com a sialometaplasia necrosante.

Assim surgem questionamentos: a) apenas a pressão do acrílico sobre a mucosa palatina é suficiente para provocar as ulcerações de sialometaplasia necrosante? ; b) existem meios de prevenir a ocorrência dessas lesões? ; c) é necessário realizar biópsia para ter a certeza dessas ulcerações serem sialometaplasias necrosantes?

A pressão do acrílico sobre a mucosa palatina pode ser suficiente para provocar ulcerações de sialometaplasia necrosante. Outras situações como a quebra do aparelho ou ativações inadequadas, bem como as associações destas, também podem provocar ulcerações. Quando elas ocorrem são doloridas, pode ocorrer exposição óssea e o tratamento consiste na remoção do aparelho, limpeza e debridamento da área, indicação de analgésico e antiinflamatório, bem como antibioticoterapia para prevenir infecções oportunistas. O reparo é espontâneo e o tempo necessário para efetuar o reparo depende da extensão da lesão. A biópsia é realizada nos casos onde não é possível associar uma relação causa-efeito. No caso das disjunções palatinas, a relação causa-efeito está estabelecida e descarta-se a necessidade de biópsia.

A prevenção da ocorrência dessas lesões foi relatada por CONSOLARO et al. ${ }^{16}$. No trabalho, os autores sugeriram a confecção de marcas nos 
modelos de gesso, em especial nas trajetórias das artérias palatinas maiores, para orientar o protético quanto aos locais de alívio (FIGURA 31).

O palato duro apresenta uma circulação terminal e arboriforme. Sua irrigação advém das artérias palatinas maiores na região posterior e da artéria nasopalatina na região anterior (FIGURA 32). Na submucosa palatina, há muitas glândulas salivares menores, especialmente na sua metade mais posterior. Apesar das anastomoses acontecerem na região dos caninos, se alguma redução do fluxo ocorrer em uma das artérias, a isquemia provocada não será devidamente compensada por outros vasos e pode levar a região isquêmica à necrose, estabelecendo-se clinicamente como lesões ulceradas.

Preocupados com a escolha de áreas doadoras de mucosas para enxertos gengivais, REISER et al. ${ }^{92}$ relataram que a partir dos pré-molares e molares, entre a junção esmalte-cemento e o sulco ósseo palatino por onde passa a artéria palatina maior, a distância varia de 7 a $17 \mathrm{~mm}$ de acordo com o grau de profundidade do palato. Eles estabeleceram os seguintes parâmetros:

a) quando o palato apresentar a abóbada alta ou em forma de "U", a artéria estaria em média 17mm da junção esmalte-cemento (FIGURA 33);

b) nos casos médios, a artéria estaria a $12 \mathrm{~mm}$ da junção esmalte-cemento (FIGURA $34)$;

c) quando o palato for raso, a distância seria de 7mm (FIGURA 35).

Os autores sugerem a palpação como método clínico de localização da artéria palatina maior e sua demarcação com caneta para a escolha da área doadora dos 
enxertos gengivais. A artéria palatina maior emerge do forame palatino maior, continua-se em direção anterior do palato, paralela aos dentes posteriores e, na altura dos caninos, angula-se em sua direção (FIGURA 36).

Para evitar a ocorrência das ulcerações durante a disjunção palatina, sugerimos levar em consideração as características morfológicas do palato como sua forma e profundidade ${ }^{16}$. Na palpação digital do palato na região dos molares, pode-se detectar o sulco palatino na superfície óssea por onde passa a artéria palatina maior. A demarcação bilateral com tinta, do local da artéria palatina maior, no modelo sobre o qual será delineada a área de apoio mucoso do acrílico permitirá a realização de alívios ou contornos, evitandose sua compressão.

Nos casos de ocorrência de sialometaplasia necrosante no palato decorrente da ação física do aparelho, as ulcerações deverão ser limpas com anti-sépticos não alcoólicos para eliminação dos restos necróticos e alimentares. As soluções anestésicas podem ser indicadas para alívio de desconforto durante a alimentação. Analgésicos podem ser administrados em caso de dor ou desconforto maior. A antibioticoterapia de largo espectro previne infecções oportunistas e deve durar até o fechamento completo da lesão.

A inclusão de um caso clínico relacionado permite-nos discutir e extrapolar com mais aplicabilidade clínica os dados levantados no estudo da casuística dos arquivos, especialmente se depararmos com a falta de descrições na literatura pertinente. Deste trabalho, outras investigações estão sendo realizadas para aprofundarmos esta relação sialometaplasia necrosante e disjunção palatina hipoteticamente estabelecida. 


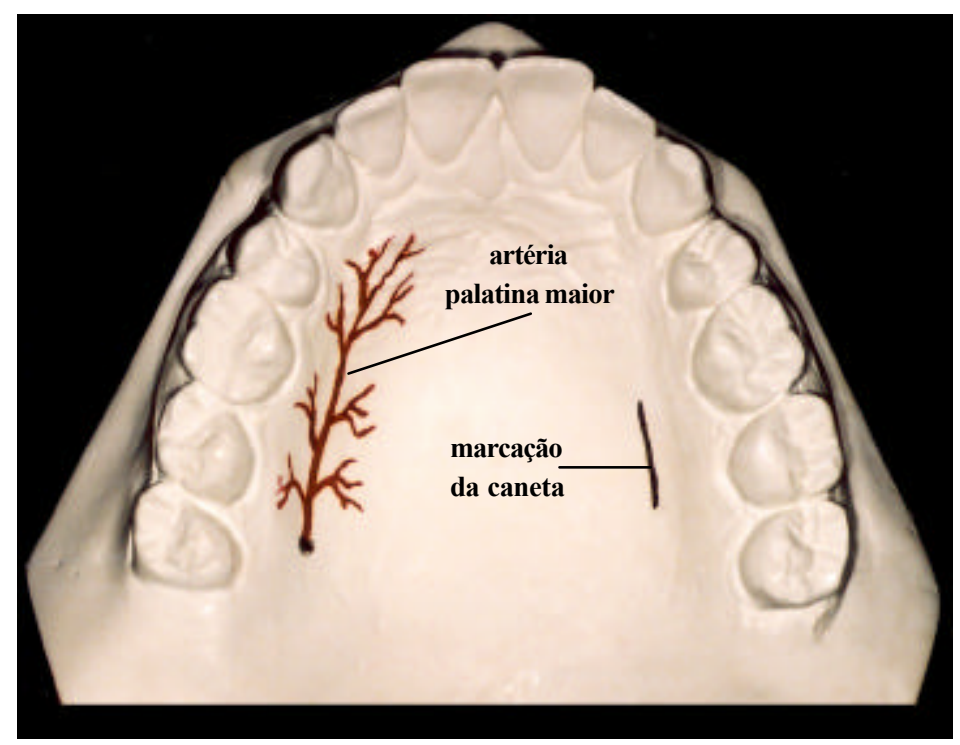

FIGURA 31 - Localização da artéria palatina maior delineada no modelo de gesso onde o acrílico do disjuntor palatino será posicionado. As marcações com caneta são realizadas nos modelos para orientar o protético a confeccionar alívios no local de inserção do acrílico e, com isso, evitar a compressão nas áreas sensíveis

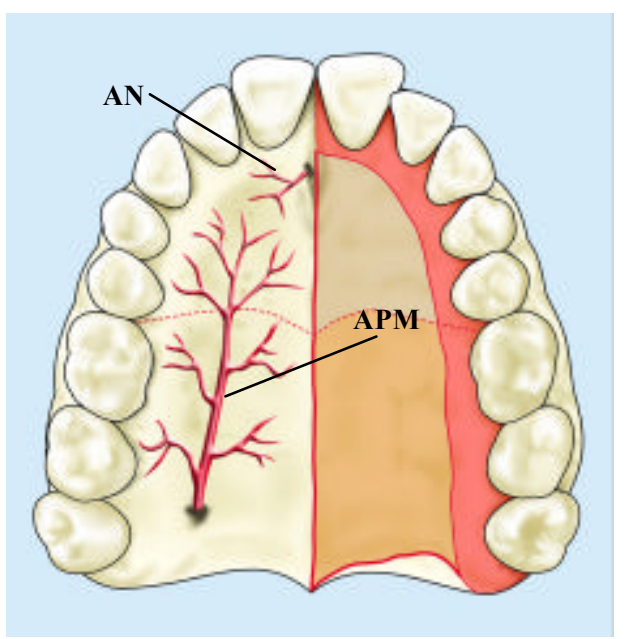

FIGURA 32 - Diagrama demonstrativo da vascularização do palato: artéria palatina maior (APM) e artéria nasopalatina (AN) (Adaptado de LINDHE*)

* LINDHE, J. Tratado de periodontia clínica e impl antologia oral. 3.ed. Guanabara-Koogan, Rio de Janeiro, 1999. 


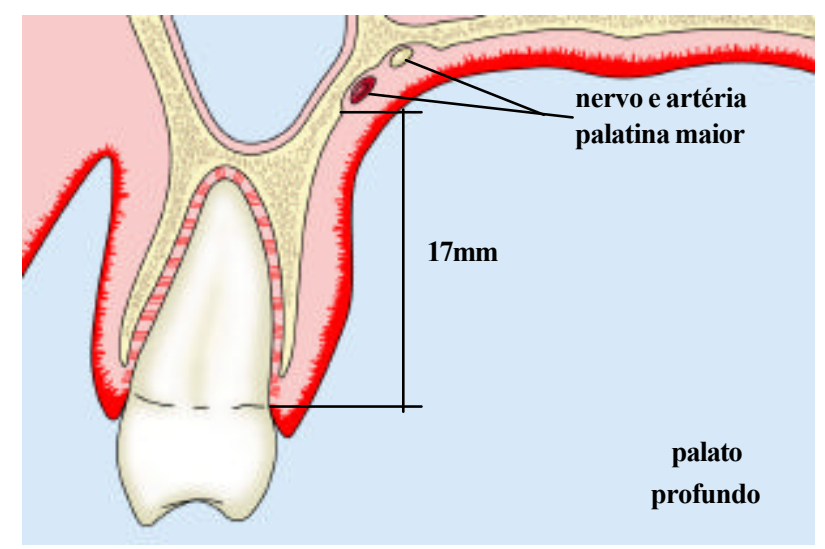

FIGURA 33 - Palato duro profundo, medindo $17 \mathrm{~mm}$ da junção esmalte-cemento à artéria palatina maior (Adaptado de REISER et al. ${ }^{91}$ )

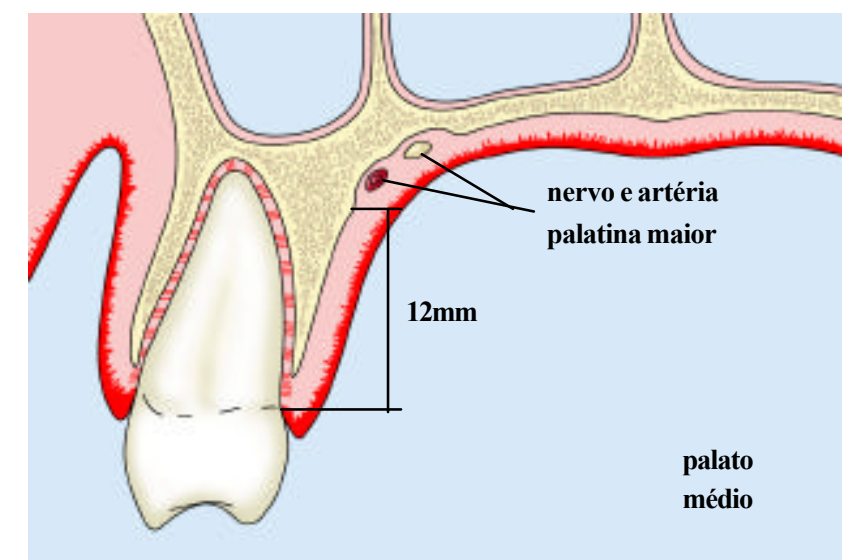

FIGURA 34 - Palato duro médio, medindo $12 \mathrm{~mm}$ da junção esmalte-cemento à artéria palatina maior (Adaptado de REISER et al. ${ }^{91}$ ) 


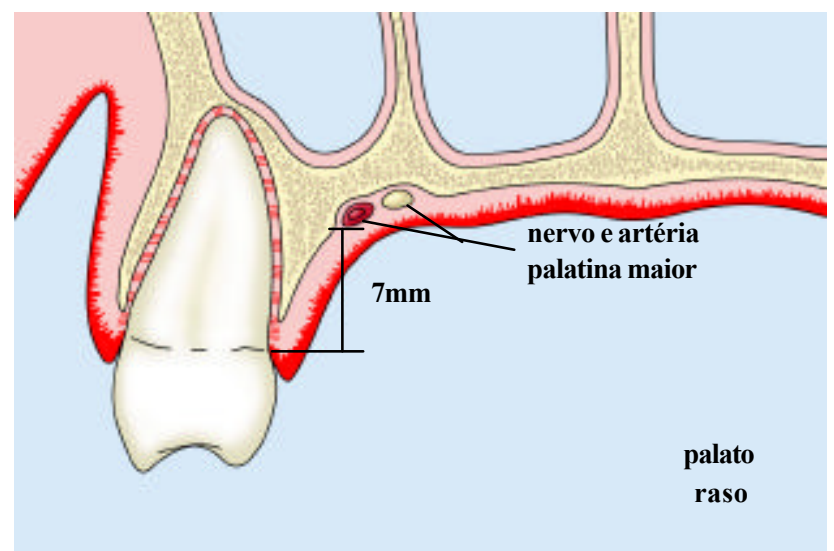

FIGURA 35 - Palato duro aso, medindo $7 \mathrm{~mm}$ da junção esmalte-cemento à artéria palatina maior (Adaptado de REISER et al. ${ }^{91}$ )

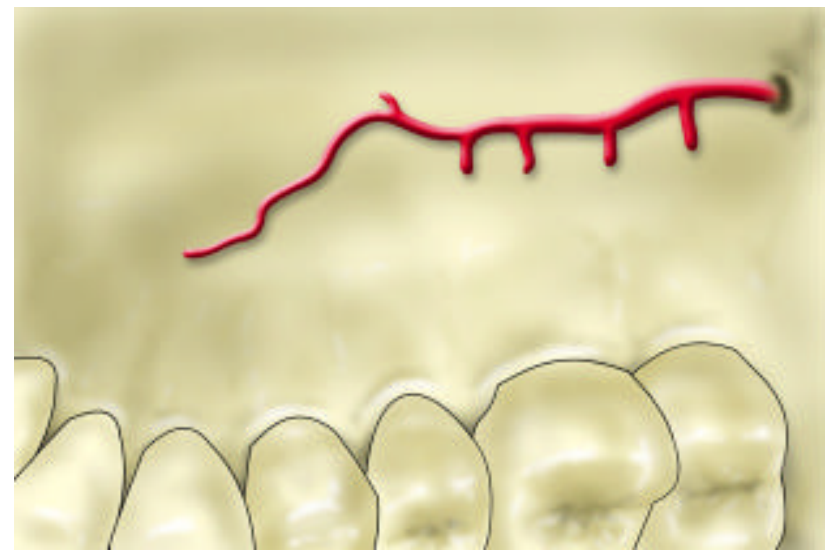

FIGURA 36 - A artéria palatina maior emerge do forame palatino maior, continua-se para a porção anterior do palato, paralela aos dentes posteriores e angula-se em direção ao canino (Adaptado de REISER et al. ${ }^{91}$ ) 
A conduta de ativação do parafuso do aparelho relatada e adotada pelo clínico deste trabalho não está de acordo com os padrões de ativação estabelecidos por HAAS $^{52,53,54,55}$, também incluídos em uma entrevista concedida à Revista Dental Press de Ortodontia e Ortopedia Faciap ${ }^{51}$ :

1. Até os 14 anos de idade:

a. quatro quartos de volta na inserção do aparelho;

b. dois quartos de volta/dia.

2. Dos 15 aos 18 anos de idade:

a. dois quartos de volta na inserção do aparelho;

b. um quarto de volta/dia.

3. Dos 18 aos 25 anos de idade:

a. um quarto de volta na inserção do aparelho;

b. um quarto de volta/dia.

4. Dos 25 anos de idade até à senilidade:

a. um quarto de volta na inserção do aparelho;

b. um quarto de volta/dia; parar no caso da pressão acostumada aumentar e ajustar a taxa de ativação baseado no conforto do paciente. 
De acordo com este protocolo de ativação ${ }^{51}$, a lesão necrótica do palato duro provocada pelo aparelho de Haas do nosso caso se deu provavelmente por uma ativação inadequada e ou por irregularidades na superfície do acrílico do aparelho em contato com a mucosa palatina do lado afetado pela lesão.

A magnitude de força do aparelho pode atingir até $10.000 \mathrm{~g} / \mathrm{cm}^{2}$ e a faixa usual mais comum está em torno de $4.500 \mathrm{~g} / \mathrm{cm}^{2}$. A sutura palatina mediana raramente se abre após os 18 anos de idade. Se o aparelho for ajustado à mesma pressão utilizada em pacientes mais jovens, também poderiam ocorrer danos teciduais facilmente evitados pelo ajuste do aparelho em pacientes sem crescimento. Quando esta sutura não se abre, há duas opções de tratamento: corticotomia previamente à disjunção palatina com aparelho dentomucossuportado ou disjunção palatina lenta com o aparelho inserido e ajustado de acordo com a idade do paciente ${ }^{51}$.

Um outro tipo de resposta ortopédica pode ser obtido conforme os blocos acrílicos comecem a comprimir as artérias palatinas. Teoricamente, num esforço para se evitar esta compressão, o tecido ósseo do palato duro abaixo destas artérias é reabsorvido, produzindo uma depressão óssea semelhante àquela que ocorre quando a sutura se abre. A pressão, em torno de $4.500 \mathrm{~g} / \mathrm{cm}^{2}$, se irradia através da maxila provocando-se torques e tensões, as quais respondem com aposição óssea na sua superfície externa, assemelhando-se aos casos onde a sutura palatina mediana se abriu. $\mathrm{HAAS}^{51}$ se refere a esta alteração ortopédica como expansão da base alveolar alta-apical baixa, com os mesmos benefícios da disjunção da sutura palatina mediana ${ }^{51}$. 
Os resultados obtidos pelo nosso trabalho não contra-indicam a utilização dos aparelhos disjuntores dentomucossuportados, apenas sugerem cuidados para prevenir a ocorrência de lesões necróticas palatinas advindas deste procedimento.

Em suma, na disjunção palatina, a anatomia do palato, em especial a vasculatura responsável pelo seu aporte sangüíneo, deve ser mais um dos fatores a ser considerado. A compressão das artérias palatinas pode ocorrer durante a disjunção palatina e promover a necrose tecidual da submucosa palatina, inclusive das glândulas salivares menores, promovendo ulceração da área, sem necessariamente caracterizar uma sialometaplasia necrosante e sim uma úlcera traumática.

A possível ocorrência da sialometaplasia necrosante associada ao uso de aparelhos disjuntores palatinos ou quando ocorre apenas uma úlcera traumática devem ser objetos de novos estudos clínicos e experimentais, relevando-se os aspectos anatômicos do palato. 
7 CONCLUSÕES 


\section{CONCLUSÕES}

A partir dos resultados obtidos pelo nosso trabalho, concluímos que:

7.1 A sialometaplasia necrosante pode ser distinguida microscopicamente das lesões malignas. Em alguns casos torna-se fundamental a história clínica para diagnosticar de forma mais precisa e segura. Quando não existe uma relação causa-efeito, a biópsia é indispensável;

7.2 O soalho bucal e o palato duro são os locais mais afetados e o trauma é o agente etiológico mais comum para a sua ocorrência;

7.3 As lesões na mucosa palatina provocadas por aparelhos dentomucossuportados podem ser sialometaplasias necrosantes. Por apresentar uma relação causa-efeito muito bem estabelecida, em geral não são biopsiadas e diagnosticadas microscopicamente. Alívios nas trajetórias das artérias palatinas maiores devem ser confeccionados para prevenir a sua ocorrência. 
REFERÊNCIAS BIBLIOGRÁFICAS 


\section{REFERÊNCIAS BIBLIOGRÁFICAS ${ }^{*}$}

1 ABAZA, N.A.; ABAZA, M.M.; SEDHOM, A.W. Necrotizing sialometaplasia: a review and two case reports. Compendium, v.13, n.1, p.12-8, Jan. 1992.

2 ABRAMS, A.M.; MELROSE, R.J.; HOWELL, F.V. Necrotizing sialometaplasia: a disease simulating malignancy. Cancer, v.32, n.1, p.130-5, July 1973.

3 ANNEROTH, G.; HANSEN, L.S. Necrotizing sialometaplasia: the relationship of its pathogenesis to its clinical characteristics. Int. J. oral Surg., v.11, n.5, p.283-91, Oct. 1982.

4 ARGUELLES, M.T. et al. Necrotizing sialometaplasia. Oral Surg., v.42, n.1, p.8690, July 1976.

5 BANNAYAN, G.; FOX, G.; TILSON, H.B. Necrotizing sialometaplasia of the palate. J. oral Surg., v.34, n.8, p.727-30, Aug. 1976.

6 BELL, G.W.; LOUKOTA, R.A. Necrotizing sialometaplasia coincident with ipsilateral infarcted antral polyps. Brit. J. oral Maxillofac. Surg., v.34, n.1, p.129-31, Feb. 1996.

7 BEN-IZHAK, O.; BEN-ARIEH, Y. Necrotizing sialometaplasia of the larynx. Amer. J. clin. Pathol., v.105, n.2, p.251-3, Feb. 1996.

8 BIRKHOLZ, H.; BROWND, C.L. Necrotizing sialometaplasia: report of an ulcerative case. J. Amer. dent. Ass., v.103, n.1, p.48-50, July 1981.

9 BIRKHOLZ, H.; MINTON, G.A.; YUEN, Y.L. Necrotizing sialometaplasia: review of the literature and report of nonulcerative case. J. oral Surg., v.37, n.8, p.58892, Aug. 1979.

10 BRANNON, R.B.; FOWLER, C.B.; HARTMAN, K.S. Necrotizing sialometaplasia: a clinicopathologic study of sixty- nine cases and review of the literature. Oral Surg., v.72, n.3, p.317-25, Sept. 1991.

11 BULLER, D.L. Nodular and ulcerated lesions of the hard palate. J. Amer. dent. Ass., v.101, n.5, p.823-4, Nov. 1980.

12 CHAKRAVORTY, R.C.; YONEYAMA, T.; MAKOOI, C. Necrotizing sialometaplasia of palate. Brit. J. Surg., v.66, n.4, p.283-4, Apr. 1979.

\footnotetext{
* Normas recomendadas para uso no âmbito da Universidade de São Paulo, com base no documento "Referências Bibliográficas: Exemplos", emanado do Conselho Supervisor do Sistema Integrado de Bibliotecas da USP, em reunião de 20 de setembro de 1990.
} 
13 CHAUDHRY, A.P. et al. Necrotizing sialometaplasia of palatal minor salivary glands: a report on 2 cases. J. oral Med., v.40, n.1, p.2-6, Jan./Mar. 1985.

14 COLEY-SMITH, A.; ELLIS, S.G.S. Necrotizing sialometaplasia: a case report. Dent. Update, v.21, n.6, p.250-2, July/Aug. 1994.

15 COLQUITT, W.N.; GOBETTI, J.P. Necrotizing sialometaplasia: a diagnostic dilemma. J. Mich. dent. Ass., v.66, n.1, p.23-5, Jan. 1984.

16 CONSOLARO, A. et al. Palatal blood supply: explanation and suggestion to prevent necrotic lesions during rapid maxillary expansion (RME). J. clin. Orthod., 2003. /no prelo/

17 COOPER, P.H. President Cleveland's palatal tumor. Arch. Dermatol., v.122, n.7, p.747-8, July 1986.

18 CORRELL, R.W.; WESCOTT, W.B.; PIERCE, G.L. Asymptomatic, nonulcerated swelling of the posterior hard palate. J. Amer. dent. Ass., v.105, n.3, p.512-3, Sept. 1982.

19 DAUDIA, A.; MURTY, G.E. First case of full-thickness palatal necrotizing sialometaplasia. J. Laryngol. Otol., v.116, n.3, p.219-20, Mar. 2002.

20 DISJUNÇÃO. In: HOUAISS: dicionário da língua portuguesa. Rio de Janeiro, Objetiva, 2001. p.1055.

21 DISJUNÇÃO. In: MICHAELIS: moderno dicionário da língua portuguesa. São Paulo, Melhoramentos, 1998. p.735.

22 DISJUNCTION. In: STEDMAN'S medical dictionary. 25.ed. Baltimore, Williams \& Wilkins, c1990. p.455.

23 DISTRAÇÃO. In: HOUAISS: dicionário da língua portuguesa. Rio de Janeiro, Objetiva, 2001. p.1061.

24 DISTRAÇÃO. In: MICHAELIS: moderno dicionário da língua portuguesa. São Paulo, Melhoramentos, 1998. p.740.

25 DISTRACTION. In: GALVÃO FILHO, S. Dicionário odonto-médico inglêsportuguês. São Paulo, Livraria Santos, 1998. p.194.

26 DISTRACTION. In: STEDMAN'S medical dictionary. 25.ed. Baltimore, Williams \& Wilkins, c1990. p.459.

27 DISTRAIR. In: NASCENTES, A. Dicionário etimológico da língua portuguesa. Rio de Janeiro, 1955. p.161. 
28 DONATH, K.; SEIFERT, G. Tumour-simulating squamous cell metaplasia (SCM) in necrotic areas of salivary gland tumours. Pathol. Res. Pract., v.193, n.10, p.68993, 1997.

29 DUNLAP, C.L.; BARKER, B.F. Necrotizing sialometaplasia: report of five additional cases. Oral Surg., v.37, n.5, p.722-7, May 1974.

30 DUNLEY, R.E.; JACOWAY, J.R. Necrotizing sialometaplasia. Oral Surg., v.47, n.2, p.169-72, Feb. 1979.

31 ENFARTE. In: FERREIRA, A.B.H. Novo Aurélio século XXI: o dicionário da língua portuguesa. São Paulo, Nova Fronteira, c1999. p.755.

32 ENFARTE. In: HOUAISS: dicionário da língua portuguesa. Rio de Janeiro, Objetiva, 2001. p.1144.

33 ENFARTE. In: MICHAELIS: moderno dicionário da língua portuguesa. São Paulo, Melhoramentos, 1998. p.805.

34 ENFARTE. In: REZENDE, J.M. Linguagem médica. São Paulo, Fundo Editorial BYK, 1992. p.151-3.

35 ENFARTO. In: HOUAISS: dicionário da língua portuguesa. Rio de Janeiro, Objetiva, 2001. p.1144.

36 ENFARTO. In: MICHAELIS: moderno dicionário da língua portuguesa. São Paulo, Melhoramentos, 1998. p.805.

37 EXPANSÃO. In: FERREIRA, A.B.H. Novo Aurélio século XXI: o dicionário da língua portuguesa. São Paulo, Nova Fronteira, c1999. p.861.

38 EXPANSÃO. In: HOUAISS: dicionário da língua portuguesa. Rio de Janeiro, Objetiva, 2001. p.1286-7.

39 EXPANSÃO. In: MICHAELIS: moderno dicionário da língua portuguesa. São Paulo, Melhoramentos, 1998. p.922.

40 EXPANSÃO. In: NASCENTES, A. Dicionário etimológico da língua portuguesa. Rio de Janeiro, 1955. p.205.

41 EXPANSION. In: MCGRAW-HILL: dictionary of scientific and technical terms. New York, McGraw-Hill Book Company, c1974. p.521.

42 EXPANSION. In: STEDMAN'S medical dictionary. 25.ed. Baltimore, Williams \& Wilkins, c1990. p.550. 
43 FECHNER, R.E. Necrotizing sialometaplasia: a source of confusion with carcinoma of the palate. Amer. J. clin. Pathol., v.67, n.4, p.315-7, Apr. 1977.

44 FORNEY, S.K. et al. Necrotizing sialometaplasia of the mandible. Oral Surg., v.43, n.5, p.720-6, May 1977.

45 FOWLER, C.B.; BRANNON, R.B. Subacute necrotizing sialadenitis: report of 7 cases and a review of the literature. Oral Surg., v.89, n.5, p.600-9, May 2000.

$46 \mathrm{GAD}$, A. et al. Necrotizing sialometaplasia of the lip simulating squamous cell carcinoma. Histopathology, v.4, n.1, p.111-21, Jan. 1980.

47 GAHHOS, F. et al. Necrotizing sialometaplasia: report of five cases. Plast. Reconstr. Surg., v.71, n.5, p.650-7, May 1983.

48 GILES, A.D. Necrotizing sialometaplasia. Brit. J. oral Surg., v.18, n.1, p.45-50, June 1980.

49 GRANICK, M.S. et al. Necrotizing sialometaplasia masquerading as residual cancer of the lip. Ann. Plast. Surg., v.21, n.2, p.152-4, Aug. 1988.

50 GRILLON, G.L.; LALLY, E.T. Necrotizing sialometaplasia: literature review and presentation of five cases. J. oral Surg., v.39, n.10, p.747-53, Oct. 1981.

51 HAAS, A.J. Entrevista. Rev. Dental Press Ortod. Ortop. Fac., v.6, n.1, p.1-10, jan./fev. 2001.

52 HAAS, A.J. Long-term posttreatment evaluation of rapid palatal expansion. Angle Orthod., v.50, n.3, p.189-217, July 1980.

53 HAAS, A.J. Palatal expansion: just the beginning of dentofacial orthopedics. Amer. J. Orthod., v.57, n.3, p.219-55, Mar. 1970.

54 HAAS, A.J. Rapid expansion of the maxillary dental arch and nasal cavity by opening the midpalatal suture. Angle Orthod., v.31, n.2, p.73-90, Apr. 1961.

55 HAAS, A.J. The treatment of maxillary deficiency by opening the midpalatal suture. Angle Orthod., v.35, n.3, p.200-17, July 1965.

56 HOVINGA, J.; DE JAGER, H. A patient with necrotizing sialometaplasia. Int. J. oral Surg., v.6, n.5, p.280-2, Oct. 1977.

57 IMBERY, T.A.; EDWARDS, P.A. Necrotizing sialometaplasia: literature review and case reports. J. Amer. dent. Ass., v.127, n.7, p.1087-92, July 1996.

58 INFARCT. In: MCGRAW-HILL: dictionary of scientific and technical terms. New York, McGraw-Hill Book Company, c1974. p.749. 
59 INFARCT. In: STEDMAN'S medical dictionary. 25.ed. Baltimore, Williams \& Wilkins, c1990. p.779.

60 INFARTO. In: BECKER, I. Nomenclatura biomédica. São Paulo, Nobel, 1968. p.212-3.

61 INFARTO. In: FERREIRA, A.B.H. Novo Aurélio século XXI: o dicionário da língua portuguesa. São Paulo, Nova Fronteira, c1999. p.1107.

62 INFARTO. In: HOUAISS: dicionário da língua portuguesa. Rio de Janeiro, Objetiva, 2001. p.1612.

63 INFARTO. In: MICHAELIS: moderno dicionário da língua portuguesa. São Paulo, Melhoramentos, 1998. p.1152.

64 INFARTO. In: REZENDE, J.M. Linguagem médica. São Paulo, Fundo Editorial BYK, 1992. p.151-3.

65 INFARTO. In: SACCONI: minidicionário da língua portuguesa. São Paulo, Atual, c2000. p.393.

66 JAINKITTIVONG, A.; SOOKASAM, M.; PHILIPSEN, H.P. Necrotizing sialometaplasia: review of 127 cases. J. dent. Ass. Thai., v.39, n.1, p.11-6, Jan./Feb. 1989.

67 KROLLS, S.O.; MCGINNIS JUNIOR, J.P. Case presentation: ulcer of palate. Miss. dent. Ass. J., v.51, n.1, p.8-9, Spring 1995.

68 LAMBERT, P.M. Necrotizing sialometaplasia: report of two cases. Spec. Care Dent., v.7, n.2, p.78-80, Mar./Apr. 1987.

69 LAMEY, P.J. et al. Necrotising sialometaplasia presenting as greater palatine nerve anaesthesia. Int. J. oral Maxillofac. Surg., v.18, n.2, p.70-2, Apr. 1989.

70 LYNCH, D.P.; CRAGO, C.A.; MARTINEZ JUNIOR, M.G. Necrotizing sialometaplasia: a review of the literature and report of two additional cases. Oral Surg., v.47, n.1, p.63-9, Jan. 1979.

71 MANDEL, L.; KAYNAR, A.; DECHIARA, S. Necrotizing sialometaplasia in a patient with sickle-cell anemia. J. oral Maxillofac. Surg., v.49, n.7, p.757-9, July 1991.

72 MARCIANI, R.D.; SABES, W.R. Necrotizing sialometaplasia: report of three cases. J. oral Surg., v.34, n.8, p.722-6, Aug. 1976.

73 MATILLA, A. et al. Necrotizing sialometaplasia affecting the minor labial glands. Oral Surg., v.47, n.2, p.161-3, Feb. 1979. 
74 MCCULLOUGH, D.T.; RYE, L.A.; REDMAN, R.S. Necrotizing sialometaplasia: a lesion of minor salivary glands that mimics malignancies. Ann. Plast. Surg., v.7, n.6, p.480-3, Dec. 1981.

75 MESA, M.; SCHNEIDER, L.; CLARK, M. Necrotizing sialometaplasia: a result of ischemia? Report of two cases and review of the literature. Q. Natl. dent. Ass., v.38, n.1, p.16-23, Oct. 1979.

76 MESA, M.L.; GERTLER, R.S.; SCHNEIDER, L.C. Necrotizing sialometaplasia: frequency of histologic misdiagnosis. Oral Surg., v.57, n.1, p.71-3, Jan. 1984.

77 MITCHELL, R.D. Necrotizing sialometaplasia: case report. Aust. dent. J., v.30, n.3, p.181-4, June 1985.

78 MORREELS JUNIOR, C.L. New historical information on the Cleveland operations. Surgery, v.62, n.3, p.542-51, Sept. 1967.

79 MURPHY, J. et al. Necrotizing sialometaplasia. Oral Surg., v.44, n.3, p.419-24, Sept. 1977.

80 NECROSANTE. In: HOUAISS: dicionário da língua portuguesa. Rio de Janeiro, Objetiva, 2001. p.2002.

81 NECROSE. In: NASCENTES, A. Dicionário etimológico da língua portuguesa. Rio de Janeiro, 1955. p.351.

82 NECROSING. In: GALVÃO FILHO, S. Dicionário odonto-médico inglêsportuguês. São Paulo, Livraria Santos, 1998. p.430.

83 NECROTIZANTE. In: HOUAISS: dicionário da língua portuguesa. Rio de Janeiro, Objetiva, 2001. p.2002.

84 NECROTIZE. In: MCGRAW-HILL: dictionary of scientific and technical terms. New York, McGraw-Hill Book Company, c1974. p.991.

85 NECROTIZING. In: GALVÃO FILHO, S. Dicionário odonto-médico inglêsportuguês. São Paulo, Livraria Santos, 1998. p.430.

86 NILSEN, R.; BERNHOFT, C.H.; GILHUUS-MOE, O. Necrotizing sialometaplasia. Int. J. oral Surg., v.7, n.6, p.580-4, Dec. 1978.

87 PAPANAYOTOU, P.H. et al. Necrotizing sialometaplasia of the cheek: report of case and review of literature. J. oral Surg., v.38, n.7, p.538-40, July 1980.

88 PHILIPSEN, H.P.; PETERSEN, J.K.; SIMONSEN, B.H. Necrotizing sialometaplasia of the palate. Ulcerative or necrotizing stage of leukokeratosis nicotina palati ?

Int. J. oral Surg., v.5, n.6, p.292-9, Dec. 1976. 
89 POULSON, T.C.; GREER JUNIOR, R.O.; RYSER, R.W. Necrotizing sialometaplasia obscuring an underlying malignancy: report of a case. J. oral Maxillofac. Surg., v.44, n.7, p.570-4, July 1986.

90 PULSE, C.L.; LEBOVICS, R.S.; ZEGARELLI, D.J. Necrotizing sialometaplasia: report of a case after lower lip mucocele excision. J. oral Maxillofac. Surg., v.58, n.12, p.1419-21, Dec. 2000.

91 RAPID MAXILLARY EXPANSION. In: OUVÍDIO, E.B.; FURQUIM, L.Z. Dicionário ilustrado de ortodontia. São Paulo, Livraria Santos, 1995. p.127.

92 REISER, G.M. et al. The subepithelial connective tissue graft palatal donor site: anatomic considerations for surgeons. Int. J. Periodont. Restor. dent., v.16, n.2, p.131-7, Apr. 1996.

93 ROSSIE, K.M.; ALLEN, C.M.; BURNS, R.A. Necrotizing sialometaplasia: a case with metachronous lesions. J. oral Maxillofac. Surg., v.44, n.12, p.1006-8, Dec. 1986.

94 RYE, L.A.; CALHOUN, N.R.; REDMAN, R.S. Necrotizing sialometaplasia in a patient with Buerger's disease and Raynaud's phenomenon. Oral Surg., v.49, n.3, p.233-6, Mar. 1980.

95 SAMIT, A.M.; MASHBERG, A.; GREENE JUNIOR, G.W. Necrotizing sialometaplasia. J. oral Surg., v.37, n.5, p.353-6, May 1979.

96 SANDMEIER, D.; BOUZOURENE, H. Necrotizing sialometaplasia: a potential diagnostic pitfall. Histopathology, v.40, n.2, p.200-1, Feb. 2002.

97 SANTIS, H.R. et al. Necrotizing sialometaplasia: an early, nonulcerative presentation. Oral Surg., v.53, n.4, p.387-90, Apr. 1982.

98 SCHÖNING, H.; EMSHOFF, R.; KRECZY, A. Necrotizing sialometaplasia in two patients with bulimia and chronic vomiting. Int. J. oral Maxillofac. Surg., v.27, n.6, p.463-5, Dec. 1998.

99 SCHROEDER JUNIOR, W.A. Necrotizing sialometaplasia. Otolaryngol. Head Neck Surg., v.111, n.3, p.328-9, Sept. 1994.

100 SEIFERT, G. Tumour-like lesions of the salivary glands. The new WHO classification. Pathol. Res. Pract., v.188, n.7, p.836-46, Oct. 1992.

101 SHIGEMATSU, H. et al. Experimental study on necrotizing sialometaplasia of the palate in rats. Role of local anesthetic injections. Int. J. oral Maxillofac. Surg., v.25, n.3, p.239-41, June 1996. 
102 SNEIGE, N.; BATSAKIS, J.G. Necrotizing sialometaplasia. Ann. Otol. Rhinol. Laryngol., v.101, n.3, p.282-4, Mar. 1992.

103 SPARK, R.P.; DUNCAN, D.G. Necrotizing sialometaplasia: a self-limited pseudotumoral palatal ulcer. Ann. Otol. Rhinol. Laryngol., v.87, n.3, p.409-11, May/June 1978.

104 SPEECHLEY, J.A.; FIELD, E.A.; SCOTT, J. Necrotizing sialometaplasia occurring during pregnancy: report of a case. J. oral Maxillofac. Surg., v.46, n.8, p.696-9, Aug. 1988.

105 STAFFORD, R.F.; SONIS, S.T.; SHKLAR, G. Bilateral necrotizing sialometaplasia: a case report. J. oral Med., v.36, n.2, p.28-30, Apr./June 1981.

106 SUCKIEL, J.M. et al. Early and late manifestations of necrotizing sialometaplasia. J. oral Surg., v.36, n.11, p.902-5, Nov. 1978.

107 TAXY, J.B. Necrotizing squamous/mucinous metaplasia in oncocytic salivary gland tumors: a potential diagnostic problem. Amer. J. clin. Pathol., v.97, n.1, p.40-5, Jan. 1992.

108 VAN DER WAL, J.E.; VAN DER WAAL, I. Necrotizing sialometaplasia: report of 12 new cases. Brit. J. oral Maxillofac. Surg., v.28, n.5, p.326-8, Oct. 1990.

109 VELLOSO, T.R.G. Análise da evolução e características de um serviço de anatomia patológica bucal durante o período de 37 anos: checagem, revisão e atualização diagnóstica. Bauru, 2001. 119p. Dissertação (Mestrado) - Faculdade de Odontologia de Bauru, Universidade de São Paulo.

110 WALKER, G.K. et al. Necrotizing sialometaplasia of the larynx secondary to atheromatous embolization. Amer. J. clin. Pathol., v.77, n.2, p.221-3, Feb. 1982.

111 WENIG, B.M. Necrotizing sialometaplasia of the larynx. A report of two cases and a review of the literature. Amer. J. clin. Pathol., v.103, n.5, p.609-13, May 1995.

112 WILLIAMS, R.F. Necrotizing sialometaplasia after bronchoscopy. J. oral Surg., v.37, n.11, p.816-8, Nov. 1979.

113 YOSHIMURA, Y. et al. Necrotizing sialometaplasia: report of a case and review of the Japanese literature. J. Osaka Univ. dent. Sch., v.25, p.171-6, Dec. 1985. 
ABSTRACT 


\section{MICROSCOPIC ANALYSIS OF NECROTIZING SIALOMETAPLASIA AND THEORY PRESENTATION OF AETIOPATHOGENIC RELATIONS, SPECIALLY WITH RAPID MAXILLARY EXPANSION}

Necrotizing sialometaplasia is an inflammatory lesion of salivary glands, which has shown self-limitation and self-repairing within one and ten weeks. Its aetiopathogenesis is associated to infarction and necrosis caused by obstruction of the blood supply. The resemblance of such lesion with other malignant lesions is very remarkable; therefore the correct diagnosis is of great importance in daily practice. Necrotic lesions on the hard palate induced by RME appliances may probably be cause-effect related to necrotizing sialometaplasia of iatrogenic nature. The analyzed specimens of necrotizing sialometaplasia were registered at the Oral Pathology Department, Bauru Dental School, University of São Paulo. The cases were randomed since 1963 according their histopathologic reports, describing clinic and microscopic features. A clinical case of necrotic lesion on the hard palate induced by RME appliance was explored concerning evolution, procedure adopted and aetiopathogenic relations. The results of our study allowed us to conclude that: 1) necrotizing sialometaplasia may be microscopically distinguished from other malignant lesions. In some cases, clinical history is indispensable for accurate diagnosis. Biopsy is vital when the cause-effect relation is not evident; 2) the hard palate and mouth floor are the most affected sites and trauma is the main aetiological factor; 3) lesions in the oral mucosa caused by dentoskeletal anchorage appliances may be iatrogenic necrotizing sialometaplasia and should not be biopsied or diagnosed microscopically due to the well established cause-effect relation. To avoid any pathological outcome, the expansion appliance acrylic, should be designed with close attention to the location of the greater palatine artery and other palatal vascular features. 


\section{Universidade de São Paulo Faculdade de Odontologia de Bauru \\ A1. Dr. Octávio Pinheiro Brisolla, 9-75 - Bauru-SP - CEP 17012-901 - C.P. 73 PABX (0XX14)235-8000 - FAX (0XX14)223-4679 \\ Comitê de Éfica em Pesquisa}

Processo $n^{0} 002 / 2003$

Bauru, 31 de março de 2003

Senhor Professor.

Informamos que após o envio da documentação pendente, o projeto de pesquisa encaminhado a este Comitê denominado "Análise microscópica da sialometaplasia necrosante e apresentação de uma hipótese sobre suas relaçōes etiopatogênicas, em especial com aparelhos disjuntores palatinos", de autoria de Valdomiro Rebellato Júnior, que será desenvolvido sob sua orientação, foi APROVADO, em reunião deste comitê realizada em 26 de março de 2003.

Comunicamos que após o envio do trabalho concluído, este Comitê enviará o parecer final, que será utilizado para a publicação do trabalho.

Atenciosamente,

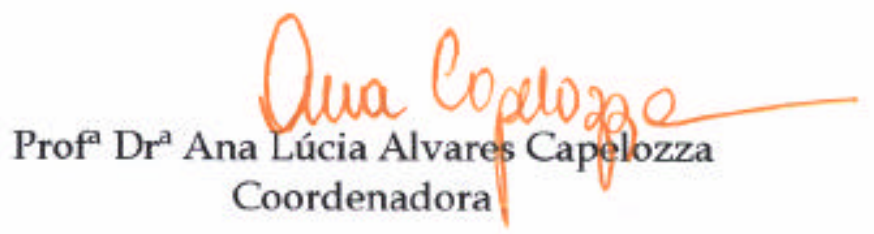

$\mathrm{Ilm}^{\circ} \mathrm{Sr}$. Prof. Dr. Alberto Consolaro

DD. Docente do Departamento de Estomatologia (Disciplina de Patologia) 
Distribuição dos achados clínicos observados nos laudos histopatológicos dos registros

do Serviço de Anatomia Patológica da FOB-USP

\begin{tabular}{|c|c|c|c|c|c|c|c|c|c|c|}
\hline \multirow{2}{*}{ PARÂMETROS } & \multicolumn{10}{|c|}{ NÚMERO DO CASO } \\
\hline & 1 & 2 & 3 & 4 & 5 & 6 & 7 & 8 & 9 & 10 \\
\hline GÊNERO & M & $\mathrm{F}$ & M & $\mathrm{F}$ & $\mathrm{F}$ & M & M & $\mathrm{F}$ & M & $\mathrm{F}$ \\
\hline IDADE & 44 & 28 & --- & 7 & 55 & 72 & 72 & 20 & 58 & 53 \\
\hline RAÇA & B & B & --- & B & B & B & B & B & B & B \\
\hline $\begin{array}{l}\text { LESÃO } \\
\text { FUNDAMENTAL }\end{array}$ & Nódulo & Ulceração & --- & Nódulo & Nódulo & Ulceração & Ulceração & Bolha & --- & Nódulo \\
\hline LOCALIZAÇÃO & Soalho Bucal & $\begin{array}{c}\text { Palato } \\
\text { Duro/Mole }\end{array}$ & --- & Palato Duro & Palato Duro & Soalho Bucal & Soalho Bucal & Palato Mole & Bochecha & Lábio Inferior \\
\hline EVOLUÇÃO & --- & 15 dias & --- & --- & 1 ano & 3 meses & 3 meses & --- & --- & Indefinida \\
\hline ETIOLOGIA & --- & --- & --- & --- & --- & Alimentação & Alimentação & Alimentação & --- & --- \\
\hline SINTOMATOLOGIA & --- & Dolorosa & --- & Indolor & Dolorosa & Dolorosa & Dolorosa & Dolorosa & --- & Indolor \\
\hline
\end{tabular}

continua 
continuação

\begin{tabular}{|c|c|c|c|c|c|c|c|}
\hline \multirow{2}{*}{ PARÂMETROS } & \multicolumn{7}{|c|}{ NÚMERO DO CASO } \\
\hline & 11 & 12 & 13 & 14 & 15 & 16 & 17 \\
\hline GÊNERO & M & M & M & $\mathrm{F}$ & M & $\mathrm{F}$ & $\mathrm{F}$ \\
\hline IDADE & -- & 22 & 34 & --- & 51 & 7 & 71 \\
\hline RAÇA & B & B & B & B & B & B & B \\
\hline LESÃO FUNDAMENTAL & Nódulo & Nódulo & --- & Ulceração & --- & --- & Nódulo \\
\hline LOCALIZAÇÃO & Palato Duro & --- & Lábio Inferior & Soalho Bucal & Palato Duro & Soalho Bucal & Lábio Inferior \\
\hline EVOLUÇÃO & 10 dias & 4 meses & --- & -- & -- & --- & 45 dias \\
\hline ETIOLOGIA & --- & Trauma & Trauma Cirúrgico & --- & -- & --- & Trauma PPR \\
\hline SINTOMATOLOGIA & Indolor & Indolor & -- & Indolor & --- & Dolorosa & Indolor \\
\hline
\end{tabular}




\section{Distribuição dos achados microscópicos observados nas lâminas dos registros}

\section{do Serviço de Anatomia Patológica da FOB-USP (Coloração HE)}

\begin{tabular}{|c|c|c|c|c|c|c|c|c|c|c|c|c|c|c|}
\hline \multirow{2}{*}{\multicolumn{5}{|c|}{ CONSTITUIÇÃO DOS DIFERENTES TECIDOS }} & \multicolumn{10}{|c|}{ NÚMERO DO CASO } \\
\hline & & & & & 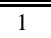 & $\overline{20}$ & 3 & 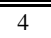 & 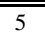 & 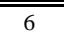 & 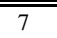 & 8 & $\overline{99}$ & 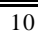 \\
\hline \multirow{7}{*}{ 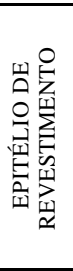 } & \multirow{7}{*}{ 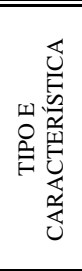 } & \multirow{3}{*}{\multicolumn{2}{|c|}{$\begin{array}{c}\text { EPITÉLIO } \\
\text { ESTRATIFICADO } \\
\text { PAVIMENTOSO }\end{array}$}} & ATRÓFICO & & & $\mathrm{X}$ & & & & & & $\mathrm{X}$ & \\
\hline & & & & NORMAL & & & $\mathrm{X}$ & $\mathrm{X}$ & $\mathrm{X}$ & & & $\mathrm{X}$ & & \\
\hline & & & & HIPERPLÁSICO & $\mathrm{X}$ & $\mathrm{X}$ & $\mathrm{X}$ & & & $\mathrm{X}$ & $\mathrm{X}$ & $\mathrm{X}$ & $\mathrm{X}$ & \\
\hline & & \multicolumn{3}{|c|}{ EXOCITOSE } & $\mathrm{X}$ & & & $\mathrm{X}$ & & & & $\mathrm{X}$ & $\mathrm{X}$ & \\
\hline & & \multicolumn{3}{|c|}{ HIPERPLASIA PSEUDO-EPITELIOMATOSA } & & & & & & & & & & \\
\hline & & \multicolumn{3}{|c|}{ DISPLASIA } & & & & & & & & & & \\
\hline & & \multicolumn{3}{|c|}{ ULCERAÇÃO } & & & & & & $\mathrm{X}$ & $\mathrm{x}$ & & & \\
\hline \multirow{15}{*}{ 兽总 } & \multirow{6}{*}{ 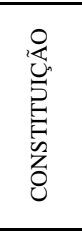 } & \multicolumn{3}{|c|}{ NERVOS } & $\bar{x}$ & $\overline{\mathrm{X} X}$ & & $\bar{x}$ & $\overline{\mathrm{X}}$ & 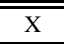 & 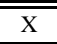 & & 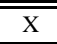 & $\overline{\mathrm{X}}$ \\
\hline & & \multicolumn{3}{|c|}{ VASOS SANGÜÍNEOS } & $\mathrm{X}$ & $\mathrm{X}$ & $\mathrm{X}$ & $\mathrm{X}$ & $\mathrm{X}$ & $\mathrm{X}$ & $\mathrm{x}$ & $\mathrm{X}$ & $\mathrm{X}$ & $\mathrm{X}$ \\
\hline & & \multirow{2}{*}{\multicolumn{2}{|c|}{$\begin{array}{l}\text { FENÔMENOS } \\
\text { VASCULARES }\end{array}$}} & TROMBOSE & & & & & & & & & & \\
\hline & & & & EMBOLIA & & & & & & & & & & \\
\hline & & \multirow{2}{*}{\multicolumn{2}{|c|}{ OUTRAS }} & NECROSE & & & $\mathrm{X}$ & & & & & & & \\
\hline & & & & TECIDO DE GRANULAÇÃO & & & $\mathrm{X}$ & & & & & & & \\
\hline & \multirow{9}{*}{ 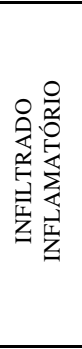 } & \multirow{3}{*}{\multicolumn{2}{|c|}{ SEVERIDADE }} & DISCRETO & & & & $\mathrm{X}$ & & & & & & \\
\hline & & & & MODERADO & & & & & & & $\mathrm{X}$ & & & \\
\hline & & & & INTENSO & $\mathrm{X}$ & $\mathrm{X}$ & $\mathrm{X}$ & & & $\mathrm{X}$ & & $\mathrm{X}$ & $\mathrm{X}$ & $\mathrm{X}$ \\
\hline & & \multirow{6}{*}{$\begin{array}{l}0 \\
\text { 它 } \\
u \\
0 \\
0 \\
\vdots \\
0 \\
0 \\
0\end{array}$} & \multirow{3}{*}{ PMN } & NEUTRÓFILO & $\mathrm{X}$ & $\mathrm{X}$ & $\mathrm{X}$ & $\mathrm{X}$ & & $\mathrm{X}$ & $\mathrm{x}$ & $\mathrm{X}$ & $\mathrm{X}$ & $\mathrm{X}$ \\
\hline & & & & EOSINÓFILO & & & & $\mathrm{X}$ & & & & $\mathrm{X}$ & $\mathrm{X}$ & \\
\hline & & & & BASÓFILO & & & & & & & & & 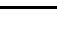 & \\
\hline & & & & LINFÓCITO & $\mathrm{X}$ & $\mathrm{X}$ & $\mathrm{X}$ & $\mathrm{X}$ & & $\mathrm{X}$ & $\mathrm{x}$ & $\mathrm{X}$ & $\mathrm{X}$ & $\mathrm{X}$ \\
\hline & & & $\mathrm{MN}$ & PLASMÓCITO & $\mathrm{X}$ & $\mathrm{X}$ & $\mathrm{X}$ & $\mathrm{X}$ & & $\mathrm{X}$ & $\mathrm{X}$ & $\bar{X}$ & $\mathrm{X}$ & $\mathrm{x}$ \\
\hline & & & & MACRÓFAGO & $\mathrm{X}$ & $\mathrm{X}$ & $\mathrm{X}$ & $\mathrm{X}$ & & $\mathrm{X}$ & $\mathrm{X}$ & $\mathrm{X}$ & $\mathrm{X}$ & $\mathrm{X}$ \\
\hline \multirow{6}{*}{ 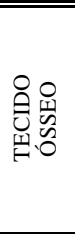 } & \multirow{6}{*}{ 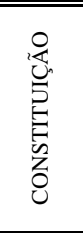 } & & & 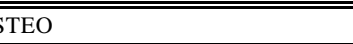 & & & & & & & & & & \\
\hline & & & & TRIENTES & & & & & & & & & & \\
\hline & & & & CROBIANOS & & & & & & & & & & \\
\hline & & & & OSTEÓCITO & & & & & & & & & & \\
\hline & & & JLAS & OSTEOBLASTO & & & & & & & & & & \\
\hline & & & & OSTEOCLASTO & & $\mathrm{X}$ & & & & & & & & \\
\hline & & & & LASIA ESCAMOSA & $\mathrm{X}$ & $\mathrm{X}$ & $\overline{\mathrm{X}}$ & & $\mathrm{X}$ & $\bar{X}$ & $\mathrm{X}$ & $\overline{\mathrm{X}}$ & $\bar{X}$ & $\bar{X}$ \\
\hline & & ÕES & & NECROSE & & & & & & & & & & $\mathrm{X}$ \\
\hline & & & & CÉLULAS MIOEPITELIAIS & $\mathrm{X}$ & $\mathrm{X}$ & $\mathrm{X}$ & & & $\mathrm{X}$ & $\mathrm{X}$ & & $\mathrm{X}$ & $\mathrm{X}$ \\
\hline & & & & & $\mathrm{X}$ & & $\mathrm{X}$ & $\mathrm{X}$ & $\mathrm{X}$ & $\mathrm{X}$ & $\mathrm{x}$ & & $\mathrm{X}$ & $\mathrm{X}$ \\
\hline 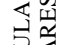 & $\stackrel{0}{=}$ & & & & $\mathrm{X}$ & & $\mathrm{X}$ & & & & & & & \\
\hline $\bar{z} \geq$ & & & & & $\mathrm{X}$ & & $\mathrm{X}$ & & & & & & $\mathrm{X}$ & $\mathrm{X}$ \\
\hline 这 & & & & ALAR & $\mathrm{X}$ & $\mathrm{X}$ & $\mathrm{X}$ & $\mathrm{X}$ & $\mathrm{X}$ & $\mathrm{X}$ & $\mathrm{X}$ & & $\mathrm{X}$ & $\mathrm{x}$ \\
\hline & & & & ADO & $\mathrm{X}$ & $\mathrm{X}$ & $\mathrm{X}$ & $\mathrm{X}$ & $\mathrm{X}$ & $\mathrm{X}$ & $\mathrm{X}$ & & $\mathrm{X}$ & $\mathrm{X}$ \\
\hline & 已 & & & TOR & $\mathrm{X}$ & & $\mathrm{X}$ & & $\mathrm{X}$ & $\mathrm{X}$ & $\mathrm{X}$ & $\mathrm{X}$ & $\mathrm{X}$ & \\
\hline & $\overrightarrow{\mathrm{D}}$ & & STFR ACÕES & DILATADO & $\mathrm{X}$ & & $\mathrm{X}$ & $\mathrm{X}$ & $\mathrm{X}$ & $\mathrm{X}$ & $\mathrm{X}$ & & $\mathrm{X}$ & $\mathrm{X}$ \\
\hline & & & ALTERAÇOES & MUCO NO INTERIOR & $\mathrm{X}$ & $\mathrm{X}$ & $\mathrm{X}$ & $\mathrm{X}$ & $\mathrm{X}$ & $\mathrm{X}$ & $\mathrm{X}$ & & $\mathrm{X}$ & $\mathrm{X}$ \\
\hline & & & 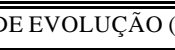 & 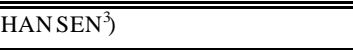 & 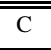 & $\overline{\mathrm{D}}$ & 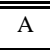 & $\overline{\mathrm{A}}$ & 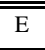 & 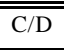 & $\overline{C \text { C/D }}$ & $\overline{\mathrm{D}}$ & $\overline{\mathrm{D} / \mathrm{E}}$ & $\overline{\mathrm{B}}$ \\
\hline
\end{tabular}




\section{continuação}

\begin{tabular}{|c|c|c|c|c|c|c|c|c|c|c|c|}
\hline \multirow{2}{*}{\multicolumn{5}{|c|}{\begin{tabular}{||c|c|} 
CONSTITUIÇÃO DOS DIFERENTES TECIDOS \\
CST
\end{tabular}}} & \multicolumn{7}{|c|}{ NÚMERO DO CASO } \\
\hline & & & & & 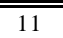 & 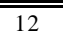 & "13 & "14 & "15 & "16 & 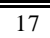 \\
\hline \multirow{7}{*}{ 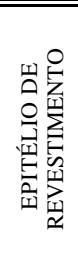 } & \multirow{7}{*}{ 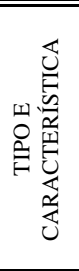 } & \multirow{3}{*}{\multicolumn{2}{|c|}{$\begin{array}{c}\text { EPITÉLIO } \\
\text { ESTRATIFICADO } \\
\text { PAVIMENTOSO }\end{array}$}} & ATRÓFICO & $\overline{\mathrm{X}}$ & & 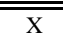 & & & & \\
\hline & & & & NORMAL & & & & & & & \\
\hline & & & & HIPERPLÁSICO & $\mathrm{X}$ & $\mathrm{X}$ & $\mathrm{X}$ & $\mathrm{X}$ & & $\mathrm{X}$ & $\mathrm{X}$ \\
\hline & & \multicolumn{3}{|c|}{ EXOCITOSE } & $\mathrm{X}$ & & $\mathrm{X}$ & $\mathrm{X}$ & & $\mathrm{X}$ & \\
\hline & & \multicolumn{3}{|c|}{ HIPERP LASIA PSEUDO-EPITELIOMATOSA } & $\mathrm{X}$ & & & & & & \\
\hline & & \multirow{2}{*}{\multicolumn{3}{|c|}{$\begin{array}{c}\text { DISPLASIA } \\
\text { ULCERAÇÃO }\end{array}$}} & & & & & & & \\
\hline & & & & & $\mathrm{X}$ & & $\mathrm{X}$ & $\mathrm{X}$ & & & \\
\hline \multirow{15}{*}{ 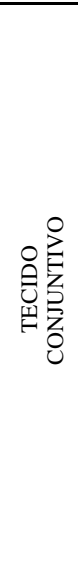 } & \multirow{6}{*}{ 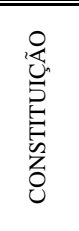 } & \multicolumn{3}{|c|}{ ULCERAÇÃO } & & 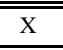 & $\overline{\mathrm{X}}$ & $\overline{\mathrm{X}}$ & & 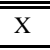 & 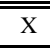 \\
\hline & & \multicolumn{3}{|c|}{ 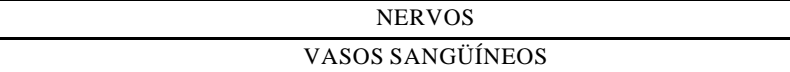 } & $\mathrm{X}$ & $\mathrm{X}$ & $\mathrm{X}$ & $\mathrm{X}$ & $\mathrm{x}$ & $\mathrm{X}$ & $\mathrm{X}$ \\
\hline & & \multirow{2}{*}{\multicolumn{2}{|c|}{$\begin{array}{l}\text { FENÔMENOS } \\
\text { VASCULARES }\end{array}$}} & TROMBOSE & $\mathrm{X}$ & & $\mathrm{X}$ & & & & \\
\hline & & & & EMBOLIA & & & & & & & \\
\hline & & \multirow{2}{*}{\multicolumn{2}{|c|}{ OUTRAS }} & NECROSE & & & & & & & $\mathrm{X}$ \\
\hline & & & & TECIDO DE GRANULAÇÃO & $\mathrm{X}$ & $\mathrm{X}$ & $\mathrm{X}$ & & & $\mathrm{X}$ & \\
\hline & \multirow{9}{*}{ 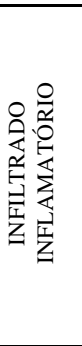 } & \multirow{3}{*}{\multicolumn{2}{|c|}{ SEVERIDADE }} & DISCRETO & & $\mathrm{X}$ & & & $\mathrm{X}$ & & \\
\hline & & & & MODERADO & & & & & & $\mathrm{X}$ & \\
\hline & & & & INTENSO & $\mathrm{X}$ & & $\mathrm{X}$ & $\mathrm{X}$ & & & $\mathrm{X}$ \\
\hline & & \multirow{6}{*}{ 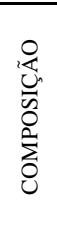 } & \multirow{3}{*}{ PMN } & NEUTRÓFILO & $\mathrm{X}$ & $\mathrm{X}$ & $\mathrm{X}$ & $\mathrm{X}$ & & $\mathrm{X}$ & $\mathrm{X}$ \\
\hline & & & & EOSINÓFILO & $\mathrm{X}$ & $\mathrm{X}$ & $\mathrm{X}$ & & $\mathrm{X}$ & $\mathrm{X}$ & \\
\hline & & & & BASÓFILO & & & & & & & \\
\hline & & & \multirow{3}{*}{ MN } & LINFÓCITO & $\mathrm{X}$ & $\mathrm{X}$ & $\mathrm{X}$ & $\mathrm{X}$ & $\mathrm{X}$ & $\mathrm{X}$ & $\mathrm{X}$ \\
\hline & & & & PLASMÓCITO & $\mathrm{X}$ & $\mathrm{X}$ & $\mathrm{X}$ & $\mathrm{X}$ & $\mathrm{X}$ & $\mathrm{X}$ & $\mathrm{X}$ \\
\hline & & & & MACRÓFAGO & $\mathrm{X}$ & $\mathrm{X}$ & $\mathrm{X}$ & $\mathrm{X}$ & $\mathrm{X}$ & $\mathrm{X}$ & $\mathrm{X}$ \\
\hline \multirow{6}{*}{ 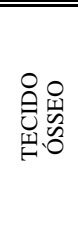 } & & & & $\overline{\text { STEO }}$ & & & & & & & \\
\hline & 岕 & & & TRIENTES & & & & & & & \\
\hline & $S_{E}^{5}$ & & & ICROBIANOS & & & & & & & \\
\hline & $\vec{E}$ & & & OSTEÓCITO & & & & & & & \\
\hline & z & & JLAS & OSTEOBLASTO & & & & & & & \\
\hline & & & & OSTEOCLASTO & & & & & & & \\
\hline & & & & PLASIA ESCAMOSA & $\overline{\mathrm{X}}$ & $\overline{\mathrm{X}}$ & 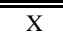 & 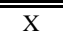 & & $\bar{x}$ & $\overline{\mathrm{X}}$ \\
\hline & & OEES & & NECROSE & & & $\mathrm{X}$ & & & & $\mathrm{X}$ \\
\hline & & & & CÉLULAS MIOEPITELIAIS & $\mathrm{X}$ & & $\mathrm{X}$ & $\mathrm{X}$ & & $\mathrm{X}$ & $\mathrm{X}$ \\
\hline & & & & $\overline{\mathrm{DSA}}$ & $\mathrm{X}$ & $\mathrm{X}$ & $\mathrm{X}$ & $\mathrm{X}$ & & $\mathrm{X}$ & $\mathrm{X}$ \\
\hline 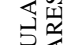 & 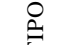 & & & & & & $\mathrm{X}$ & & & & $\mathrm{X}$ \\
\hline 它㫣 & & & & & & & $\mathrm{X}$ & & & $\mathrm{X}$ & $\mathrm{X}$ \\
\hline 还 & & & & ALAR & $\mathrm{X}$ & $\mathrm{X}$ & $\mathrm{X}$ & $\mathrm{X}$ & & $\mathrm{X}$ & $\mathrm{X}$ \\
\hline & n & & & ADO & $\mathrm{X}$ & $\mathrm{X}$ & $\mathrm{X}$ & $\mathrm{X}$ & & $\mathrm{X}$ & $\mathrm{X}$ \\
\hline & $E$ & & & ETOR & $\mathrm{X}$ & & $\mathrm{X}$ & $\mathrm{X}$ & & $\mathrm{X}$ & $\mathrm{X}$ \\
\hline & $\vec{a}$ & & ITFR ACÕES & DILATADO & $\mathrm{X}$ & $\mathrm{X}$ & $\mathrm{X}$ & $\mathrm{X}$ & & $\mathrm{X}$ & $\mathrm{X}$ \\
\hline & & & ILIERAÇUES & MUCO NO INTERIOR & $\mathrm{X}$ & $\mathrm{X}$ & $\mathrm{X}$ & $\mathrm{X}$ & & $\mathrm{X}$ & $\mathrm{X}$ \\
\hline & & & 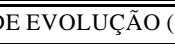 & HANSEN $\left.{ }^{3}\right)$ & C/D & $\overline{\mathrm{D} / \mathrm{E}}$ & $\mathrm{C} / \mathrm{D}$ & C/D & & A A & $\overline{\mathrm{A} / \mathrm{D}}$ \\
\hline
\end{tabular}

